\title{
Cure Shrinkage Effects in Epoxy and \\ Polycyanate Matrix Composites
}

\author{
Gordon P. Spellman
}

(MS Thesis)

December 22, 1995 


\section{DISCLAIMER}

This document was prepared as an account of work sponsored by an agency of the United States Government. Neither the United States Government nor the University of California nor any of their employees, makes any warranty, express or implied, or assumes any legal liability or responsibility for the accuracy, completeness, or usefulness of any information, apparatus, product, or process disclosed, or represents that its use would not infringe privately owned rights. Reference herein to any specific commercial product, process, or service by trade name, trademark, manufacturer, or otherwise, does not necessarily constitute or imply its endorsement, recommendation, or favoring by the United States Government or the University of California. The views and opinions of authors expressed herein do not necessarily state or reflect those of the United States Government or the University of California, and shall not be used for advertising or product endorsement purposes.

This report has been reproduced directly from the best available copy.

Available to DOE and DOE contractors from the Office of Scientific and Technical Information P.O. Box 62, Oak Ridge, TN 37831

Prices available from (615) 576-8401, FTS 626-8401

Available to the public from the

National Technical Information Service

U.S. Department of Commerce 5285 Port Royal Rd., Springfield, VA 22161

Work performed under the auspices of the U.S. Department of Energy by Lawrence Livermore National Laboratory under Contract W-7405-Eng-48. 
Cure Shrinkage Effects in Epoxy and Polycyanate Matrix Composites

by

GORDON PAUL SPELLMAN

B.S. (University of California, Davis) 1970

\section{THESIS}

Submitted in partial satisfaction of the requirements for the degree of

\section{MASTER OF SCIENCE}

in

Mechanical and Aeronautical Engineering

in the

OFFICE OF GRADUATE STUDIES

of the

UNIVERSITY OF CALIFORNIA

DAVIS

Approved:

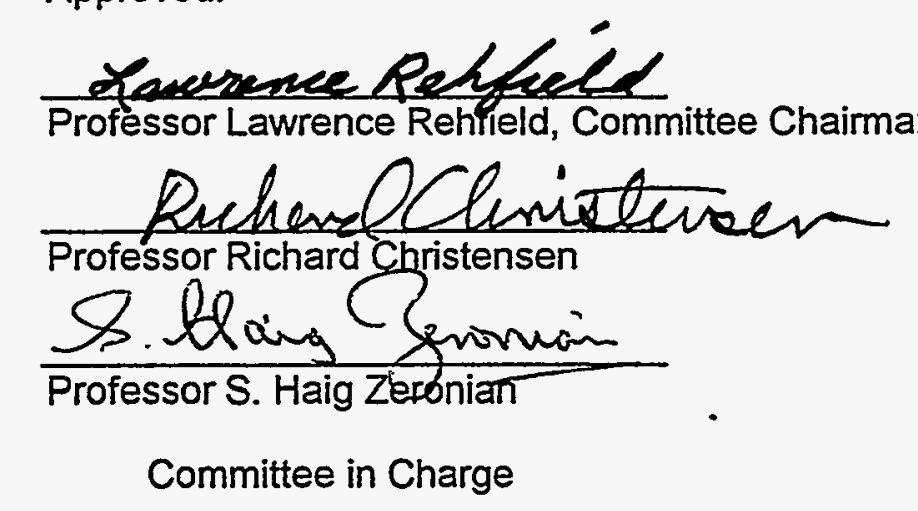

1995 



\section{TABLE OF CONTENTS}

TABLE OF CONTENTS

ACKNOWLEDGMENTS iii

ABSTRACT iv

LIST OF FIGURES vi

LIST OF TABLE vii

INTRODUCTION 1

THEORY

Cure shrinkage of the matrix material 5

"B" Staged resins

$\begin{array}{lc}\text { Laminate theory } & 8\end{array}$

EXPERIMENTAL METHODS

Neat resin shrinkage $\quad 11$

Laminate shrinkage $\quad 12$

Operational details $\quad 15$

Deflection measurement techniques.

RESULTS $\quad 25$

Data Reduction $\quad 26$

The baseline - Hercules 3501-6/IM6 27

Evaluation of the polycyanate systems

$\begin{array}{ll}\text { Overall Results } & 38\end{array}$

CONCLUSIONS AND RECOMMENDATIONS

REFERENCES $\quad 43$

APPENDIX 1 --MANUFACTURERS RHEOLOGY INFORMATION 45

APPENDIX 2 - DATA FORMS $\quad 49$

APPENDIX 3 -- BAGGING PROCEDURES

APPENDIX 4 -- CURE CYCLES

APPENDIX 5 -- DEFLECTION DATA 60

APPENDIX 6 -- CURED MATERIAL PROPERTIES 80 


\section{Acknowledgments}

This work transpired over a period from the middle 1994 to the middle of 1995. The work was performed in the Plastics and Advanced Composite Group at Lawrence Livermore National Laboratory in Livermore California. The principal investigator for this effort was Gordon P. Spellman. My committee members, Major Professor Lawrence Rehfield and Professors S. Haig Zeronian and Richard Christensen have been patient and understanding of the numerous changes and variations during the evolution of this work. A large portion of the detailed material processing that is required in this type of effort was performed by Steve Winchester who remained dedicated and helpful throughout periods of intense demands on his time. The concept for this effort was suggested by Mr. Brad Frye of Boeing Commercial Aircraft and I hope he will understand how helpful that has been. Material and processing advice was provided by Fiberite Inc., YLA Inc., and Bryte Technologies Inc. The materials involved are of very high value and we appreciate the consideration of these companies and the individuals involved. Time for class attendance and research was made available through the education program at Lawrence Livermore National Laboratory and the graciousness of my Division management. Lastly, thanks to the friends who have provided support throughout the work, especially as time grew short. 


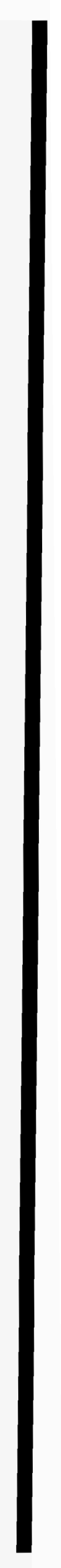




\begin{abstract}
A relatively new advanced composite matrix, polycyanate ester, was evaluated for cure shrinkage. The chemical cure shrinkage of composites is difficult to model but a number of clever experimental techniques are available to the investigator. In this work the method of curing a prepreg layup on top of a previously cured laminate of identical ply composition is utilized.

The polymeric matrices used in advanced composites have been primarily epoxies and therefore a common system of this type, Fiberite 3501-6, was used as a base case material. Three polycyanate matrix systems were selected for the study. These are: Fiberite 954-2A, YLA RS-3, and Bryte Technology BTCy-1. The first three of these systems were unidirectional prepreg with carbon fiber reinforcement. The Bryte Technology material was reinforced with E-glass fabric. All systems were processed similarly although each required certain variation in cure cycle profile as recommended by the manufacturer. Details of the processing technique are fully described.
\end{abstract}

The technique used to evaluate cure shrinkage results in distortion of the flatness of an otherwise symmetric laminate. The first laminate is cured in a conventional fashion. An identical layup is cured on this first laminate. During the second cure all constituents are exposed to the same thermal cycles. However, only the new portion of the laminate will experience volumetric changes associate with matrix cure. The additional strain of cure shrinkage results in an unsymmetric distribution of residual stresses and an associated warpage of the laminate. The resulting distortion was measured using conventional mechanical methods.

The baseline material, Fiberite 3501-6, exhibited cure shrinkage that was in accordance with expectations. Cure strains were $-4.5 E-04$. The YLA RS-3 material had cure strains somewhat lower at $-3.2 \mathrm{E}-04$. The Fiberite $954-2 \mathrm{~A}$ cure strain was 

$-1.5 \mathrm{E}-04$ that is $70 \%$ lower than the baseline material. The glass fabric material with the Bryte BTCy-1 matrix did no result in meaningful results because the processing methods were not fully compatible with the material. 


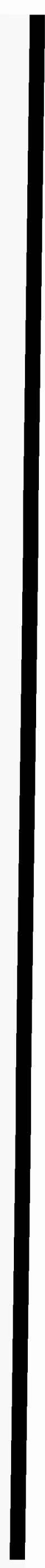




\section{List of Figures}

Figure 1 Measurement Setup .....................................................................23

Figure 2 Unidirectional Base Case -- Hercules 3501-6.....................................30

Figure 3 Multidirectional Base Case - Hercules 3501-6....................................31

Figure 4 YLA RS-3 Polycyanate Matrix..................................................................35

Figure 5 Bryte Technologies BTCy-1 Polycyanate Matrix...................................37

Figure 6 Fiberite 954-2A Polycyanate Matrix.......................................................39 


\section{List of Table}

Table 1 Description of Operating Materials .................................................. 15

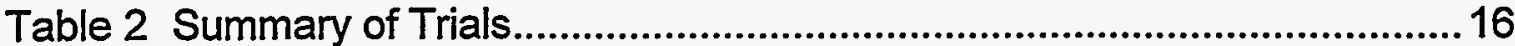

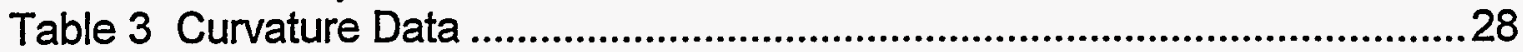

Table 4 Curvature of Second Cure Panels ........................................................40 



\section{Introduction}

A relatively new advanced composite matrix, polycyanate ester, is becoming available in a variety of product forms. These material systems are being used in a number of high performance applications in the aerospace, electronics and other industries. There are numerous benefits to this system and an excellent review of the full technology of polycyanate resins and their uses is presented in Fang and Shimp [1]. The benefit to be studied in this work is low cure shrinkage, or low effective cure shrinkage. Cure shrinkage is a parameter of concern in composites due to the effects it can have on residual ("curing") stress, warpage, and tooling and process requirements.

Cure shrinkage effects in a composite system are difficult to model fully because of the large changes in viscoelastic properties during the resin cure and the relative large thermal shrinkage that occurs after cure. These factors are complicated by the presence of the relatively high modulus reinforcement that can absorb large amounts of stress with little strain. This leads to use of clever experimental techniques to develop useful information about the causes and effects of differential volumetric changes in the composite components during processing.

One of the first considerations in evaluating matrix cure shrinkage is the choice of a method for assessing the true cure shrinkage of the matrix during composite fabrication. The two portions of this assessment are numerical methods and experimental methods. The experimental methods may be further subdivided into those which assess the neat resin and those that deal with the resin in the composite structure.

There are many methods for assessing the cure shrinkage of neat resins and composite systems. These include the peel ply technique [2], the stress free temperature [2,3], and the curing of a laminate on top of a previously cured laminate [4]. 
The later of these was the basic method used in this thesis. However, the Moire measurement technique developed by Zewi et al [5] was not utilized due to lack of required test equipment.

Dimensional changes in the different components of a composite during processing are important for a number of reasons. A major result of differential strain is residual stress in the fabricated component. The majority of the residual stress is due to the mismatch of coefficients of thermal expansion (CTE) of the matrix and fiber [2] combined with the large temperature excursions, $150-300^{\circ} \mathrm{C}$ above ambient, involved in processing [6]. There is also a large anisotropy in aramid and carbon fiber CTE that can contribute to differential dimensional changes on a micromechanical scale [6].

In thermosetting composites there is an additional effect due to the cure shrinkage [2] that the matrix resin undergoes. More importantly, when the resin is cured below its $T_{g}$ the effects of cure shrinkage on overall matrix dimensional changes can be significant. Daniel et al [4] state that "when cure occurs above $T_{g}$ the polymerization shrinkage is small", and "when curing takes place below the $T_{g}$ the chemical shrinkage and its attendant residual stresses can be significant." The total shrinkage, at a specific degree of cure, will be independent of path, within reason, but shrinkage which occurs above the $T_{g}$ is allowed to occur primarily at the free surfaces of the matrix and does not contribute significantly to residual stress.

Typical cure shrinkage for the most common advanced composite matrix, epoxy resin, is $1-6 \%[6,7]$. Since these resins are often cured above the $T_{g}$ the effective shrinkage is often much smaller. Polycyanate resins are cured below the resultant $\mathrm{T}_{\mathbf{g}}$ but they are known to have low cure shrinkage [1]. The total cure shrinkage for $100 \%$ conversion is about $3.5 \%$ according to Snow and Armistead [8]. Effective shrinkage should then be similar to or lower than conventional epoxy system. 
The residual stresses which are built up in the laminate are due to differential dimensional changes between components as well as between layers of the laminate. Specifically, in multidirectional laminates, anisotropy between plies in the directionality of both CTE [2] and cure shrinkage results in these residual stresses. The stresses can manifest themselves as warpage, matrix cracking, delamination, and reduced strength at first ply failure [3]. These stresses exert a marked influence on the onset of damage in fiber-reinforced composites under applied load and may even be large enough to induce microcracking in the part during cool down from the processing temperature [2]. In some cases the stresses are large enough to cause ply failure at room temperature prior to application of any load [9]. In some cases, however, the effect may prove beneficial [3]. Some examples are the generation of desired pre-stress, use of residual stress to resist delamination and an actual enhancement of usable properties at elevated temperature where the residual stresses are relieved.

A less often considered effect is on the relationship between a part and the tooling. Since graphite reinforcement has an axial CTE near zero, the dimensional changes during processing are fully controlled by the matrix. Thus, the lower the overall dimensional change of the matrix, the lower the eventual residual stresses and the more stable and predictable the laminate will be during processing. In the case where shrinkage is reduced sufficiently, matched metal, near net shape molding becomes practical. This allows for the next generation of low cost composite manufacturing for these types of materials.

The relationship between the dimensions of the tooling and the final part is controlled by the reversible and irreversible dimensional changes of both components. Thus tooling must be dimensioned to account for these effects and this is a difficult task. In addition, the whole concept is dependent on uniformity and reproducibility in a 
number of material parameters. If cure shrinkage can be eliminated from this list of variables, the ability to retain the proper relationship in production can be increased. 


\section{Theory}

The theoretical treatment of the resin cure shrinkage effects on composites can be separated into neat resin shrinkage and the resulting macroscopic laminate behavior.

\section{Cure shrinkage of the matrix material}

The polymeric matrices utilized in advanced composites have been primarily of the epoxy type. Lower performing systems utilize polyester and vinyl ester and very high performance systems utilize bismaleimides, polyimides and thermoplastic resins. A relatively new matrix which competes at all but the lowest performance level is polycyanate and it is the major interest in this study.

All thermosetting resins exhibit some degree of shrinkage during cure. With each system the shrinkage can take place at different times during the cure cycle and the viscoelasticity of each system can be dramatically different during the cure shrinkage. This is of major interest since clearly if shrinkage occurs while the resin is in a state of very low modulus there is no resulting stress imparted to the system due to the volume changes of the shrinking resin.

Typical results of resin matrix shrinkage show total shrinkage of $1-6 \%[6,7,9]$. The most detailed study of the actual shrinkage of specific resins used in composites (Hercules 3501-6 included) is presented by Russell [10]. The 3501-6 neat resin system exhibits $.89 \%$ shrink during the first hold at $116^{\circ} \mathrm{C}$ and an additional $2.49 \%$ during the final cure at $177^{\circ} \mathrm{C}$.

Detailed information such as that in Russell [10] is rarely available for most systems. Generally, the information available is viscosity versus time data either at a constant ramp temperature or a temperature profile representative of the cure cycle. Examples of this are shown in Appendix 1. Similarly, data is usually provided for gel time of the systems and examples of this are included in Appendix 1. Generally the 
processes are operated according to the manufacturers' recommended cure cycles and bagging procedures such as those described later.

More important than basic cure shrinkage information from a composite point of view is the relationship of the shrinkage to the viscoelasticity. Again, it is unusual for the composites engineer to have the necessary information to actually execute "smart processing" schemes. The theoretical approach to comprehensively defining the behavior of the matrix resin during the full process of curing is well described by Peretz and Weitsman $[11,12]$.

In the fabrication of a thermoset composite the matrix is initially in a fluid state at the ultimate processing temperature. As the temperature rises to cure temperature the resin viscosity can decrease due to thermal effects but will, at some point, begin to increase due to cure effects. The composite viscosity increases rapidly at the cure temperature to a constant value and then increases again upon cool down. In the fluid state the resin cannot sustain any shear stress and consequently the composite system is usually considered to be initially in a stress-free state at the final cure temperature. During the normally isothermal cure, stresses begin to build up due to the increase in viscosity and volumetric changes associated with cure which are commonly known as cure or chemical shrinkage.

The significant point is that cure shrinkage can lead to residual stresses in a cured composite in some cases. Fortunately there is very little residual stress when the composite is cured above the glass transition temperature, $\mathrm{T}_{\mathrm{g}}$, of the matrix. In the case of the polycyanate, which is of primary interest here, the cure temperature is generally below the $T_{g}$ which is typically $240-290^{\circ} \mathrm{C}$ for these systems [1]. However, the cure shrinkage is low and therefore the "chemical" residual stresses will be low.

A brief discussion of the volume changes of thermoplastic systems is included here for completeness. In thermoplastic systems there can be large volume changes at 
the melting point, $T_{m}$, and at $T_{g}$. The volume shrinkage of thermoplastics from the processing temperature to the use temperature can range from $10 \%-30 \%$ [6]. This effect is mitigated to some extent in high pressure processing, such as injection molding, due to compressibility effects. However, in the normal low pressure molding of thermoplastic composites it can be a major effect.

The thermoplastic resins have no "cure" shrinkage, but crystalline types can exhibit large volume changes during crystallization and amorphous types can have somewhat smaller volumetric coefficients of thermal expansion above the $T_{g}[6]$. What is critical, of course, are the volume changes below the point where the matrix can support internal shear stress. This is typically near the $T_{g}$ for amorphous polymers or within the primary crystallization range for others.

\section{"B" Staged resins}

The curing mechanism for advanced composites produced from prepreg is complex. The curing occurs in two very separate process steps. The first step occurs at the material supplier's facility during the prepreg manufacturing operation and results in a "B" stage material. The second occurs during processing by the composite part manufacturer. This later stage includes very slow changes during handling at room temperature and the primary cure occurring at the elevated temperatures of the process.

The "B" stage cure, which is accomplished at the material supplier's facility, produces a partially cured matrix which has very low mechanical properties. The matrix is a near solid at room temperature, but does have some "tack" or stickiness. This tack is useful in the laminating operation and helps in the "stacking" of plies. In a typical operation, the material will be stored under refrigeration for up to one year. A roll is routinely removed from the refrigerator, portions are used, and the remainder is returned to cold storage. During this "out time", the matrix resin will be warmed to ambient 
temperature for some period of time and during this time a slight amount of curing will take place.

The major curing step is initiated during the final laminate processing, usually in an autoclave, by increasing the material temperature. During this process there are competing parameters which determine the modulus of the matrix at any time. The increase in temperature causes a reduction in modulus to a point where significant flow of the resin occurs. At the same time, crosslinking is occurring and this drives the modulus of the matrix upward as the cure shrinkage occurs. It is the relationship between these factors which is the leading edge of composites' process modeling at this time.. Additional complexity results from non-uniform temperatures, especially in thick laminates where there may actually be some higher temperatures in the center of the laminate due to the exothermic nature of the curing process. Often the assumption is made that during this initial phase the matrix never has sufficient modulus to retain any residual stress [13]. This may be a valid assumption for many systems, especially those which are cured above their $T_{g}$. Jones et al [14] present an example where stress relaxation phenomena can play a role. In their work the rate of cooling affects the final residual stresses and this is attributed directly to viscoelastic effects.

\section{Laminate theory}

There are numerous textbooks, such as "Mechanics of Composite Materials" [15], which develop the routinely used forms of the theory of laminates. A common practice when dealing with non-mechanical effects is to treat the total strain as a sum of mechanical strain and the individual strains from various physio-chemical processes. The two most common additional strains are from the hygrothermal effects [16]. In this thesis we follow the trail of Daniel et al and work with the "chemical shrinkage strain", $e^{c}$. 
The method developed by Daniel consists of curing a prepreg layup (layer 2) on top of an identical symmetric layup (layer 1 , or base panel), which has previously been cured. Both layers will undergo the same thermal effect during the curing of layer 2 , but layer 2 will undergo cure shrinkage effects which took place previously in layer 1 . Thus there is no cure shrinkage effect introduced into layer 1 during the second cure cycle and the chemical shrinkage strain would be zero in that layer as shown in Eqn 1:

$$
\left|\begin{array}{l}
e_{x}^{c} \\
e_{y}^{c} \\
e_{x y}^{c}
\end{array}\right|=\left|\begin{array}{l}
0 \\
0 \\
0
\end{array}\right|
$$

Similarly, the strains in the second layer are those resulting from chemical shrinkage as shown in Eqn 2:

$$
\left|\begin{array}{l}
e_{x}^{c} \\
e_{y}^{c} \\
e_{x y}^{c}
\end{array}\right|_{2}=\left|\begin{array}{c}
e_{1}^{c} \\
e_{2}^{c} \\
0
\end{array}\right|
$$

\section{[Eqn 2]}

In the primary portion of this study, the $x$ and $y$ directions coincide with the material axes 1 and 2 and the laminates are "specially orthotropic". By using the normal simplifying assumptions such as plane stress, plane strain and no external loads one arrives at:

$$
\left(\frac{4 h}{3}\right)\left|\begin{array}{ll}
Q_{11} & Q_{12} \\
Q_{12} & Q_{22}
\end{array}\right|\left|\begin{array}{l}
k_{1} \\
k_{2}
\end{array}\right|=\left|\begin{array}{ll}
Q_{11} & Q_{12} \\
Q_{12} & Q_{22}
\end{array} \| \begin{array}{c}
e_{1}^{c} \\
e_{2}^{c}
\end{array}\right|
$$

where $h$ is the thickness of layer 1 or 2 , the $Q_{i j}$ are the normal components of modulus, and the are the curvatures. The two simultaneous equations above may be reduced to:

$$
e_{1}^{c}=\left(\frac{4 h}{3}\right)\left(k_{1}\right) \quad \text { and } \quad e_{2}^{c}=\left(\frac{4 h}{3}\right)\left(k_{2}\right) \text {. }
$$

for both the 1 and 2 directions. Thus the relationship is totally independent of the properties of the materials. This is the equation used to present the results of the experimental program undertaken in this work. 
The experimentally determined factor from the measuring and data reduction routine is the deflection profile of the plate. This data must be translated into curvature in the principal axes. The curvature translation is accomplished by use of the sagitta formula such as used in Timonshenko's bimetallic strip paper [17] which is shown in Eqn 4:

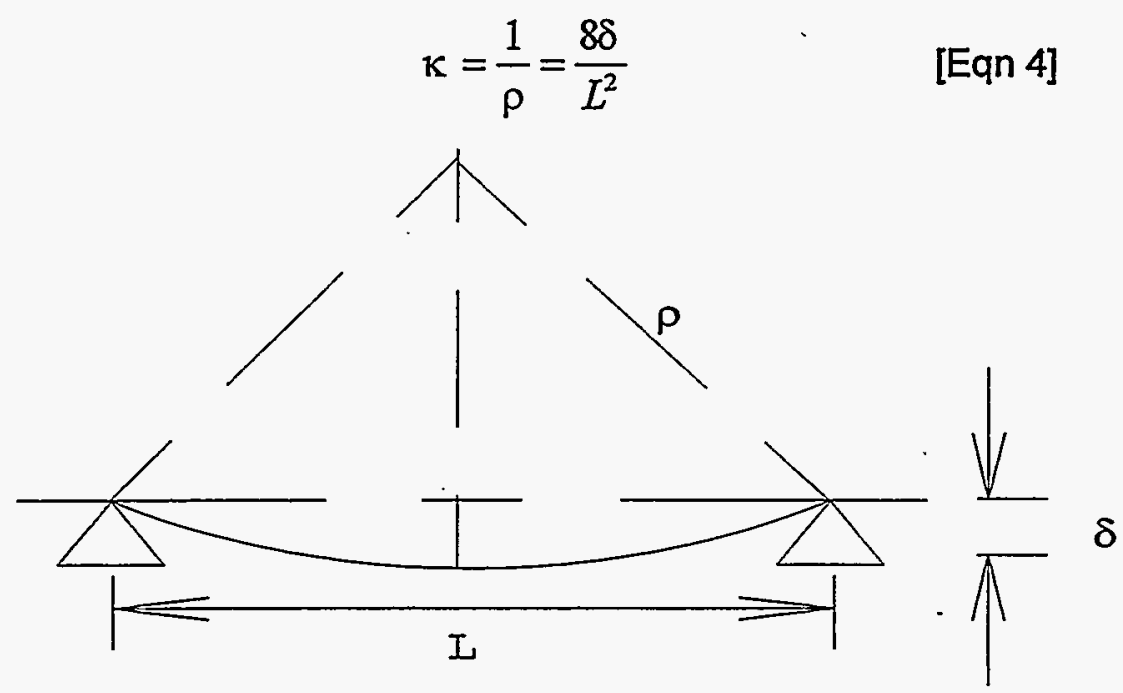

This equation is an approximation for use when the deflections are small in comparison to the radius of curvature. The precise equation [14] is shown in Eqn 5:

$$
\frac{1}{\rho}=\frac{2}{L} \cos ^{-1}\left(1-\frac{\delta}{\rho}\right)
$$

For the range of dimensions used in this work the approximation in Eqn 4 is accurate to $.02 \%$ and is therefore utilized. 


\section{Experimental Methods}

The experimental approach consists of two separate but related issues. The first is the definition of a technique which will result in measurements that can be related to cure shrinkage. The second is the actual physical mechanisms for obtaining the measurements. Both issues will be discussed jointly under each basic approach.

There is an interesting choice to be made between obtaining fundamental information and more applied information. The shrinkage of the resin matrix is clearly the dominant factor for composite shrinkage in carbon fiber composites since the carbon fiber is quite stable dimensionally in the reinforcing direction over the temperature ranges of concern. However, the effective shrinkage of the composite laminate is the value of concern to the composite engineer. In this study we concentrate on the latter but also offer the following discussion of resin shrinkage measurement techniques which might be employed.

\section{Neat resin shrinkage}

The simplest methods for quantifying matrix shrinkage involve measurements on the matrix alone. Three common methods are dynamic mechanical analysis (DMA), dilatometry [7], and the beam test [18]. DMA and dilatometry have the advantage of being direct measurements, whereas the beam test involves a calculation based on certain assumptions and a confidence in the test procedures. In all methods, there is the difficulty of transitioning from a liquid to a solid system and, at the same time, the rapid changes in adhesive properties. This obviously presents the problem of not being able to utilize a single, simple method of determining shrinkage.

A more important weakness in using neat resin shrinkage in this type of effort is that the effect on the composite is dominated by the portion of the shrinkage which is "frozen into" the final laminate. For example, if all of the shrinkage took place while the 
matrix was still very liquid, the effect on the final laminate would be quite minimal. However, as discussed earlier, for laminates cured below the $T_{g}$, there is a higher likelihood of the cure shrinkage being "captured" in the final laminate.

\section{Laminate shrinkage}

Evaluation of cure shrinkage effects using laminates rather than neat resin provides more directly applicable information. It does not provide any direct measure of matrix cure shrinkage but rather a measure of the effective results in the composite system. There are numerous methods which have been developed for determining laminate shrinkage. Most of these techniques have difficulty separating chemical cure effects from thermal cure effects. We will review some of the more common techniques and discuss in detail the method used in this work.

a) "Stress free" temperature of unbalanced laminates

When this approach is used, the "stress free" temperature is defined as the temperature at which the maximum deflection of an unsymmetric laminate plate is reduced to zero [2]. This stress free temperature is usually somewhat below the maximum cure temperature but in Crasto and Kim's work [2] it was higher than the process temperature. They postulate that the difference between the stress free and cure temperatures is a measure of the stress induced by chemical shrinkage. Thus they state that the ratio of that difference to the difference between the stress free and end use temperatures is a measure of the contribution of cure shrinkage to residual stress. However, they do point out that other investigators $[3,14]$ have demonstrated zero deflection below the cure temperature. They do not feel this can be reconciled at this time (1993).

An advantage of the use of unsymmetric laminates is the large deflection which is easily measured. One of the experimental difficulties with this method is the 
measurement of beam deflections at elevated temperatures. This can be accomplished by a number of methods which range somewhat in difficulty and precision. The methods include a traveling microscope [2], a coordinate measuring machine (CMM), and a laser theodolyte.

b) Curvature of unbalanced laminate beams

Jones et al [14] discuss this technique which involves determining the radius of curvature of a narrow, long beam constructed in an unbalanced fashion. The approach is direct and simple and avoids the need to discretely determine coefficients of thermal expansion. Any stress relaxation is taken directly into account.

c) Peel ply technique

This technique [2] involves determining the residual strain in the exterior layers of a symmetric laminate upon removal of equal exterior layers from both faces. These strains are then used to calculate a stress free temperature. The resultant information can be utilized as previously described in the section above on stress free temperature. d) Photoelasticity

A technique was used by Nairn and Zoller [6] which utilizes photoelastic measurement of thermal stresses in composites. This technique, as developed, is restricted to low fiber volumes, $30-40 \%$, but are still useful models, especially for evaluating stresses in the fiber direction. However, this technique is more instructive for unidirectional laminate or single layer investigations since there is free shrinkage of the layer. In actual multidirectional laminates there will be high transverse stress in a layer due to the strain limits imposed by the overall laminate structure.

e) Single ply shrinkage

Perhaps the simplest approach for assessing the cure shrinkage of a composite material is to allow a single ply to shrink in an unrestrained condition as it undergoes a 
normal cure. This approach is used by White and Hahn [19] to evaluate a bismaleimide system, American Cyanamid IM6/3100. Their assessment was that overall chemical cure strain was $3 \%$, but they assert that the strains occur early in the cycle and contribute very little to the residual stress of an actual laminate.

f) Balanced laminate except for cure effects.

This approach was proposed by Daniel et al [4] and is the basis for the present work. The basic thesis is that if a laminate is cured on an identical laminate which has already been cured, the resulting deflections are a result of processing strains which are fully associated with matrix cure shrinkage. That is, "Both halves undergo the same thermal deformations, but only the new half (prepreg) undergoes the additional chemical deformation. Thus, any warpage observed after cooldown is due to chemical shrinkage." This method evaluates strain directly without reference to material properties of the laminate layers. The measured results are particular to the specific layup of the composite and do not provide a direct measure of a material property. Thus, we use the term "effective" cure shrinkage to describe the results. It is possible to estimate matrix shrinkage from this information using conventional laminate code calculations.

Perhaps the most difficult portion of this approach is the precise measurement of the out-of-plane deflections of the laminate. The actual construction of the laminate is straight forward although care must be taken. Details of the fabrication and measurement procedures used in this thesis are presented in the operational details section which follows.

We have deviated from the methods of Daniel in a number of ways. A more conventional method for measuring deflection, dial indicator gauging, was utilized. Unidirectional prepreg tape was used in place of fabric prepreg in some cases. Deflection of the base, first, laminate was measured prior to the curing of the second 
laminate on the base laminate. Daniel assumed that the "composite plate consisting of the cured half and the uncured (prepreg) half, is flat initially." As we will see, that was not really true in this study although Daniel's use of compression molding rather that autoclave molding may have produced flatter first layer panels.

\section{Operational details}

The operational details describe the preparation and processing of the laminates used in this study. These steps are critical to the quality of the effort since residual stress can be a result of many factors [4] other than the thermal and cure shrinkage strains. These factors include, fiber misalignment [5], matrix non-uniformity, nonuniform porosity and resin flow [20] and uneven laminate cure.

Information on the specific prepreg materials used in the study $a$ is included in Table 1. A sample of the comprehensive data collection set for the preparation of panels is shown in Appendix 2. Summary data describing the makeup of the 61 panel produced for this work is shown in chronological order in Table 2. There are some preparatory runs with Hexcell's F263 epoxy prepreg fabric listed in Table 2. These runs are not detailed further.

Table 1

Description of Operating Materials

\begin{tabular}{|l||l|l|l|l|}
\hline Manufacturer & Hercules & ICl Fiberite & YLA Inc. & Bryte Technologies \\
\hline Description & IM6/3501-6 & HYE 1354-2AT & RS-3 M55 J 6K & 7781 Fg/BTCy-1, 38 \\
\hline Quantity & $30 \mathrm{lb}$ & $5 \mathrm{lb}(-110 \mathrm{ft})$ & $255 \mathrm{ft}$ & 8 yd's \\
\hline Form & $12 "$ uni-tape & 12 " uni-tape & 12 uni-tape & 38 " wide fabric \\
\hline Resin & Epoxy 3501-6 & PCy 954-2A & PCy RS-3 & PCy BTCy-1 \\
\hline Fiber & Hercules IM6 & Hercules IM7 & Toray M55J, 6K & E Glass \\
\hline Lot No. & $6747-2$ & $43228 \mathrm{C}$ & FB2K109 & $061093-2$ \\
\hline Roll & $46 \mathrm{~A}$ & & 2 & 2 \\
\hline Resin Content wt \% & 33 & 34 & 34.7 & \\
\hline Areal wt., g/sq m & 146 & 147 & 69.2 & \\
\hline Date Mfg. & $10 / 22 / 91$ & $8 / 30 / 94$ & $10 / 26 / 93$ & \\
\hline
\end{tabular}


Table 2

Summary of Trials

\begin{tabular}{|c|c|c|c|c|c|}
\hline \multirow[b]{2}{*}{ Run No. } & \multirow[b]{2}{*}{ Material } & \multirow[b]{2}{*}{ Layup } & \multirow[b]{2}{*}{ Comments } & \multicolumn{2}{|c|}{ Total Deflections } \\
\hline & & & & Data Sets & Average, mils \\
\hline $05 \ldots 11 a$ & Hexcell F263/CF tabric & $(0,90,180,270) \mathrm{s}$ & separator taces out & 1 & 28 \\
\hline $05,13 a$ & Hexcell F263/CF fabric & $(0,90,180,270) s$ & all faces up & 1 & 47 \\
\hline $05 \_13 b$ & Hexcell F2o3/CF fabric & $(0,90,180,270) \mathrm{s}$ & all faces up & 1 & 114 \\
\hline 05_17a & Hexcell F253/CF fabric & $(0,180) 2 \mathrm{~s}$ & all faces up & 1 & 24 \\
\hline $05 \_17 b$ & Hexcell F203/CF fabric & $(0) 8$ & faces opposed at $\mathrm{Cl}$ & 1 & 181 \\
\hline $05 \_19 a$ & Hexcell F263/CF tabric & $(0,180) 2 \mathrm{~s}$ & & 1 & 33 \\
\hline $05=19 \mathrm{~b}$ & Hexcell F263/CF tabric & $(0) 8$ & & 1 & 95 \\
\hline $05 \_25 a / 05 \_17 a$ & Hexcell F263/CF tabric & $((0.180) 2 \mathrm{~s}) \mathrm{s}$ & $\operatorname{ton} 5 \_17 a$ & 1 & 99 \\
\hline $05 \_25 \mathrm{~b}$ & Hexcell F263rCF fabric & & & 1 & 53 \\
\hline $06,06 a$ & Hercules $3501-6 / \mathrm{M} 6$ uni-tape & $(0) 16$ & & 1 & 14 \\
\hline $06 \_06 \mathrm{~b} \#$ & Hercules 3501-6/1M6 uni-tape & $(0) 16$ & Peel ply & 1 & 20 \\
\hline 05_06c $\#$ & Hercules $3501-6 / \mathrm{M} 6$ uni-tape & $(0,90) 4 s$ & & 1 & 13 \\
\hline O5_06d\# & Hercules 3501-6nM6 uni-tape & $(0,90) 4 s$ & Peel ply & 1 & 8 \\
\hline 06 09a/6_06a & Hercules 3501-6nM6 uni-tape & $((0) 16) \mathrm{s}$ & & 3 & 44 \\
\hline $06 \_09 \mathrm{~b} / 6,06 \mathrm{~b}$ & Hercules 3501-61M6 uni-tape & $((0) 16) s$ & Autoclave failure, peel ply & 2 & 59 \\
\hline $06 \_08 \mathrm{e} / 6 \_06 \mathrm{c}$ & Hercules 3501-6/M 6 uni-tape & $((0,90) 4 s) s$ & Autoclave failure & 2 & 17 \\
\hline 06_09d/6_06d & Hercules 3501-6nM6 unttape & $((0,90) 4 s) s$ & Autoclave fallure. peel ply & 2 & 13 \\
\hline 06_13a\# & Hercules 3501-6nM6 unttape & $(0) 16$ & & 1 & 25 \\
\hline 06_13b\# & Hercules 3501-6nM6 unitape & $(0) 16$ & Peel ply & 1 & 16 \\
\hline 06 13cen & Hercules $3501-6 n \mathrm{M} 6$ unttape & $(0,90) 4 s$ & & 1 & 12 \\
\hline $06.130 \#$ & Hercules 3501-6/M6 unl-tape & $(0,90) 45$ & Peel piy & 1 & 9 \\
\hline $06 \_17 a \sqrt{6} \_13 a$ & Hercules 3501-6nu6 uni-tape & $((0) 16) s$ & & 2 & 47 \\
\hline $0617 \mathrm{~b} / 6,13 \mathrm{~b}$ & Hercules 3501-6nM6 unt-ape & $((0) 16) s$ & Peel ply & 2 & 58 \\
\hline $08 \_17 \mathrm{~d} / 6 \_13 \mathrm{C}$ & Hercules 3501-6nim6 unltape & $((0,90) 4 s) \mathrm{s}$ & & 2 & 8 \\
\hline $06 \_17 d / 6 \_13 d$ & Hercules 3501-6nM6 unitape & $((0,90) 4 s) \mathrm{s}$ & Peel ply & 3 & 11 \\
\hline Q8_04a & Biyte BTCy-1/T718 E-glass fabric & $(0,90,+1-45)_{3}$ & Inncorect ply orientation, peel ply on top & 4 & 57 \\
\hline $08_{2} 04 b$ & Biyte BTCy-1/7718 E-glass fabric & $(0,90,+1-45) \mathrm{s}$ & Inncorect ply orientation, peel ply on top & 4 & 86 \\
\hline 08 18a & Biyte BTCy-1/7718 E-glass fabric & $(0,+1-45,90) \mathrm{s}$ & Peel ply on top & 2. & 47 \\
\hline $08 \_30 a / 08$ 18a & Bryte BTCy-1/7718 E-glass fabric & $((0,+f-45,90) s) \mathrm{s}$ & & 5 & 29 \\
\hline 10_21a\# & Hercules 3501-5nM6 unitape & $(0) 16$ & & 4 & 26 \\
\hline $1021 b=$ & Hercules 3501-6nM6 unitape & $(0) 16$ & & 4 & 34 \\
\hline $10 \_25 a / 10 \_21 a$ & Hercules 3501-6nM6 unt-tape & $(0) 16 s$ & & 2 & 54 \\
\hline $10 \_25 b / 10 \_21 b$ & Hercules $3501-6 n M 6$ uni-tape & $(0) 16 s$ & & 3 & 67 \\
\hline $10 \_31 a$ & Hercules 3501-6nM6 unitape & $(0) 8$ & & 3 & 46 \\
\hline 11_04a & Hercules 3501-6nM6 unt-tape & $(0) 8$ & & 1 & 38 \\
\hline 11_04b: & Hercules 3501-6nh6 uni-tape & $(\mathrm{O} /+1-45 / 90) \mathrm{s}$ & & 1 & 9 \\
\hline 11_14a/11_04b & Hercules 3501-6nM6 unitape & $((0 /+\gamma-45 / 90) s) s$ & & 2 & 8 \\
\hline 11_14b & Hercules $3501-69 M 6$ uni-tape & $(01++15 / 90) s$ & & 1 & 12 \\
\hline 11.22a & Hercules 3501-6nM6 unttape & (orgo)2s & & 2 & 13 \\
\hline 11 28a/11_22a & Hercules $3501-6 n$ m6 uni-tape & $((0 / 90) 2 s) s$ & & 2 & 16 \\
\hline $1128 \mathrm{~b}$ & Hercules 3501-6nk6 unjfape & $(0 / 90) 2 s$ & all taces up & 1 & 10 \\
\hline$x_{3}=05 a$ & Hereules 3501-6nM6 unitape & $(0) 8$ & gravity sag. see new data & 1 & 104 \\
\hline X3_056 & Hercules $3501-67 \mathrm{M} 6$ uni-tape & $(0) 8$ & & 3 & 55 \\
\hline$x 3$ 31a & Hercules 3501-6nM6 uni-tape & $(0) 12$ & & 1 & 35 \\
\hline$\not 3$ 31b & Hercules 3501-6nM6 uni-tape & $(0) 12$ & & 1 & 19 \\
\hline$x 5,15 a$ & YLA Inc. RS.3MS5S unitape & $(0) 12$ & Debulk every 6 plies & 3 & 73 \\
\hline$x x_{2} 22 a$ & MLA Inc., RS-3M55J unitape & $(0) 12$ & & 2 & 134 \\
\hline$\times 6 \_13 a=$ & YLA Inc., RS-3M55J uni-tape & $(0) 12$ & & 2 & 130 \\
\hline$\times 6$ _ $162 / \times 6 \_13 a$ & YYA Inc., RS-3/M55J unt-tape & $\mid((0)+2) s$ & & 1 & 62 \\
\hline$\times 6,23 a *$ & YLA Inc., RS-3nu55J unt-tape & $(0) 18$ & & 3 & 118 \\
\hline$x 6 \_30 a$ & Fibente 954-2AniMnM7 uni-tape & $(0) 16$ & Moderate snap/spring & 2 & 145 \\
\hline$\times 6 \_30 \mathrm{~b}=$ & Fiberite 954-2A/MUM7 uni-tape & $(0) 16$ & & 2 & 37 \\
\hline x7_05at & Bryte BTCy-1/7718 E-glass fabric & $(0) 8$ & Debulk every 4 plies & 1 & 75 \\
\hline$x 7 \_06 a / \times 6$ _30b & Fiberite 9542AMIMMM7 uni-tape & $((0) 16) s$ & Debulk every 8 plies & 3 & 22 \\
\hline$x 7 \_102=$ & Fiberite 954-2AIMUM7 uni-tape & $(0) 16$ & Debulk every ply & 4 & 30 \\
\hline$x 7.12 a \#$ & YLA Inc., RS-3/M55J uni-tape & $(0) 16$ & Debulk every ply & 4 & 125 \\
\hline$x 7,13 a / x 7 \_10 a$ & Fiberite 954-2A/M/M7 uni-tape & $((0) 16) s$ & Debulk every ply & 2 & 24 \\
\hline$x 7=14 a \times 7=12 a$ & YLA Inc., RS-3M55J unitape & $((0) \div 6) s$ & Debulk every ply & 2 & 75 \\
\hline$x 7 \_146 \#$ & YLA Inc, RS 3 M55J uni-tape & $(0) 96$ & Debulk every ply & 2 & 148 \\
\hline$x 7=17 \mathrm{a} / \times 7 \_14 \mathrm{~b}$ & YLA Inc., RS-3M55J unitape & $((0) 16) s$ & Debulk every ply & 1 & 100 \\
\hline$x 7 \_17 \mathrm{~b} / \times 6$ _23a & YLA Inc. RS-3M55J uni-tape & $((0)+8) s$ & Debulk every ply & 1 & 75 \\
\hline$x 7$ 18abr?_05a & Bryte BTCy-1/7718 E-glass tabric & $((0) 8) s$ & Debulk every piy & 1 & 23 \\
\hline$\times 7$ 18b: & Bryte BTCy-1/7718 E-glass tabric & $(0) 6$ & Debulk every ply & 2 & 128 \\
\hline x7_18a/x7_18b & Bryte BTCy-1/7718 E-glass tabric & $((0) 6) s$ & Debulk every ply & 1 & 42 \\
\hline
\end{tabular}

Note 1: Bold figures indicate a second cure laminate

Note 2 \# indicates a base panel which subsequently was used in a second cure

Note 3: The normal laminate code is modified. The second set of outside parentheses with the symmetric symbol, s, indicates a second cure panel. 


\section{a) Layup and bagging}

The laminates used in this study varied as to type of fiber and type of matrix resin. Each different system required certain details peculiar to that material. There are portions of the procedures which are common to all materials and those are discussed first. This is followed by explanations of variations for each special case. There are various layups used and the reason for each is discussed in the Results section. One key factor was to make unidirectional tape laminates thick enough so bending was negligible during deflection measurements of the base laminate.

b) Material storage

All of the materials used in this study were pre-impregnated fiber products which are know in the industry as "prepreg". This means that a matrix material is applied to the fibers of the composite in a partially cured form so that further exposure to elevated temperatures will cause the matrix to cure to the final state desired. This matrix material must be kept at relatively low temperatures during storage so that curing does not proceed to any extent during storage. This is accomplished by storing the materials at sub-ambient temperatures. The requirements, as supplied by the manufacturers, for our materials were:

\begin{tabular}{|l|l|l|}
\hline Manufacturer & $\begin{array}{l}\text { Material } \\
\text { Description }\end{array}$ & $\begin{array}{l}\text { Storage } \\
\text { Temperature }\end{array}$ \\
\hline YLA Inc. & RS-3 & $<40$ OF \\
\hline Bryte Technologies & BTCy-1 & $<32$ OF \\
\hline ICI Fiberite & $954-2 \mathrm{~A}$ & 0 OF \\
\hline
\end{tabular}

During this cold storage, the material is contained in a plastic bag which is sealed to protect the prepreg from external contamination, primarily moisture. The material must be allowed to come to room temperature while still in its storage bag or excessive condensation will occur. Moisture, if left in or on the prepreg, can lead to processing 
problems. The most notable of these is void formation due to the generation of water vapor during the high temperature processing of the laminate.

c) Ply preparation

Each material is delivered as a roll of pre-impregnated fiber. Rolls of unidirectional materials are 12 " wide and the woven material is $38^{\prime \prime}$ wide. The spools holding the material are of large, approximately $10 "$, diameter to minimize bending of the fiber. Rolled material may be cut manually with any sharp-edged device, such as scissors or a razor edge. For our study, the 12" unidirectional material was first cut on a machine which automatically unwound the roll and cut the plies to the desired length with a guillotine blade. Later this material was cut with a box knife for increased precision. The fabric material was cut with a box knife.

During the unrolling of the Bryte Technologies material extreme care had to used to prevent transfer of some matrix to the separator film. This was not discovered until a number of laminates had been fabricated and it may have been be the cause of some of the unusual results in earlier tests. (This points out one of the many problems that can arise in a production environment and which may contribute to residual stresses even more dramatically than the relatively well-defined and well-studied phenomena.) Some of these transfer areas were many square inches resulting in a ply which contained less resin than was intended. Unless the resin content of the prepreg was sufficient and resin flow very preferential, resin starved areas could result leading to voids in the finished laminate.

d) Layup

The next step in processing is to perform the "layup" of the laminate. This is the process of stacking individual plies in the desired orientation. However, there are some details which must be closely controlled. In this study both multidirectional and unidirectional layups were used. 
The alignment of each ply in the unidirectional layup is the same and this simplifies the layup procedure since all plies must be oriented in one direction. However, even in this case, handling of the relatively stiff plies, which are stacked from between 8 and 18 layers, requires good technique to ensure proper alignment. Improper alignment can cause problems as explained by Radford [20].

In the case of multidirectional layups, there are the problems discussed above and also the possibility of plies placed in gross misalignment. There is no reasonable method for checking ply stack alignment after the laminate is cured. There is one case in our work, 08_04a\&b, where ply misalignment was detected and the panels were not evaluated.

As part of the layup process, it is often necessary to "debulk" the laminate at some frequency [10]. It is common to debulk every two to four plies and in some cases a debulk step is required for each ply. The debulking process is simply the application of one atmosphere of pressure to the surface of the layup. The pressure is applied by use of a vacuum bag similar to that described in the next section. This debulk can be done at ambient temperature or at a slightly elevated temperature. The debulk time is usually short, a few minutes, but may range up to tens of minutes. The unintentional elimination of the debulk process led to some operational difficulties during this study, and will be discussed in the Results section.

e) Bagging and labeling

The bagging step of the process involves locating the laminate in a complex arrangement of plates and plastic films so that a uniform pressure may be applied to the laminate during the cure process. The application of pressure is accomplished by placing the assembly in a hydrostatic pressure vessel and applying a vacuum on the laminate side of the bagging. During this process any trapped gasses must be removed in order to minimize voids in the final product. A "breather" material is incorporated into 
the layup in order to allow volatiles to escape from the laminate. Also, some control must be maintained on the flow of the matrix resin during the low viscosity period of the process. The flow is controlled by "bleeder", which was not used in this work, and "dams" which keep the matrix contained laterally. The typical bagging system used in this program is shown in Appendix 3.

There were damming problems during the production of parts for this effort. A low cost dam material was used which lead to intrusion of the dam material into the laminate at the edges. This caused problems both in preparing the first laminate layer for subsequent cure and also in handling the second cure laminate and measuring the deflections.

Laminate labeling, a seemingly minor detail of the procedures, is nevertheless important. It is essential to have the directionality of the fiber orientation carefully described by the labeling as there is no simple method to determine it after cure. In addition, it is very important to know the vertical orientation of the top surface since the direction of any curvature is critical to the interpretation of results.

f) Curing

The matrix resin must be cured in order to develop the desired properties of the composite laminate. With prepreg material the most common curing technique in the aerospace industry is to utilize a combination of pressure and vacuum. This is accomplished in an autoclave which can provide a high pressure gas environment at high temperatures. All process runs from this study were done using a $4^{\prime} \times 8^{\prime}$ Devine or $4^{\prime}$ by $15^{\prime}$ Baron autoclave. A processing check list and sample data collection sheets are shown in Appendix 2.

Cure temperatures for many advanced composites are $250^{\circ} \mathrm{F}$ to $350^{\circ} \mathrm{F}$. Cure cycles can vary and are established by a combination of polymer chemistry and fluid 
mechanics combined with empirical investigations. The cure cycles used in this work are shown in Appendix 4.

When the laminate is removed from the autoclave, all of the bagging materials are stripped away and discarded. The laminate is marked with indelible gold ink and the edges are cleaned of any excess resin. The laminate is then ready for further use. In this study, the original laminate was measured and then prepared for use as the base laminate for the next portion of the testing. If the laminate was one that had been cured twice the only step remaining was the measurement of deflections.

g) Surface preparation

Laminates which were to be used as bases for the second cure of a symmetric laminate on top had to be prepared for that process to ensure the second cure laminate bonded well. There are a number of possible methods for accomplishing this. The . most common is the use of peel ply. This method was tried on some panels, but there was some concern that the peel ply could effect the surface enough to cause some warpage [20]. For most of our trials, preparation consisted of cleaning both surfaces and lightly abrading the surface that would be in contact with the next laminate. This process was done after the base laminate deflections were measured.

\section{Deflection measurement techniques.}

a) Moire measurements of surface

In the work of Daniel et al [4,] and Zewi et al [5], the Moire shadow technique was used to determine out-of-plane defections. This is a very good technique for determining deflections of large surfaces. Its major advantage for thin laminates is the ability to measure deflection with the laminate on edge with no significant gravitational effects. This technique does suffer somewhat from lack of precision due to the gradual variation of shading from the dark to light fringes. It was discovered, after many 
attempts, that with the resources available, the Moire shadow technique was to difficult to execute. We believe that the majority of the problem was due to the unavailability of a high quality master grating.

b) $\mathrm{CMM}$

There is equipment available today which allows for non-contact measurement of laminate deflections. The laminate can be arranged on edge with kinematic support to eliminate both gravitational and positioning device effects. A laser system then determines the surface form with very high precision. Unfortunately, this equipment was unavailable for this study.

c) Gauging

Guaging was the method used for determining the deflections of the panels produced during this program. It is straightforward and inexpensive to execute. The method lacks the sensitivity to determine changes in laminates that are not unidirectional. Uni-directional laminates have large deflections due to cure shrinkage in this type of testing. A diagram of the gauging setup is shown in Figure 1.

This method consists of supporting the $12^{\text {" by }} 12$ " panel on a triangle of jack screws with small radius cone tops. The surface of the panel is gauged using a light force dial indicator on a 12" extension which is attached to a very heavy base. The base slides on the granite surface plate that supports the jack screws and panel. Thus three points above the jack screws define a plane which is parallel to the surface which fixes the dial indicator height. The granite surface is marked with a grid which relates the position of the base to the position of the laminate panel.

Measurements are made at the intervals in both the $x$ and $y$ directions. Measuring begins one inch in from the edge of the panel and continues at three, six, nine and eleven inches. Thus there are 25 total measurements for each panel. Many 
Figure 1

Measurement Setup

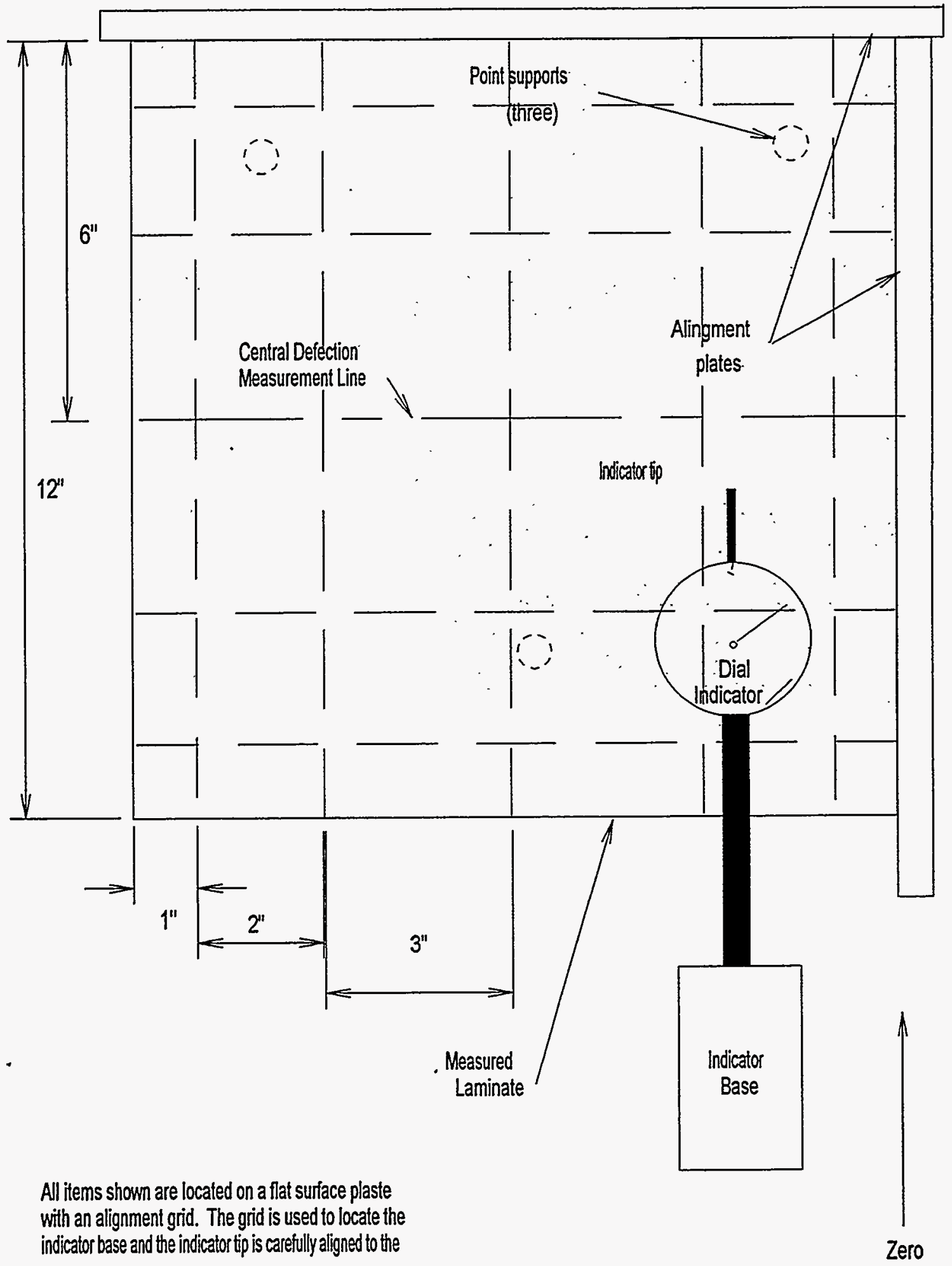

Fiber Axis 
panels were measured a number of times. All of the detail measured data is included in Appendix 5.

Care must be taken to design the experiment to minimize gravitational effects. If a laminate is too thin the gravitational effects are large. For instance, with a 12-ply unidirectional laminate of RS-3/M-55J, .030 "thick, a weight of $5 \mathrm{gm}$ 's at the center between supports 8 " apart resulted in a deflection of $.005 "$. If the laminate is made too thick, the residual stresses of cure shrinkage will not cause enough deflection for meaningful measurement. One possible concept of correcting for gravity is to measure with each face on top and then average the results.

One aspect of this form of measurement is that at high curvature the sensitivity to precise $\mathrm{x}, \mathrm{y}$ positioning is high. That is, a small change in $\mathrm{x}, \mathrm{y}$ position results in a large change in measured deflection, $z$. If the $x, y$ positioning is not highly accurate, there is not the increase in sensitivity that one might expect with high curvature. This, of course, would be different if an accurate coordinate measuring machine (CMM) were used to establish the surface profile. A scheme was devised to support the panels vertically with kinematic supports and to measure the surface profile with a non-contact gauging system on a CMM. However, resources did not permit this approach. 


\section{Results}

The test program consisted of three separate tasks. The first was to ensure that flat initial laminates could be produced and flatness could be measured. Second was to produce a set of laminates to demonstrate the usefulness of the test procedures on a well-characterized epoxy system, Hercules 3501-6. Third was to evaluate the polycyanate materials in the final phase of testing. A complete listing of all runs was presented earlier in Table 2. Appendix 5 contains details of all gauging measurements and includes three-dimensional plots of the gauged surfaces.

As the work progressed it became apparent that there were some interesting results which were not directly related to the initial intentions of this study. The principal side issue was the production of relatively flat laminates in routine layups. This is partially addressed in the work of Radford [20]. Because this is significant for the overall results, a number of the trial runs are directed at this issue. One factor affecting laminate quality was the lack of proper debulking. It would be of value to review the existing literature and, if necessary, do some experimental work to fully define the contribution of this procedure to panel quality, especially residual stress as evidenced by warpage.

The majority of the results are related to uni-directional panels. We have included data for the multidirectional laminates produced from unidirectional tape, but the results can not be analyzed with the approach described earlier since one requirement is for specially orthotropic laminates. Deflections for the multidirectional laminates were too small to be useful with mechanical gauging. These laminates do give an indication of how residual stresses can be contained withing a laminate with very little external evidence. 
We were unable to produce a reasonably flat laminate as a base laminate when using the Bryte BTCy-1 prepreg and data for that set of panels is limited and actually indicates a reversed effect. There were some early trails which used a carbon fabric reinforced, F263 epoxy matrix prepreg from Hexcell. These were very early developmental trials and are included only for completeness. They were not utilized in the analysis.

Panel identification was made using a month-of-day method. A panel produced in 1994 was given the designation MM_DDi. Where MM is the month of fabrication and DD is the day of fabrication and both include leading zeros. The "i" is an alpha character, beginning with "a", which signifies the sequence of panel produced on that day. For panels produced in 1995 the system was the same except that the month was XM where $x$ replaces the leading zero of the month. Thus in 1995 the second panel produced on June 30 would be $\times 6 \_30 \mathrm{~b}$.

\section{Data Reduction}

The theory presented earlier sets the stage for the analysis of the results. The data must be organized and reduced. This is followed by the relatively simple calculations of radii of curvature and chemical cure strains. However, some judgments must be made as to which measurement profile to select for use in curvature calculations.

Any number of presentations of the data are possible because rigid body rotations may be performed freely without changing the meaning of the information. However, the most useful presentation developed was the placement of the two edge mid-points at zero deflection followed by alignment of the centerline end points parallel to a plane containing the two edge points. This was the method used to generate the final database used throughout this thesis. The method is more clearly visualized by referring to one of the three-dimensional plots in Appendix 5. 
For the unidirectional laminates produced from unidirectional prepreg, the choice of data reduction methodologies is simplified. For all practical purposes, there will be no curvature in the longitudinal fiber direction. In the transverse direction, the curvature should be uniform along the full length of the fiber axis. There will be some slight anticlastic behavior at the ends. Qualitatively, this appears to the case for the results from this study. Thus, one is left with the choice to average the data along the five measured transverse curves or to just select one. We have chosen the latter technique and use the middle transverse set of measurements. This choice is based primarily on the fact that there is some slight tendency for the corners to sag a small amount at one end due to the type of support used during measurements.

The data used for the determination of curvature are, then, the deflections at the center of the plate relative to the datum lines parallel to the fibers $0^{\circ}$ degree direction and one inch in from each edge. This is shown in Figure 1. These central deflections and curvatures are presented in Table 3 as average values from multiple measurements. The F263 runs have been excluded from Table 3 for clarity.

There is also a result of the measurements which is referred to as total deflection. This data is listed in Tables 2 and also on the individual data sheets in Appendix 5. Total deflection refers to the full range from minimum to maximum deflection over the full panel surface. The total deflection is seen as a measure of the severity of warpage overall.

\section{The baseline - Hercules 3501-6/IM6}

The Hercules 3501-6 work was done using a 12" wide, unidirectional prepreg tape. There were ample quantities of this material available and therefore no restrictions on the thickness or number of laminates which could be produced. A total of 32 runs were made of which 12 were second cure runs where the new prepreg laminate is cured on the previously cured laminate panel. Eighteen runs were made using 
Table 3 -- Curvature Data

\begin{tabular}{|c|c|c|c|c|c|c|c|c|c|c|c|}
\hline & & & Thickness, & & Centra & Ilection & & & Radius of & Cure Straln & \\
\hline Run\# & Material & Layup & Inches & Comments & \begin{tabular}{|l} 
Sets \\
\end{tabular} & mils & JAvg & STdDev & Curvature, in. & Absolute & as \% \\
\hline $06,09 a 6,06 a$ & Hercules $3501.6 / \mathrm{mg}$ uni-tape & $((0) 16) 5$ & 0.185 & Autoclavo fallure cure repeated & 3 & 39 & & & 321 & $-3.8 E-04$ & $.0 .1 \%$ \\
\hline $08,09 \mathrm{~b} / 6.06 \mathrm{~b}$ & Herculos $3501-6 / 1 \mathrm{M} 6$ uni-tape & $(0) 16)^{s}$ & 0.180 & Autoclave reilure, cure repeated, peel ply & 2 & 51 & & & 246 & $-4.9 E-04$ & $-0.2 \%$ \\
\hline $06-17 a / 6-13 a$ & Hercules $3501-6 n \mathrm{M} 8$ uni-tape & $f(0) 16)^{5}$ & 0.189 & & 2 & 43 & & & 294 & $.4 .3 \mathrm{E}-04$ & $-0.1 \%$ \\
\hline $06.17 b / 613 b$ & Hercules $3501-8 / \mathrm{MB}$ uni-tape & 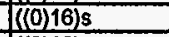 & 0.185 & Peel ply & $\frac{\pi}{2}$ & 48 & & & 260 & $-4.7 E-04$ & $-0.2 \%$ \\
\hline $1026 \mathrm{a} / 1021 \mathrm{a}$ & Hercules $3501-6 / \mathrm{M}$ B unl-tape & $\frac{1(0) 16) \mathrm{s}}{4}$ & 0.180 & & 2 & 48 & & & 260 & $-4,6 \mathrm{E}-04$ & $.0 .2 \%$ \\
\hline $10 \_26 \mathrm{~b} / 10 \_21 \mathrm{~b}$ & Hercules $3501-6 /$ Mm uni-tape & $\frac{f(0) 16) s}{(10)}$ & 0.180 & & 3 & 51 & 47 & $10.5 \%$ & 243 & $-4.9 E-04$ & $-0.2 \%$ \\
\hline $08,09 \mathrm{c} / 6,06 \mathrm{C}$ & Hercules $3501-8 / \mathrm{MB}$ uni-tape & $((0,90) 4 \mathrm{~s}) \mathrm{s}$ & 0.175 & Autoclave fallure cure repeated & 2 & 5 & & & 2778 & $-4.2 E=05$ & $0.0 \%$ \\
\hline $06,08 d 16,06 d$ & Hercules $3501.6 / \mathrm{hM} 6$ unf-tape & $((0,90) 45) \mathrm{s}$ & 0.175 & Autoclave fallure, cure ropeated, peel ply & 2 & 4 & & & 3125 & $.3 .7 E-05$ & $0.0 \%$ \\
\hline $08.17 \mathrm{c} / 6$. $13 \mathrm{C}$ & Hercules 3501 - 6 /IM6 uni-tape & $((0,90) 4 \mathrm{~s}) \mathrm{s}$ & 0.178 & & 2 & 4 & & & 3333 & $-3.6 \mathrm{E} \cdot 05$ & $0.0 \%$ \\
\hline $0617 \mathrm{~d} 16$ 13d & Hercules $3501.6 / 1 \mathrm{MB}$ unl-tape & $((0,90) 4 \mathrm{~s}) \mathrm{s}$ & 0.175 & Peel ply & 3 & 5 & 4 & $10.1 \%$ & 2679 & $-4.4 \mathrm{E} \cdot 05$ & $0.0 \%$ \\
\hline $11.14 a / 11.04 b$ & Hercules $3501.6 \mathrm{Am}$ unl-tape & $((0 /+1-45 / 90) \mathrm{s}) \mathrm{s}$ & 0.088 & & 2 & -2 & & & .5556 & $1.1 \mathrm{E}-05$ & $0.0 \%$ \\
\hline $1128 \mathrm{a} / 1122 \mathrm{a}$ & Herculos $3501.6 / \mathrm{M} 6$ uni-tapo & $f(0 / 90) 2 \mathrm{~s}) \mathrm{s}$ & 0.086 & & 2 & .7 & & & -1724 & $3.3 \mathrm{E}-05$ & $0.0 \%$ \\
\hline 06 _06a & Hercules $3501-8 / 1 \mathrm{M} 6$ uni-tape & $(0) 16$ & 0.090 & & 1 & -7 & & & -1786 & $3.4 \mathrm{E}-05$ & $0.0 \%$ \\
\hline $0606 \mathrm{bH}$ & Hercules $3501-6 / \mathrm{M} 6$ uni-lape & $(0) 16$ & 0.090 & Peel ply & 1 & -10 & & & -1316 & $4.6 E-05$ & $0.0 \%$ \\
\hline OB_13a\# & Harcules $3501-6 / 1 \mathrm{M} 6$ uni-tape & (0) 16 & 0.090 & & 1 & 2 & & & 8333 & $-7.2 \mathrm{E}-06$ & $0.0 \%$ \\
\hline 06 13b\# & Hercules $3501-6 / 1 \mathrm{M} 6$ unl-tape & $(0) 16$ & 0.090 & Peel ply & 1 & 10 & & & 1316 & $-4.6 \mathrm{E}-05$ & $0.0 \%$ \\
\hline $1021 \mathrm{aH}$ & Hercules $3501-6 / \mathrm{M} 6$ un -lape & $(0) 16$ & 0.090 & & 4 & $\frac{\pi}{2}$ & & & 6944 & $-8.6 \mathrm{E}-06$ & $0.0 \%$ \\
\hline $1021 \mathrm{~b} \#$ & Hercules $3501-6 / \mathrm{M}$ B unl-lape & $(0) 16$ & 0.090 & & 4 & -13 & .3 & $-299.7 \%$ & -929 & 6.5E-05 & $0.0 \%$ \\
\hline $06.06 \mathrm{cA}$ & Hercules $3501.6 / 1 \mathrm{M} 6$ uni-tape & $(0.90) 45$ & 0.088 & & $T$ & 1 & & & 12500 & $-4.7 E-06$ & $0.0 \%$ \\
\hline $0606 \mathrm{dAf}$ & Hercules $3501-6 / \mathrm{Mm}$ uni-tape & $(0,90) 4 \mathrm{~s}$ & 0.087 & Poel ply & 1 & -1 & & & -12500 & $4.6 \mathrm{E} \cdot 06$ & $0.0 \%$ \\
\hline $0613 \mathrm{c} \#$ & Hercules $3501-6 / \mathrm{M} 6$ un 1 -tape & $(0,90) 45$ & 0.087 & & 1 & $\frac{1}{1}$ & & & 12500 & $-4.6 \mathrm{EE}=06$ & $0.0 \%$ \\
\hline 06 .13d\# & Hercules $3501-6 / \mathrm{M} 6$ uni-tape & $(0,80) 4 \mathrm{~s}$ & 0.087 & Peolply & 1 & 2 & 1 & $167.8 \%$ & 6250 & $-9.3 \mathrm{E}-06$ & $0.0 \%$ \\
\hline $11.04 \mathrm{b \#}$ & Hercules $3501-6$-6IM6 unt-tape & $(001+1.45180) 5$ & 0.044 & & 1 & -2 & & & -8333 & $3.5 \mathrm{E}-06$ & $0.0 \%$ \\
\hline $1122 \mathrm{a} \#$ & Hercules $3501-6 / \mathrm{M} 6$ uni-tape & $(0 / 90) 25$ & 0.043 & & 2 & 3 & & & 4310 & $.6 .7 E-06$ & $0.0 \%$ \\
\hline$X 7 \_06 \mathrm{a} / \times 6$ 6 30b & Fiberite $554-2 \mathrm{M} M M M \mathrm{M} 7$ uni-tape & $((0) 16) \mathrm{s}$ & 0.188 & Debulk every 8 plles & $\overline{3}$ & 12 & & & 1087 & $-1.2 E \cdot 04$ & $0.0 \%$ \\
\hline$x 7^{133 a / \times 7+10 a}$ & Fiberite 954-2A1M/M7 unl-taps & ((0)16)s & 0.186 & Debulk every ply & 3 & 18 & 15 & $31.2 \%$ & 694 & $-1.8 \mathrm{E}-04$ & $-0.1 \%$ \\
\hline$\times 630 \mathrm{~b} \#$ & Fiberite 954-2A1MnM7 uni-tape & $(0) 16$ & 0.087 & & 2 & -6 & & & -2174 & $2.7 E \cdot 05$ & $0.0 \%$ \\
\hline X7_10a\# & Fiberite 954-2A/M/M7 uni-tape & (0) 16 & 0.090 & Debulk every ply & $\frac{\pi}{4}$ & $\frac{7}{1}$ & -2 & $-192.2 \%$ & 14286 & $-4.2 \mathrm{E}-06$ & $0.0 \%$ \\
\hline$\times 630 a$ & Fiberite 954-2AlMUIM7 unl-tape & $1(0) 16$ & 0.085 & Moderate snap/spring & 2 & -16 & & & -806 & $7.0 E \cdot 05$ & $0.0 \%$ \\
\hline$x 7$ 19a/x7_18b & Brie BTCy-17718 E-glass fabric & $(\langle(0) 6) \mathbf{s}$ & 0.134 & Debulk every ply & 1 & -37 & & & -338 & $2.6 \mathrm{E}-04$ & $0.1 \%$ \\
\hline$x 7$ 18a/x7,05a & Bryto BTCy-17718 E-glass fabric & $((0) 8) \mathrm{s}$ & 0.182 & Dobulk every ply & 1 & -13 & -25 & $-67.9 \%$ & -962 & $1.3 \mathrm{E} \cdot 04$ & $0.0 \%$ \\
\hline$x 7.18 \mathrm{~b} \#$ & Bryta BTCy-1/7718 E-glass fabric & $(0) B$ & 0.065 & Dabulk every ply & 2 & -81 & & & -154 & $2.8 E \cdot 04$ & $0.1 \%$ \\
\hline$\times 705 a$ & Brta BTCy-1/7718 E-glass fabric & $1(0) 8$ & 0.087 & Debulk every 4 plies & 1 & -51 & .66 & $-32.1 \%$ & -245 & $2.4 E-04$ & $0.1 \%$ \\
\hline 08 30a/08 18a & Bryta BTCY-1/7718 E-glass fabric & $((0,+1-45,90) \mathrm{s}) \mathrm{s}$ & 0.180 & & 6 & -20 & & & .638 & $1.9 \mathrm{E} \cdot 04$ & $0.1 \%$ \\
\hline 08 18äp & Bryte BTCY-17718 E-glass fabric & $(0,+l-45,90) \mathrm{s}$ & 0.088 & Peel ply on top & $\frac{5}{2}$ & .29 & & & -435 & $1.3 \mathrm{E}-04$ & $0.0 \%$ \\
\hline $08 \quad 04 a$ & Bryta BTCy-177718 E-glass fabric & $(0,90,+1-45) \mathrm{s}$ & 0.088 & Inncorect ply orientation & 4 & -11 & & & -1111 & $5.3 E-05$ & $0.0 \%$ \\
\hline $0804 \mathrm{~b}$ & Bryte BTCy-1/7718 E-glass fabric & $(0,90,+1-45) \mathrm{s}$ & 0.090 & Inncorect ply orlentation & 4 & 6 & & & 2000 & $-3.0 E-05$ & $0.0 \%$ \\
\hline$\times 6$-16a $\times 6 \ldots 13 a$ & YLAInC., RS-3/M55J UnI-tape & $((0) 12) s$ & 0.068 & & 1 & 52 & & & 243 & $-1.8 \mathrm{E} \cdot 04$ & $-0.1 \%$ \\
\hline$x 7,14 a d \times 7,12 a$ & YLAInc., RS-3/M55J uni-tape & $\frac{10016) \mathrm{s}}{4(0)}$ & 0.008 & Dobulkevery ply & 2 & 67 & & & 186 & $-3.2 E-04$ & $-0.1 \%$ \\
\hline$x 7 \_17 a / \times 7 \_14 b$ & YLAInc., RS-3/M55J uni-tape & $((0) 16) s$ & 0.088 & Debulk every ply & 1 & 74 & & & 169 & $-3.5 \mathrm{E}-04$ & $.0 .1 \%$ \\
\hline$x 7 \quad 17 b / \times 6$ & YLAIInC., RS-3/M55J Uni-tape & $f(0) 18) s$ & 0.100 & Debulk every ply & 1 & 62 & 64 & $14.9 \%$ & 202 & $-3.3 \mathrm{E}-04$ & $-0.1 \%$ \\
\hline$x 6$ 13a\# & YLA Inc., RS-3/M55J uni-tape & 10012 & 0.033 & & 2 & 98 & & & 128 & $-1.7 E-04$ & $-0.1 \%$ \\
\hline$x 7_{12} 12 a$ & YLAIInC., RS $3 /$ ML5JJ uni-tape & $\frac{10) 16}{16}$ & 0.044 & Debulk every ply & $\frac{2}{4}$ & 27 & & & $\frac{2.00}{457}$ & $\frac{-1.01-04}{.6 .4 E-05}$ & $-0.0 \%$ \\
\hline$x 7,14 \mathrm{bH}$ & YLAInc. RS-3/M55J UnI-tape & 0 & 0.043 & Debulk every ply & 2 & 86 & & & 146 & $-2.0 E-04$ & $-0.1 \%$ \\
\hline$\times 6$ 23a\# & YLAInc. RS-3/M55J unI-tape & $\frac{10) 18}{10}$ & 0.050 & & 3 & 20 & 58 & $68.9 \%$ & 625 & $-5.3 E-05$ & $0.0 \%$ \\
\hline$\times 5.15 a$ & YLAInC., RS -3MM5J J uni-tape & 0 & 0.034 & Debulkevery 6 plies & 3 & 30 & & & 417 & $-5.4 E-05$ & $0.0 \%$ \\
\hline$\times 5,22 a$ & YLAInC., RS-3/M5SJ Uni-tape & $(0) 12$ & 0.033 & & 2 & 44 & & & 282 & $-7.8 \mathrm{E}-05$ & $0.0 \%$ \\
\hline
\end{tabular}


unidirectional layups and six of these were second cure runs. The remaining 14 runs were multidirectional layups and six of these were second cure runs.

\section{a) Base Panels}

The production of relatively flat laminates from the 3501-6 material was straightforward. The properties of the first cure panels and the total deflections are in Table 2. The unidirectional panels have an average out of flatness of $+1-.007^{\prime \prime}$ and the multidirectional panels of $+/ .002$ inches. This is reasonably good quality for large flat panels. However, there are some anomalies which are not included in the above averages. Panel x3_06a exhibited severe distortion. This was partially due to its thinness, 8 ply, which leads to very low stiffness in the transverse direction. Even with careful technique, it was difficult to obtain deflection measurements which are free from gravitational effects on the thinner panels. These very thin panels were not used as bases for second cure panels.

b) Second cure panels

The overall comparison of the base laminates to second cure laminates is easily visualized in Figures 2 and 3 where the curvature of the base and second cure lateral deflection profiles are plotted for each laminate. In these plots, the second cure face is downward. Complete, detailed measurements are presented in Appendix 5 where three-dimensional plots of the deflection surfaces are also provided.

It became very clear early in the program that, in order to utilize conventional deflection measurement techniques, unidirectional laminates would be necessary to produce significant deflection. For the multidirectional laminates the total out-of-flatness of first cure and second cure laminates are virtually identical and also small at $+1-5$ mils. The direction of curvature is in accordance with expectations for 0/90 laminates. For the more stable $0 /+1-45 / 90$ laminates, the direction of curvature does not even have the proper sense in that it is concave toward the first panel side. This situation is 
Figure 2

Unidirectional Base Case

Hercules 3501-6/IM6

Cross Section Profiles
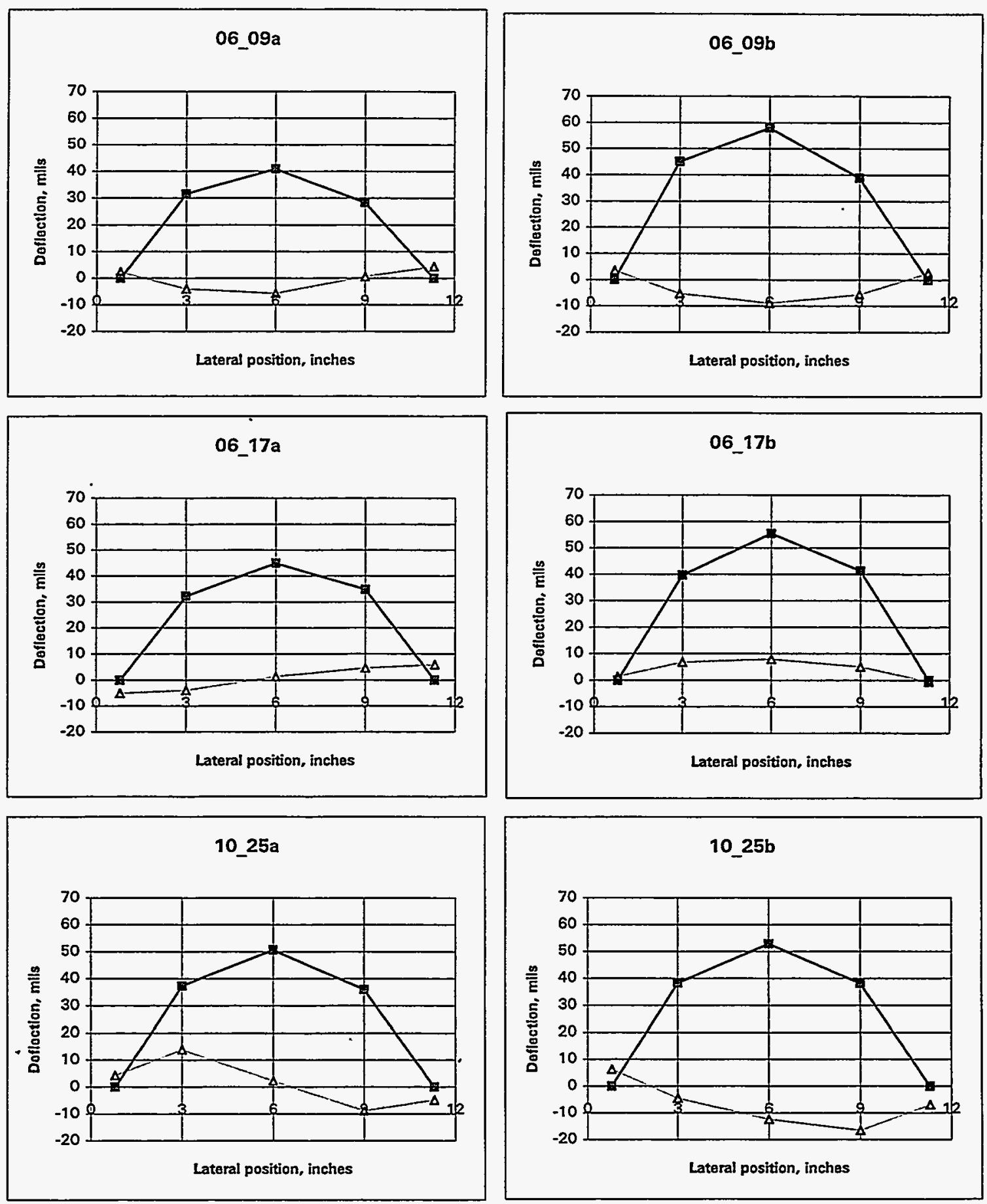

$\square-$ Second Cure Laminate

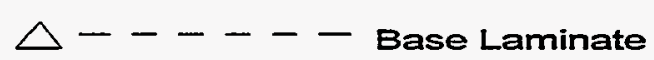


Figure 3

Multidirectional Base Case

Hercules 3501-6/IM6

Cross Section Profiles
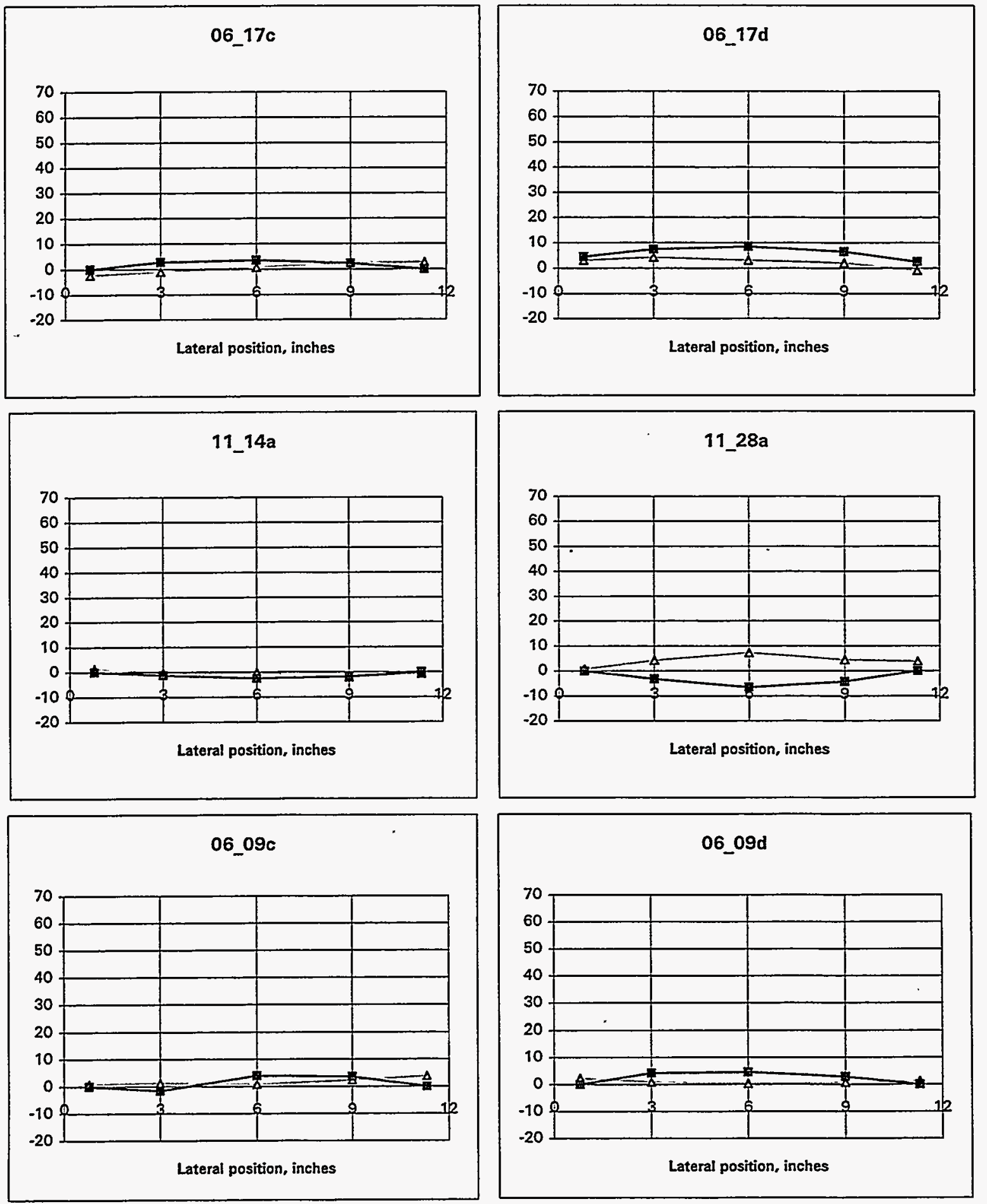

$\square \longrightarrow$ Second Cure Laminate

$\triangle-----$ Base Laminate 
probably a result of other process factors, such a individual ply alignment, beginning to dominate the cure shrinakage effects.

The data for the unidirectional laminates are very clearly indicative of cure shrinkage in the second cure laminate. The central deflection increases from -3 mils to 55 mils and the curvatures are clearly in the direction one would predict. The variation in out-of-plane deflections for the base panels is and the standard deviation is $300 \%$ of the average value. However, the second cure panels have a standard deviation of only $11 \%$ of the average deflection. Thus, the more uniform and longer lever arm stress field imposed by the cure shrinkage of the second cure laminate is dominant over the more random causes of non-flatness in the base laminate. The calculated cure shrinkage strain for these panels is $-4.5 \mathrm{E}-04$ with a standard deviation of $9 \%$. The above information is tabulated in Table 3.

For this system, Hercules 3501-6, there is some well defined information on cure shrinkage from Russell [10]. In that work, the total cure shrinkage is assessed to be $3.38 \%$ for the matrix and $1.89 \%$ for the composite. While that work does ignore the curing which occurs during the heating stages, it is a good first approximation of unconstrained shrinkage.

It is beyond the scope of this thesis to evaluate the unrestrained shrinkage which would result in the observed deflections. However, the strain values above indicate an effective, constrained, second layer cure shrinkage of $.05 \%$.

Evaluation of the polycyanate systems

Three manufacturers provided polycyanate ester matrix prepreg systems which were evaluated. The matrix resins for the systems were 954-2A from ICl Fiberite, RS-3 from YLA Inc., and BTCy-1 from Bryte Technology. The fiber types differed among the samples as did the form of the reinforcement. A summary of the individual systems is 
presented in Table 1 and more detail is included in Appendix 6. Because of the high cost of this type of prepreg, only a limited amount of material was available for evaluation.

There can be no direct comparison of the three systems because of the differences in the reinforcement types. Each system required certain accommodations in order to use it in this study. This was a result of a number of issues which included operational difficulties, lack of experience in producing flat laminates from these very low viscosity materials, the limited amount of material available, and the inability to measure deflections with the panel vertical,

Some of the operational difficulties were those which might be expected in routine procedures. The most significant are included as comments in the tables. Some of the problems were specific to a system and are discussed below in the section for that system.

A significant problem occurred due to the unintentional lack of inclusion of a debulk step. With the unidirectional polycyanate systems this led to incomplete elimination of vapors from the laminate. The surfaces were mottled with pockets of vapor and it is presumed that significant internal voids were present. There were not sufficient resources to determine the actual void content of the laminates. The introduction of a proper debulk step improved the situation and resulted in laminates of superior visual quality.

a) YLA Inc. - RS-3

The material supplied by YLA contained a 6K, 77 MSI modulus fiber, Toray M55J, as the reinforcement. The $6 \mathrm{~K}$ M55J fiber results in an single ply areal weight of only 69 $\mathrm{gm} / \mathrm{sq} \mathrm{m}$ and a thickness of only 2.5 mils per ply. Our lack of familiarity with the combination of this resin and fiber demanded some preliminary runs in order to begin 
producing quality laminates. When the first laminates were produced debulking was unintentionally not included in the processing. This resulted in the previously described poor removal of volatiles. The was corrected and debulking was incorporated into the procedures.

The first panels of this material were 12 ply unidirectional laminates which were only .030" thick. These were thought to be of very little value to the study due to the low transverse stiffness associated with the thinness of the panels. A non-contact, vertical plate measuring system, described earlier, would have alleviated the problem to a large extent. A qualitative measure of curvature at the end edges was assessed using simple photocopying techniques but is not included here for sake of brevity. The panel was supported on edge on the copying machine and the edge curvature could be determined from the photocopy.

The panels included in the analytical results are one $12 \mathrm{ply}$, two $16 \mathrm{ply}$, and one 18 ply laminates. The higher ply count laminates were more useful since base laminate deflections could be obtained with a minimum of bending imposed by gravity and the measurement device. The data is summarized in Table 3 and details are in Appendix 5. Plots of the central deflection profiles are presented in Figure 4. The central deflection of these panels changed only from 58 mils to 64 mils between the first and second cure. However the standard deviation of the data decreased from $69 \%$ to $15 \% .$. Since the base panels were warped, the use of second cure panel curvature to estimate cure strain is not justified from these trials.

b) Bryte Technology Inc. -- BTCy-1

The woven glass fabric prepreg supplied by Bryte Technology Inc. is representative of material used for the production of high performance circuit boards. This material contained reinforcement similar to that used by Daniel et al [4] and so no difficulty was expected in obtaining similar results. 

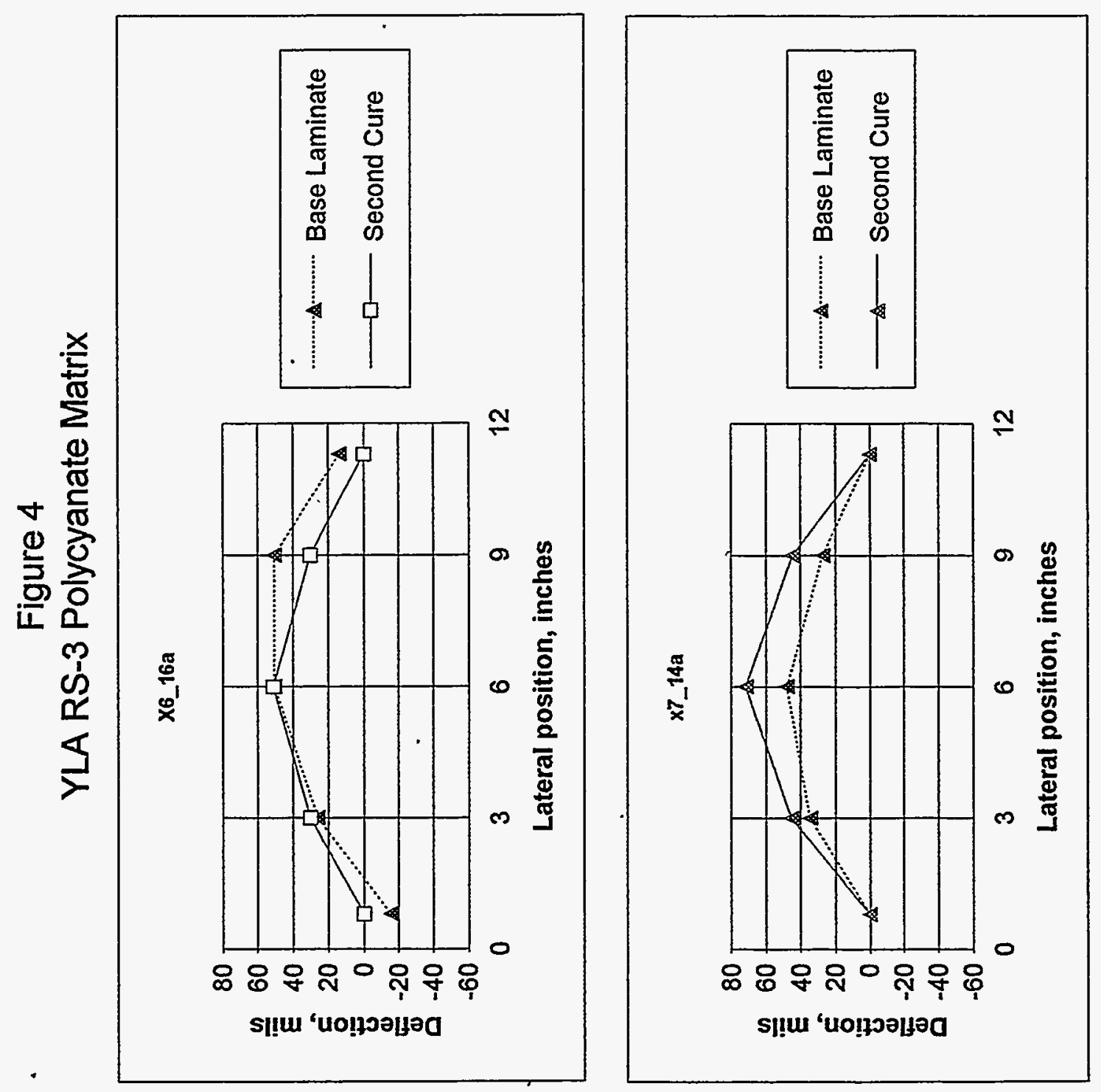
In an attempt to make the deflection field symmetrical, a 0/+/45/90 layup was used for the first set of samples. A mistake in the ply orientation on runs $08 \_04 a$ and $b$ resulted in badly warped panels with total defection of 60-90 mils. A second trial, 08_18a, produced a panel which was only slightly improved, 47 mils total deflection, even though no known problems had occurred in fabrication. A second cure panel, 08_30a, was cured on the 08_18a base panel and this panel actually had reduced warpage with a total deflection of 29 mils. The results of the second cure panel are similar in magnitude to what Daniel found on the second cure laminates in his work, but the curvatures have the opposites sense. The gross curvature is in the wrong direction for a cure shrinkage effect. However, the change is curvature from the base to second cure panel is in the direction expected for cure shrinkage. It is important to remember that Daniel did not report the flatness of the first cure plates.

Two more panels was produced using the unidirectional layup as used by Daniel. One panel was 8 plies per layer ( 16 total) and the other was 6 plies per layer. The base panel warped in a saddle shape in both cases. The total deflection was again high at 75 mils.

The cure shrinkage strains which have been determined are presented in summary in Table 3. Total deflection data is summarized in Table 2 and complete deflection profiles are in Appendix 5. Plots of the central deflection profiles are presented in Figure 5. The two uni-directional panels resulted in gross curvatures which were opposite to expectations. This effect is likely a result of other variables as discussed in the theory section. The use of a non-bleeding process system can result in significant variations in resin distribution and associated residual stresses because there is little or no resin movement during processing. The second cure panels did demonstrate a large change in curvature in the expected direction. 


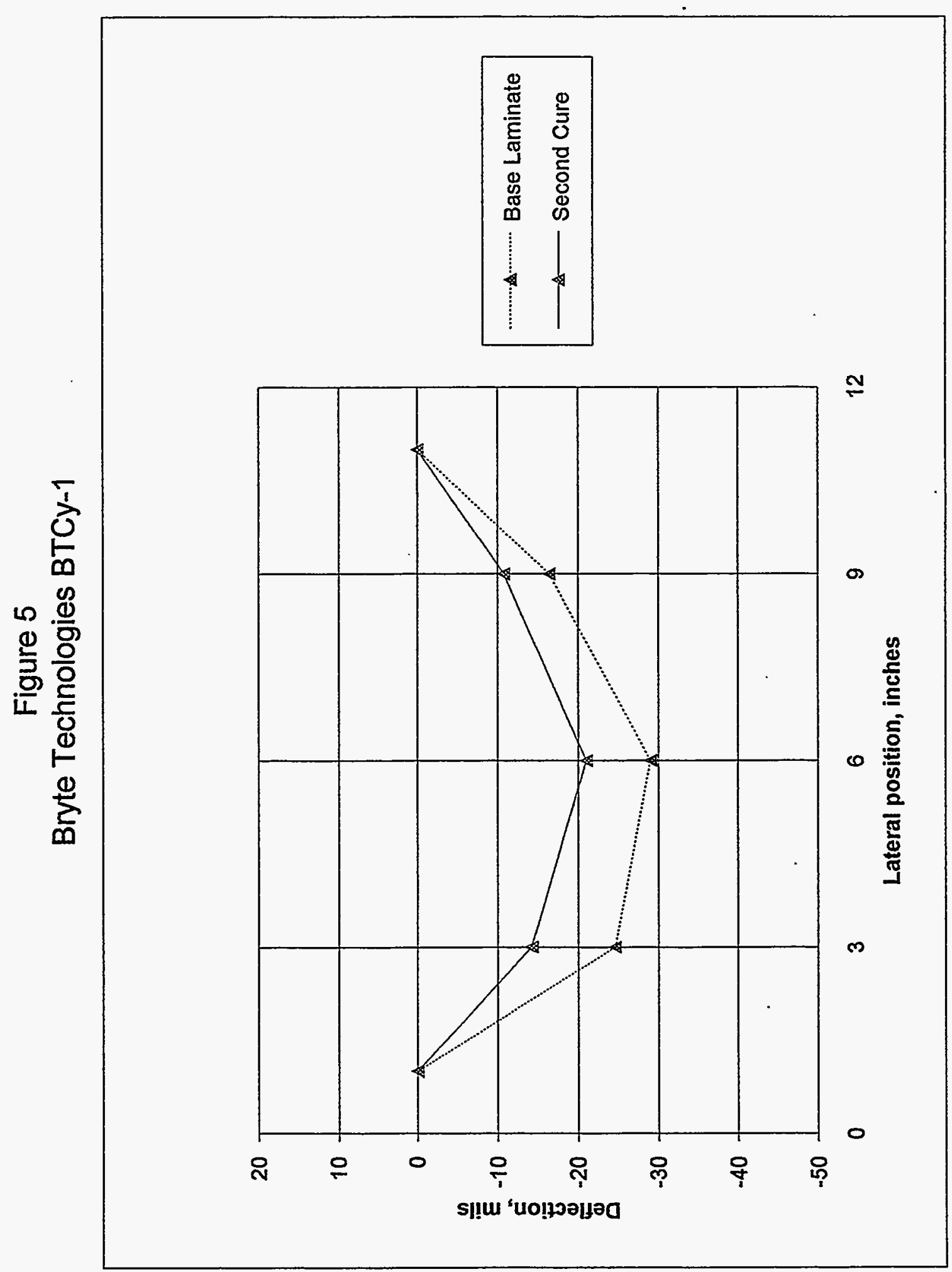




\section{c) Fiberite $954-2 \mathrm{~A}$}

There was a very limited amount, 109 lineal feet, of this material available. A 16 ply unidirectional layup was chosen for these trials. This provided a balance between the number of replicate runs and the gravitational effects involved in deflection measurements. As a result only two complete test panels were produced.

The cure shrinkage strains which have been determined are presented in summary in Table 3. Total deflection data is in Table 2 and deflection surface profiles are in Appendix 5. Plots of the central deflection profiles are presented in Figure 6. The measured results for the panels show reasonably good agreement. For the second cure panels the total deflections were 22 and 24 mils and the central deflections were 12 and 17 mils. The central deflection increased from -2 mils in the base case to 15 mils in the second cure panels. The cure strain calculated from equations 1 through 5 was $-1.5 \mathrm{E}-$ 04 . This value is about $70 \%$ less than seen with the Hercules $3501-6$ epoxy system.

\section{Overall Results}

The summary of results along with basic statistical information is presented in Table 4. As mentioned before, direct comparisons would not be valid since the reinforcements are different for all of the systems. However, the Hercules 3501-6 with IM6 fiber and the Fiberite 954-2A with IM7 fiber have similar reinforcements. Comparisons of these two systems show the polycyanate to have about one third the cure strain of the epoxy. 
Figure 6

Fiberite 954-2A Polycyanate Matrix
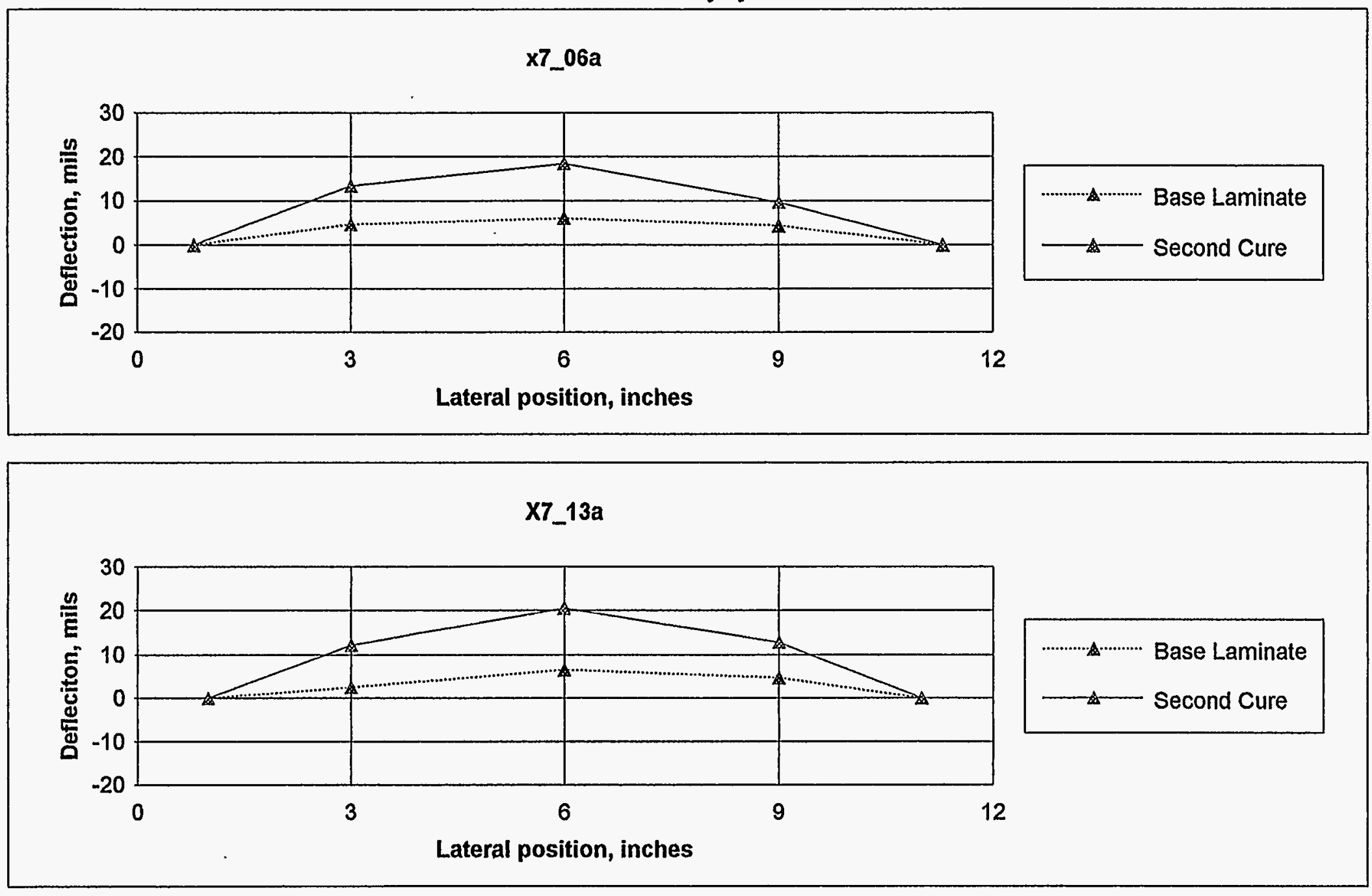
Table 4.

Curvature of Second Cure Panels

\begin{tabular}{|c|c|c|c|c|c|c|c|c|c|c|c|}
\hline \multirow[b]{2}{*}{ Run \# } & \multirow[b]{2}{*}{ Material } & \multirow[b]{2}{*}{ Layup } & \multirow{2}{*}{$\begin{array}{c}\text { Thickness, } \\
\text { inches }\end{array}$} & \multirow[b]{2}{*}{ Comments } & \multicolumn{2}{|c|}{ Central Deflection } & \multirow{2}{*}{$\begin{array}{c}\text { Radius of } \\
\text { Curvature, in }\end{array}$} & \multicolumn{3}{|c|}{ Cure Strain } & \multirow[b]{2}{*}{ as \% } \\
\hline & & & & & Sets & mils & & Absolute & Average & Std.Dev. & \\
\hline $06 \quad 09 a / 6 \quad 06 a$ & Hercules 3501-6/M6 uni-tape & $((0) 16) s$ & 0.185 & Autoclave fallure cure repeated & 3 & 39 & 321 & $-3.8 \mathrm{E}-04$ & & & $.0 .1 \%$ \\
\hline $06 \quad 09 b / 6 \quad 06 b$ & Hercules 3501-6/M6 uni-tape & $((0) 16) s$ & 0.180 & Autoclave fallure, cure repeated, peel ply & 2 & 51 & 246 & $-4.9 E-04$ & & & $-0.2 \%$ \\
\hline $06 \_17 a / 6 \quad 13 a$ & Hercules 3501-6/M6 uni-tape & $((0) 16) s$ & 0.189 & & 2 & 43 & 294 & $-4.3 \mathrm{E}-04$ & & & $-0.1 \%$ \\
\hline $06 \_17 b / 6 \_13 b$ & Hercules 3501-6/M6 uni-tape & $((0) 16) s$ & 0.185 & Peel ply & 2 & 48 & 260 & $-4.7 E-04$ & & & $.0 .2 \%$ \\
\hline $10 \_25 a / 10 \_21 a$ & Hercules 3501-6/M6 uni-tape & $((0) 16) s$ & 0.180 & & 2 & 48 & 260 & $-4.6 E-04$ & & & $-0.2 \%$ \\
\hline $10 \_26 \mathrm{~b} / 10 \quad 21 \mathrm{~b}$ & Hercules 3501-6/M6 uni-tape & $((0) 16) s$ & 0.180 & & 3 & 51 & 243 & $-4.9 E-04$ & $-4.5 \mathrm{E}-04$ & $-9.1 \%$ & $-0.2 \%$ \\
\hline $06.09 \mathrm{c} / 6 \quad 06 \mathrm{c}$ & Herculos 3501-6/M6 un1-tape & $((0,90) 4 s) \mathrm{s}$ & 0.175 & Autoclave failure cure repeated & 2 & 5 & 2778 & $-4.2 E-05$ & & & $0.0 \%$ \\
\hline $06 \quad 09 d / 6 \quad 06 d$ & Hercules 3501-6/M6 uni-tape & $((0,90) 4 s) \mathrm{s}$ & 0.175 & Autoclave fallure, cure repeated, peel ply & 2 & 4 & 3125 & $-3.7 E-05$ & & & $0.0 \%$ \\
\hline $06 \_17 \mathrm{c} / 6 \_13 \mathrm{c}$ & Hercules 3501-6/Mm6 uni-tape & $((0,90) 4 \mathrm{~s}) \mathrm{s}$ & 0.178 & & 2 & 4 & 3333 & $-3.6 \mathrm{E}-05$ & & & $0.0 \%$ \\
\hline $06.17 d / 6,13 d$ & Hercules 3501-6/MB uni-tape & $((0.90) 4 s) \mathrm{s}$ & 0.175 & Peel ply & 3 & 5 & 2679 & $-4.4 E-05$ & $-4.0 E-05$ & $-9.5 \%$ & $0.0 \%$ \\
\hline $11.14 a / 11,04 b$ & Hercules 3501-6/IM6 uni-tape & $((0 /+1-45 / 90) s) s$ & 0.088 & & 2 & -2 & -5556 & 1.1E-05 & $1.1 \mathrm{E}-05$ & NA & $0.0 \%$ \\
\hline 11_28a/11_22a & Hercules 3501-6/MG unl-tape & $((0 / 90) 2 s)_{s}$ & 0.086 & & 2 & .7 & -1724 & 3.3E-05 & 3.3E-05 & $\mathrm{NA}$ & $0.0 \%$ \\
\hline$x 7 \quad 06 \mathrm{a} / \times 6 \quad 30 \mathrm{~b}$ & Fiberite 954-2A/M/IM7 unl-tape & $((0) 16) \mathrm{s}$ & 0.188 & Debulk every 8 plles & 3 & 12 & 1087 & $-1.2 E-04$ & & & $0.0 \%$ \\
\hline$x 7 \quad 13 \mathrm{a} / \times 7 \quad 10 \mathrm{a}$ & Fiberite 954-2A/M/M7 unl-tape & $((0) 16) s$ & 0.186 & Dabulk every ply & 3 & 18 & 694 & $-1.8 \mathrm{E}-04$ & $-1.5 E-04$ & $-30.4 \%$ & $-0.1 \%$ \\
\hline$x 7$ 19a/x7_18b & Bryte BTCy-1/7718 E-glass fabric & $((0) 6) s$ & 0.134 & Dobulk overy ply & 1 & -37 & -338 & 2.6E-04 & & & $0.1 \%$ \\
\hline$\times 7 \quad 18 a / \times 7 \quad 05 a$ & Bryte BTCy-1/7718 E-glass fabric & $((0) 8) \mathrm{s}$ & 0.182 & Debulk overy ply & 1 & -13 & -962 & 1.3E-04 & 2.0E-04 & $50.0 \%$ & $0.0 \%$ \\
\hline $08 \quad 30 a / 08 \quad 18 a$ & Bryte BTCy-1/7718 E-glass fabric & $((0,+1-45,90) s) \mathrm{s}$ & 0.180 & & 6 & -20 & -638 & $1.9 \mathrm{E}-04$ & $1.9 \mathrm{E}-04$ & $\mathrm{NA}$ & $0.1 \%$ \\
\hline$\times 6 \quad 16 a / \times 6 \quad 13 a$ & YLA Inc., RS-3/M55J uni-tape & $((0) 12) s$ & 0.066 & & 1 & 52 & 243 & $-1.8 \mathrm{E}-04$ & & & $-0.1 \%$ \\
\hline$\times 7 \quad 14 a / \times 7 \quad 12 a$ & YLA Inc., RS-3/M55J unl-tape & $((0) 16) s$ & 0.088 & Dabulk every ply & 2 & 67 & 186 & $-3.2 \mathrm{E}-04$ & & & $-0.1 \%$ \\
\hline$x 7 \quad 17 \mathrm{a} / \times 7 \quad 14 b$ & YLA inc., RS-3/M55J uni-tape & $((0) 16) s$ & 0.088 & Debulk overy ply & 1 & 74 & 169 & $-3.5 \mathrm{E}-04$ & & & $-0.1 \%$ \\
\hline$x 7 \_17 b / \times 6 \_23 a$ & YLA Inc., RS-3/M55J uni-tape & $((0) 18) s$ & 0.100 & Debulk every ply & 1 & 62 & 202 & $-3.3 E-04$ & $-2.9 E-04$ & $-25.9 \%$ & $-0.1 \%$ \\
\hline
\end{tabular}

Note 1: Bold figures indicate a second cure laminate

Note 2: \# indicates a base panel which subsequently was used in a second cure

Note 3: The normal laminate code is modified. The second set of outside parentheses with the symmetric symbol, s, indicates a second cure panel. 


\section{Conclusions and Recommendations}

This work was performed with the intent of providing cure shrinkage data on the relatively new polycyanate matrix composites. No direct comparisons can be made between the various systems evaluated because of differences in reinforcement types and limited quantities of data. What is clear, is that in unidirectional composites, cure shrinkage effects can contribute significantly to residual stress and the resulting warpage. In multidirectional composites the obvious effects, as determined by out-ofplane defections, are very much diminished since the panel stiffnesses are very much higher in the non-zero axis directions.

The measurement of the flatness of the base laminates provided a clear picture that there are other processing variables which can lead to warpage. However, even where there was significant warpage in the base panel, the resulting second cure panels exhibited especially uniform warpage results. Because of this, we believe that the use of the unidirectional laminate approach can provide a relatively low resource method for evaluation of the cure shrinkage of matrix systems.

Significant improvements in the technique would be provided by use of noncontact CMM measurements of the plates in an on-edge, kinematically supported mode. This would allow the use of thinner laminates with larger deflections associated with the cure shrinkage.

As with any test program, care must be taken to provide a minimum of impact of non-test variable on the results. In the case of composites this requires directing a significant portion of the test effort to assuring that the many small details are done with a high quality level. Creating a laminate with "text book" properties is difficult. If one pursues this work we advise that a base laminate capability be proven for each system prior to proceeding to the second cure portion of the program. We believe that the most critical parameter is controlling the uniformity of resin distribution in the laminate. We 
also suggest investigating the concept of trimming the second cure panel and conducting a second set of deflection measurements. There is a significantly increased chance of having non-uniform conditions in the laminate near the edges.

The usefulness of Daniel's approach has been confirmed. The expected lower "effective" cure shrinkage of the polycyanate resin systems in composite laminates is clearly evident. Further work to define cure shrinkage differences using the approach of this thesis is justified by the results. 


\section{References}

1. Fang, T. and Shimp, D. A., "Polycyanate Esters: Science and Applications," Progress in Polymer Science, Vol. 20, 1995, pp. 61-118

2. Crasto, A. S. and Kim, R. Y., "On the Determination of Residual Stresses in Fiber-Reinforced Thermoset Composites", Journal of Reinforced Plastics and Composites, Vol. 12, May 1993, pp. 545-558

3. Pagano, N. J. and Hahn, H. T., "Evaluation of Composite Curing Stresses," Composite Materials: Testing and Design (Fourth Conference), ASTM STP 617, American Society for Testing and Materials, 1977, pp. 317-329

4. Daniel, I. M., Wang, T. M., Karalekas, D., and Gotro, J. T., "Determination of Chemical Cure Shrinkage in Composite Laminates," Journal of Composites Technology \& Research, Vol 12, No. 3, Fall 1990, pp. 172-176

5. Zewi, I. G., Daniel, I. M., and Gotro, J. T., "Residual Stresses and Warpage in Woven-Glass/Epoxy Laminates," Experimental Mechanics, March 1987, pp. 44-50

6. Nairn, J. A., and Zoller, P., "Matrix Solidification and the Resulting Residual Thermal Stresses in Composites," Journal of Materials Science, Vol. 20, 1985, pp. 355367

7. Yates, B., McCalla, B. A., Phillips, L. N., Kingston-Lee, D. M., and Rogers, K. F., "The Thermal Expansion of Carbon Fibre-Reinforced Plastics," Journal of Materials Science, Vol 14, 1979, pp. 1207-1217

8. Snow, A. W. and Armistead, J. P., "A Simple Dilatometer for Thermoset Cure Shrinkage and Thermal Expansion Measurements," Journal of Applied Polymer Science, Vol. 52, 1994, pp. 401-411

9. Penn, L. S., Chou, R. C. T., Wang, A. S. D., and Binienda, W. K.; "The Effects of Matrix Shrinkage on Damage Accumulation in Composites," Journal of Composite Materials, Vol. 23, June 1989, pp 570-586

10. Russell, J. D., "Cure Shrinkage of Thermoset Composites," SAMPE Quarterly, January 1993, pp. 28-33

11. Peretz, D., and Weitsman, Y., "Nonlinear Viscoelastic Characterization of FM-73 Adhesive,"Journal of Rheology, Vol. 26, No. 3, 1982, pp. 245-261

12. Peretz, D., and Weitsman, Y., "The Nonlinear Thermoviscoelastic

Characterizations of FM-73 Adhesives,"Journal of Rheology, Vol. 27, No. 2, 1983, pp. 97-114

13. Hahn, H. T., and Pagano, N. J., "Curing Stresses in Composite Laminates," Journal of Composite Materials, Vol. 9, January 1975, pp. 91-106

14. Jones, F. R., Mulheron, M., and Bailey, J. E., "Generation of Thermal Strains in GRP. Part 2: The Origin of Thermal Strains in Polyester Cross-Ply Laminates," Journal of Materials Science, Vol. 18, 1983, pp. 1533-1539

15. Jones, R.M., Mechanics of Composite Materials, New York, Hemisphere Publishing Corporation, 1975. 
16. Tsai, S. W. and Hahn, H. T., Introduction to Composite Materials, Connecticut, Technomic Publishing Co., 1980.

17. Timoshenko, S., "Analysis of Bi-Metal Thermostats," Journal of the Optical Society of America and Review of Scientific Instruments, Vol. 11, No. 3, September 1925, pp. 233-255

18. Harper, B., Peretz, D., and Weitsman, Y., "Assessment of Chemical CureShrinkage Stresses in Two Technical Resins,", pp. 29-35

19. White, S. R. and Hahn, H. T., "Process Modeling of Composite Materials:

Residual Stress Development During Cure. Part II. Experimental Validation," Journal of Composite Materials, Vol. 26, No. 16, 1992, pp. 2423-2453

20. Radford, D. W, "Cure Shrinkage Induced Warpage in Flat Uni-Axial Composites," Journal of Composites Technology \& Research, Vol. 15, No. 4, Winter 1993, pp. 290-296 


\section{Appendix 1 --Manufacturers Rheology Information}

A set of samples of typical rheological data which is available from the manufacturers of prepreg materials. 


\section{A Data Sheet from}

\section{(C) FIBERITE}

937A EPOXY RESIN

Straight Heat-Up Cure Cycle to $350^{\circ} \mathrm{F}\left(177^{\circ} \mathrm{C}\right)$

\section{A VISCOSITY PROFILE}

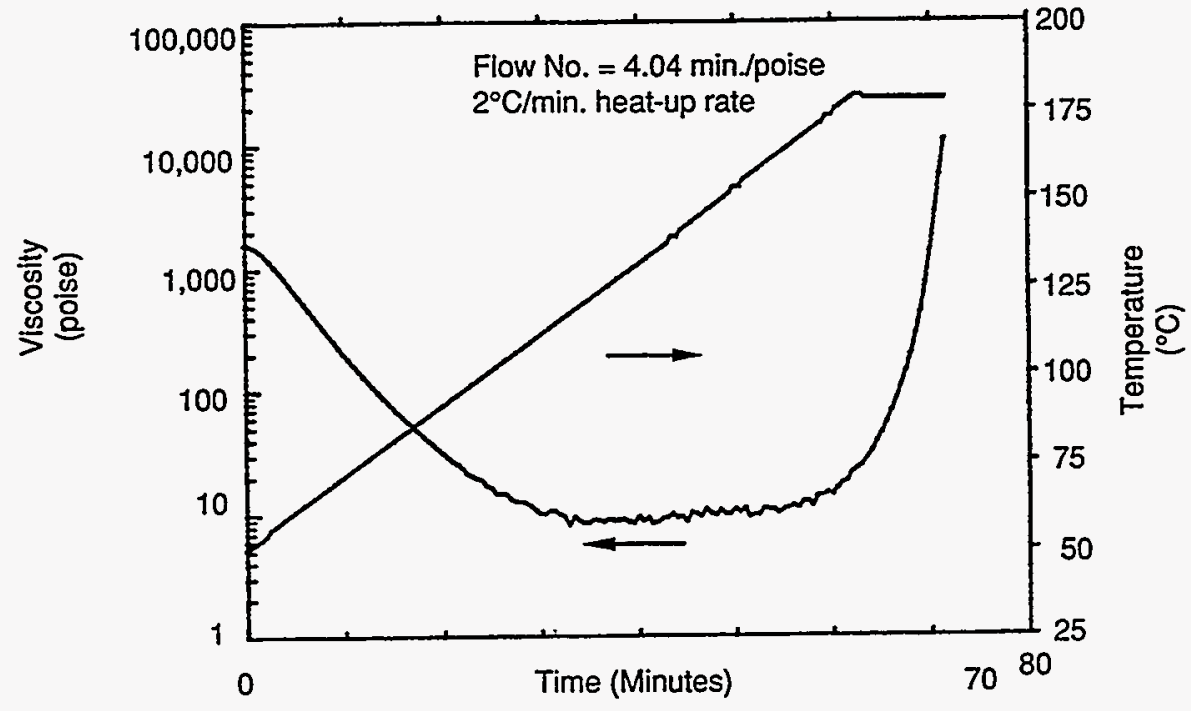

937A VISCOSITY PROFILE

Stepped Cure Cycle: Heat-up to $250^{\circ} \mathrm{F}\left(121^{\circ} \mathrm{C}\right)$, hold for 60 minutes, heat-up to $350^{\circ} \mathrm{F}\left(177^{\circ} \mathrm{C}\right)$

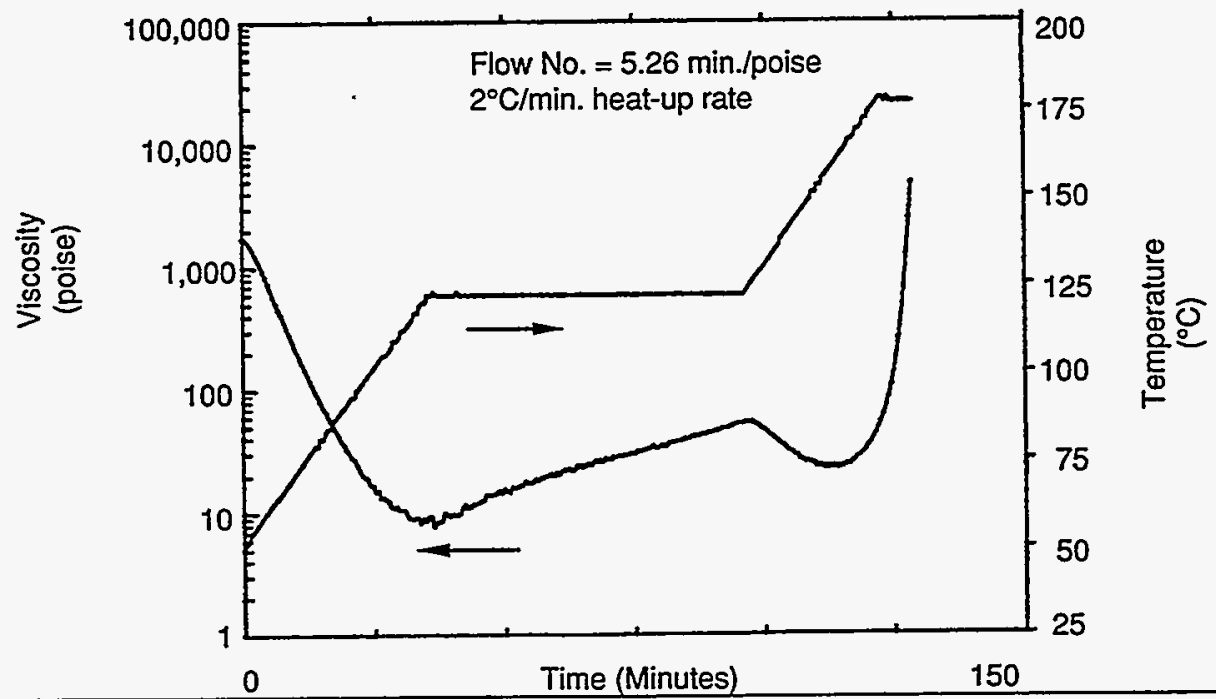

The data listed has been obtained from carefully controlled samples considered to be representative of the product described. Because the properties of this product can be significantly affected by the fabrication and testing techniques employed and since ICI Fiberite does not control the conditions under which its products are tested and used, ICI Fiberite cannot guarantee that the properties listed will be obtained with other processes and equipment. 
The polycyanate system used in this study

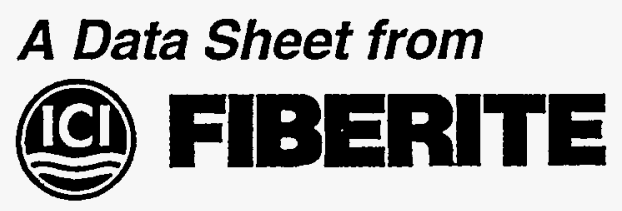

\section{TYPICAL PROPERTIES OF FIBERITE ${ }^{\circledR}$ 954-2A COMPOSITE LAMINATES}

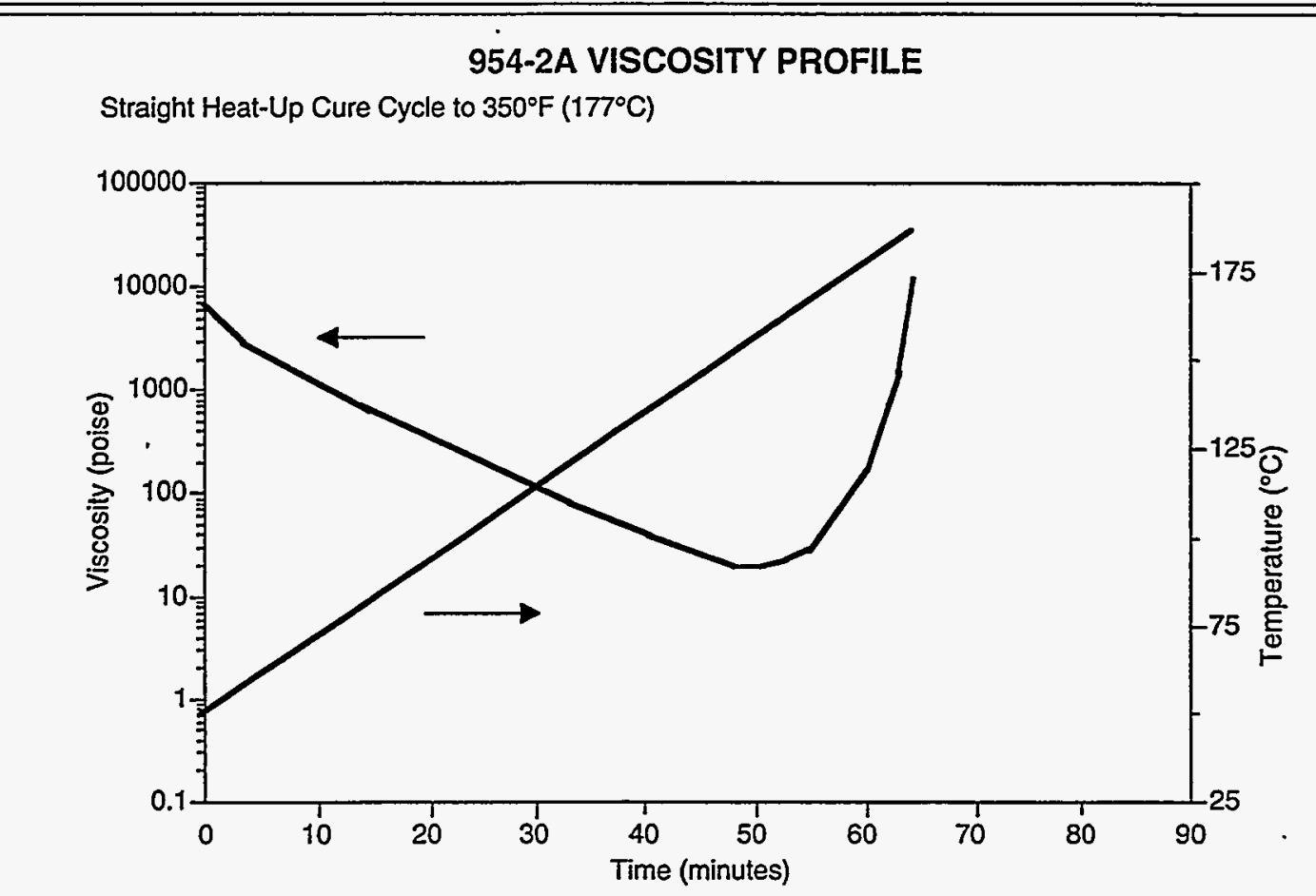

954-2A NEAT RESIN CURE STUDY

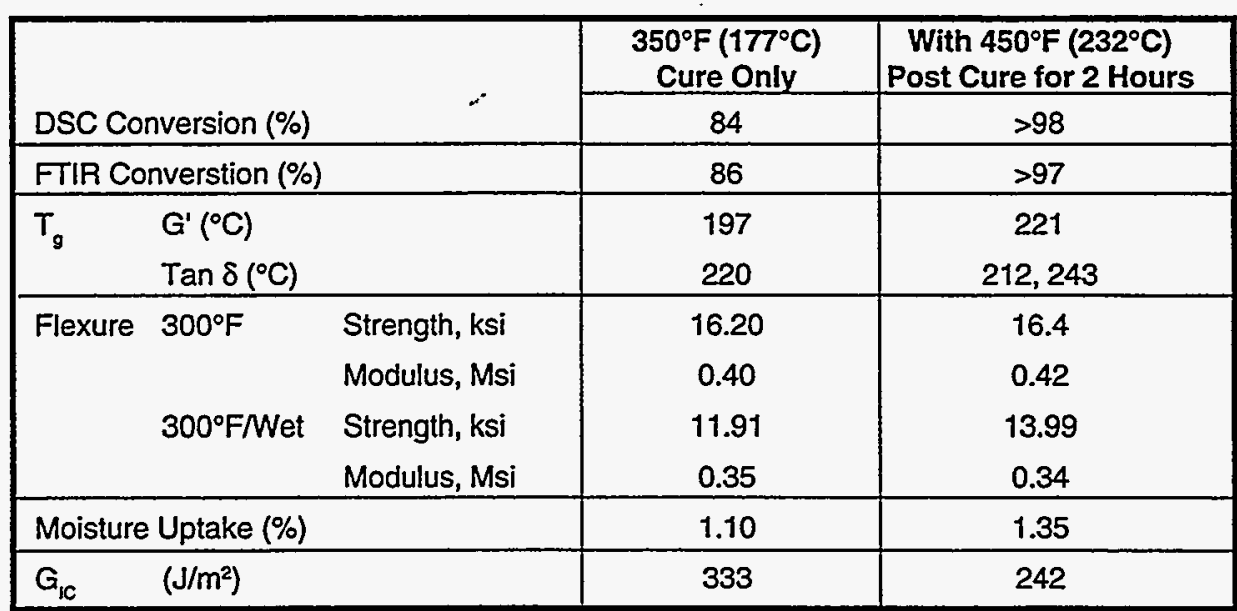

Wet $=$ Immersion at $160^{\circ} \mathrm{F}$ for 7 days.

The data listed has been obtained from carefully controlled samples considered to be representative of the product described. Because the properties of this product can be significantly affected by the fabrication and testing techniques employed and since ICI Fiberite does no control the conditions under which its products are tested and used, ICI Fiberite cannot guarantee that the properties listed will be obtained with other processes and equipment. 


\section{A Data Sheet from

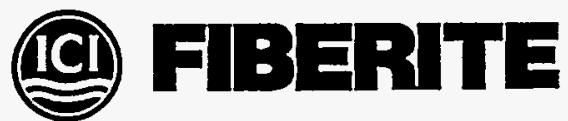

966C POLYIMIDE RESIN

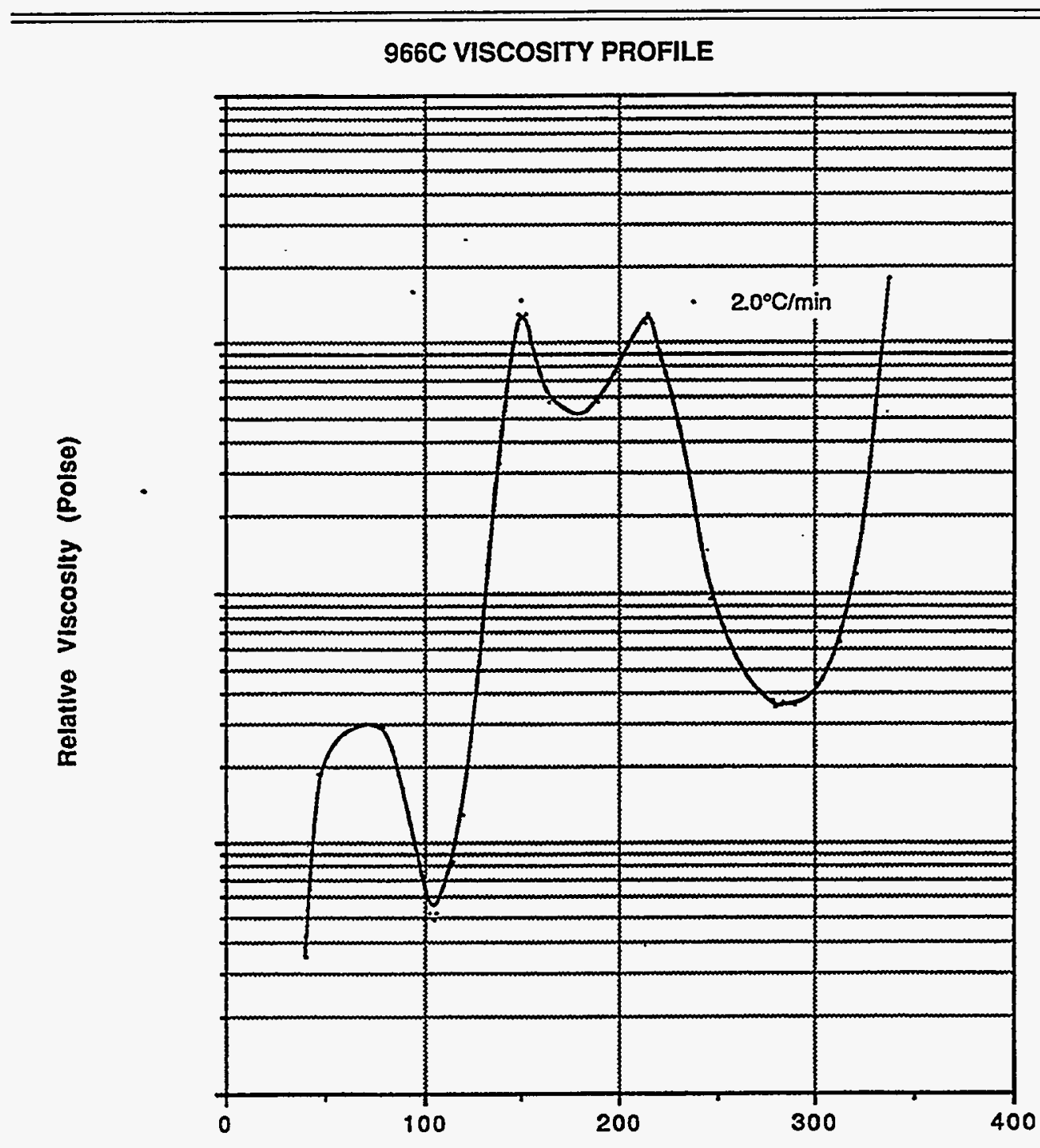

Temperature ${ }^{\circ} \mathrm{C}$

The data listed has been obtained from carefully controlled samples considered to be representative of the product described. Because the
properties of this product can be significantly affected by the fabrication and testing techniques employed and since ICI Fiberite does not
control the conditions under which its products are tested and used, ICI Fiberite cannot guarantee that the properties listed will be obtained
with other processes and equipment. 


\section{Appendix 2 - Data Forms}

A sample of the data sheet which is filled out prior to a composite fabrication autoclave process. An autoclave checklist is inlcuded to demonstrate the complexity of operating an autoclave cycle. 
The pre-fabrication data sheet

LLNL: MMED; Plastics and Advanced Composites Facility Composites Fabrication Request

Computer file info: DEVINE RUN 024 Date: 7-6-95 W.O. Item no. Acct. no.

Requester: GORDON SPELLMAN

Description: LAY UP A (0)16 PANEL, PLACE ON IOP OF A PREVIOUSLY CURED PANEL (O)16 AND CURE AGAN IE: 7.06 a BONDED to $6.30 \mathrm{~b}$

Specifications:

Due Date: $7-7-95$

Fabrication spec/drawing nos. VERBAL PER G.SPECLMAN

Material(s): FIBERUTE 1354 : CARBON FIBER CYANATE ESTER

Number of plys \& Orientation:

16 PLES

ALL ZERO

Cure cycle: FIBERITE ${ }^{\circ} \mathrm{C}-33$

Quality Control Functions; (check all requested by customer)

Thickness:

Resin: wt.\%:

Photos:

Dimensions:

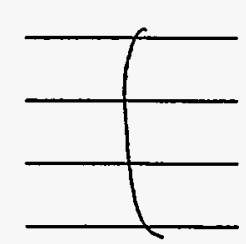

Density:

- Fiber: volume \%

Witness plate:

Other:

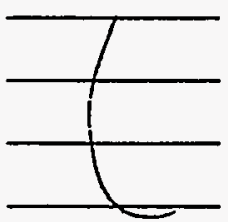

Additional Instructions: MEASURE AND CUT ALL PLES BY HANS 
Pre-fabrication data sheet - continued

\section{Fabrication Data}

W. O.\# DEVINE RUN 024, Item Fabrication start date: $7-6-95$

, Acct.\#

Fab spec/drwg \#: USE FIBERITE L-7 LAY UP PROCEDURE AS REFERENCE

Fabrication Method: Lay-up $x$ Filament wind

Materials: Mfr. $1 \mathrm{Cl}$ EIBERITE Lot\# 432286 Resin content Form: Tape $\swarrow 12^{\prime \prime}$ Tow ID HYE $1354-2 A T$. Accumulated Out Time: LESS THAN 36 NRS.

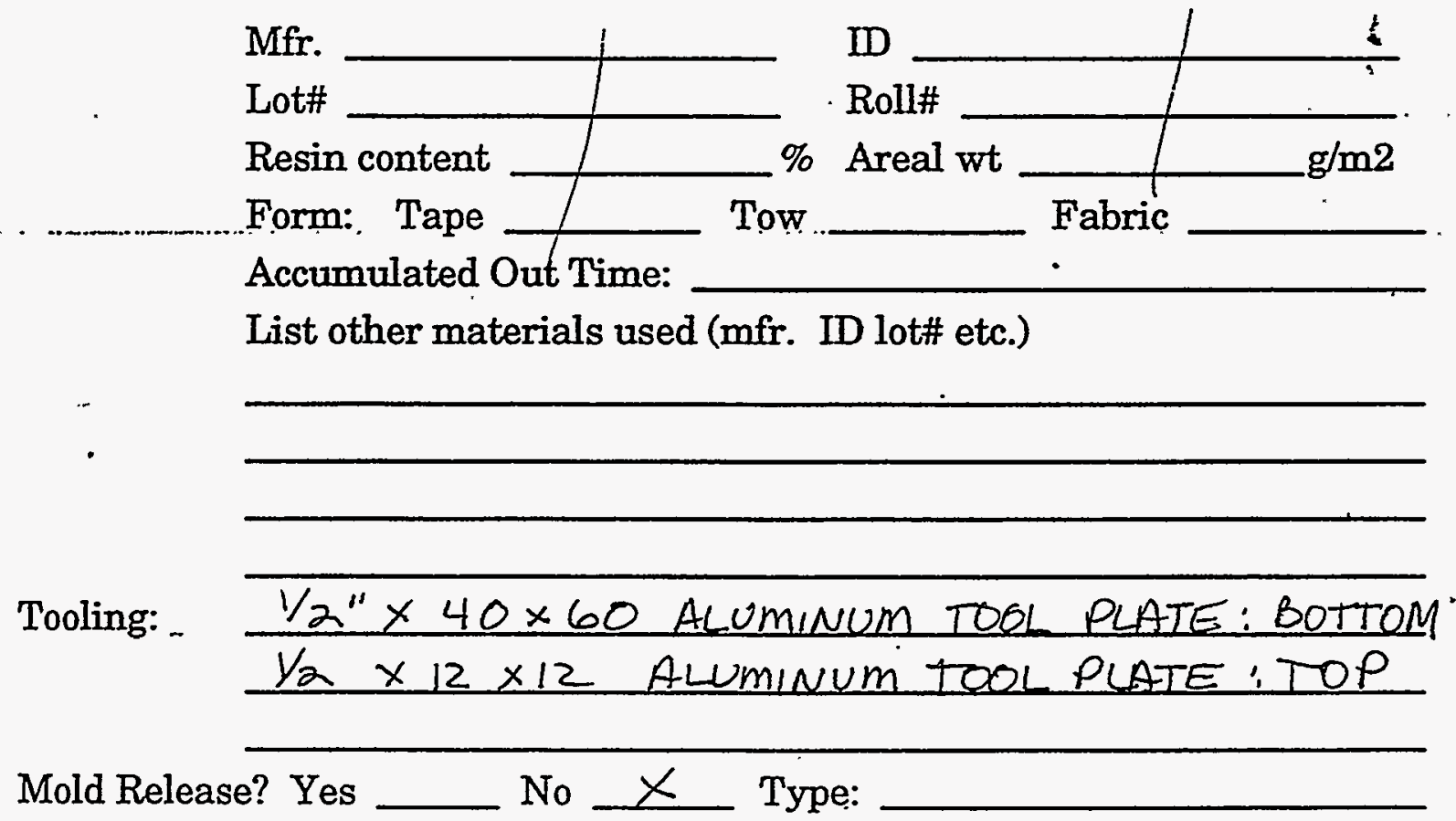
Roll\# IA 
Pre-fabrication data sheet - continued

\section{Lay-Up \& Bagging Procedures:}

References: GORDON SPELIMAN, FIBERITE $L-7+C-33$

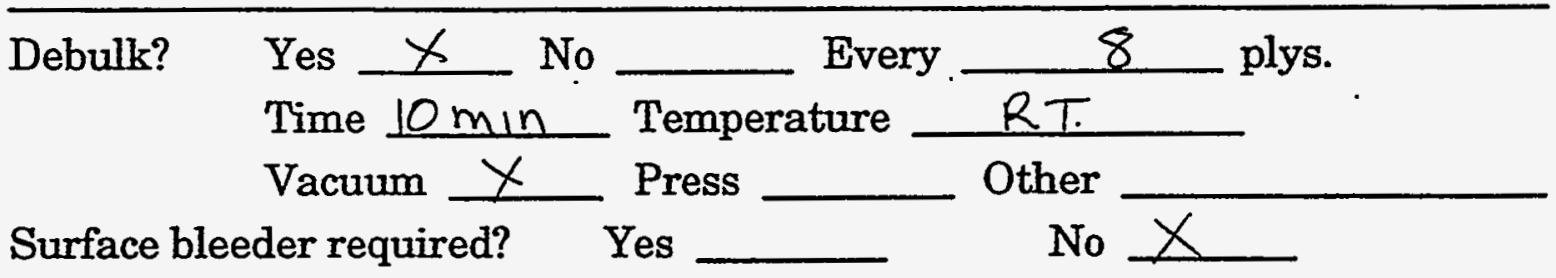

Prepreg resin wt \%

Calculated resin bleed

Bleeder used;

Sensors: type;

" $I$ " Thermocouple

Location(s); NEXT TO LOWER RIGHT HAND

CORNER, TOUCHING PQRT

Lay-up Detail: On the Lay-up sketch, check the box and identify each material used in the lay-up.

Additional infor; MAKE A "LOOSE BAG" TO PREVENT ANY BRIDGING

Post cure info; Time NONE; Temp

Inspection Report: PANEL GIVEN TO GORDOAL TO INSPECT

Facility Reps:

Steve Winchester

Job completion date: 
Autoclave Start-up Checklist

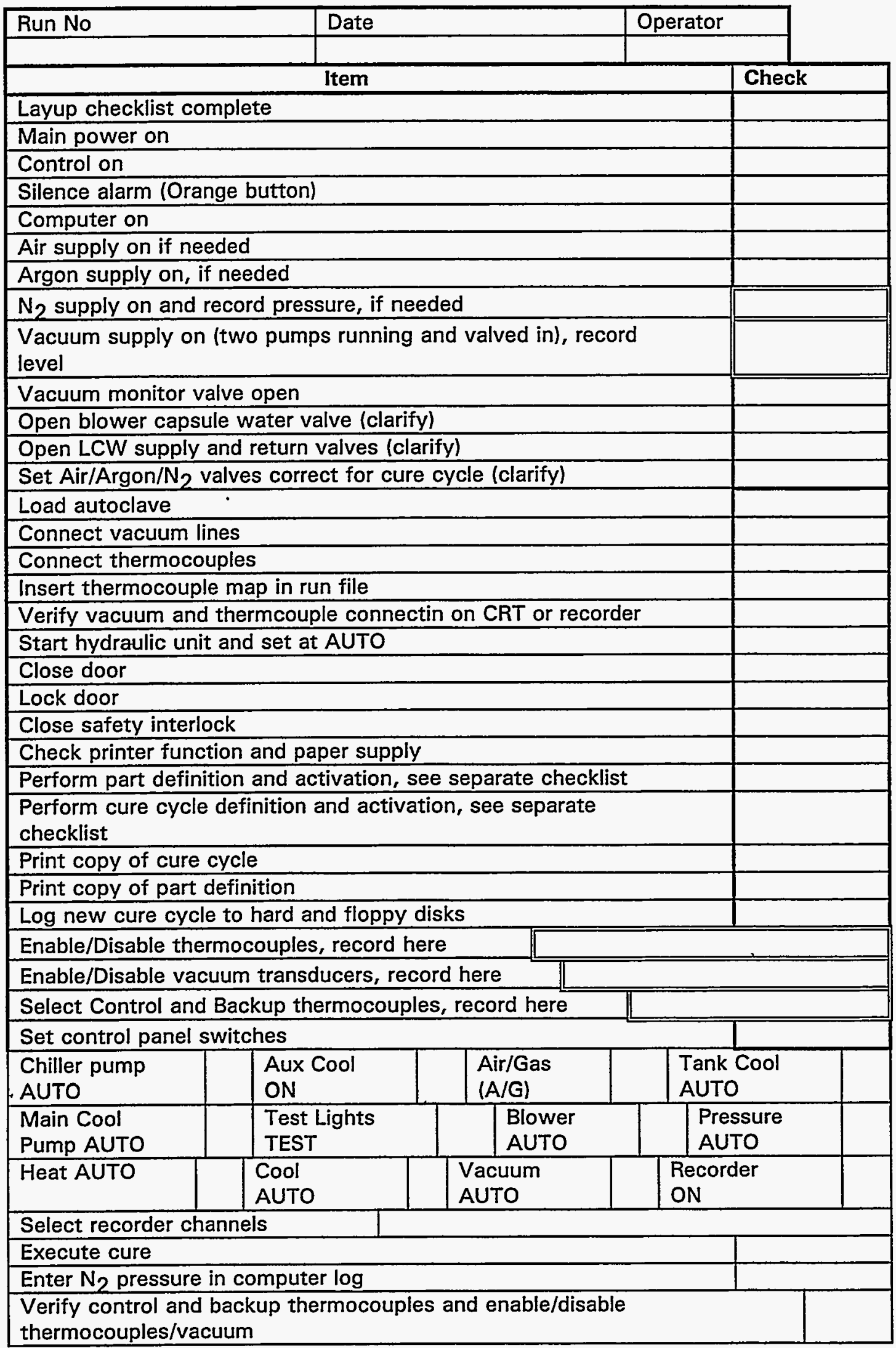


RUN NO.

\begin{tabular}{|c|c|c|}
\hline Action & Keys & Check \\
\hline Begin from Main display & $\begin{array}{l}\text { F3, Part } \\
\text { select }\end{array}$ & NA \\
\hline \multicolumn{3}{|l|}{$\begin{array}{l}\text { Delete/disable part descriptions to not be used } \\
\text { (or edit to use) }\end{array}$} \\
\hline Create part & $\begin{array}{l}\text { F1, } \\
\text { Create } \\
\text { part }\end{array}$ & NA \\
\hline \multicolumn{3}{|l|}{$\begin{array}{l}\text { Enter part name, serial numbers, and ?, (all } \\
\text { alpha-numeric) }\end{array}$} \\
\hline Go to Sensor display & Enter & $\overline{N A}$ \\
\hline $\begin{array}{l}\text { Select category, Temperature, Transducer } \\
\text { (vacuum), ?? }\end{array}$ & $\mathrm{F} 1$ & NA \\
\hline For each category add sensors desired & F2 & \\
\hline Go to transducers and add channels & F6 & \\
\hline Assign control and backup thermocouple & $\mathrm{F} 1, \mathrm{~F} 4$ & \\
\hline Designate $\mathrm{min} / \mathrm{max} / \mathrm{AVG} / \mathrm{blank}$ & Enter & \\
\hline Enter vacuum action desired & F9 & \\
\hline Edit title and descriptions if desired & $\begin{array}{l}\text { F6, } \\
\text { F7orF8 }\end{array}$ & NA \\
\hline Check control thermocouple & $\mathrm{F} 10, \mathrm{~F} 5$ & NA \\
\hline Highlight control Thermocouple & F3 & NA \\
\hline $\begin{array}{l}\text { Move red tab to Backup thermocouple and } \\
\text { check }\end{array}$ & F4 & \\
\hline Disable thermocouples not in control, & F2 & \\
\hline Disable/enable vacuum transducers & F1orF2 & \\
\hline Return to main display & $\begin{array}{l}\text { F10, } \\
\text { F10 }\end{array}$ & NA \\
\hline Select sensor display & F5 & NA \\
\hline Connect thermocouples to part, tab to each & F3 & \\
\hline Select vacuum sensors & F5 & NA \\
\hline Connect vacuum sensors to part & F3 & \\
\hline Return to Main display & F10 & NA \\
\hline Enter Part Select & F3 & NA \\
\hline Print part definition & F9 & \\
\hline Return to Main Display & F10 & NA \\
\hline Select Cure Select & F4 & NA \\
\hline Return to startup checklist & & NA \\
\hline
\end{tabular}




\section{Appendix 3 -- Bagging Procedures}

This is typical of manufacturers supplied layup or bagging procedures. The $\mathrm{ICI}$

Fiberite L-7 procedure is the recommend layup for $\mathrm{ICl}$ Fiberite 954-2A. 
The recommended layup for ICl Fiberite 954-2A polycyanate matrix prepreg.

\section{(C) FIBERTTE}

\section{LAY-UP PROCEDURE L-7}

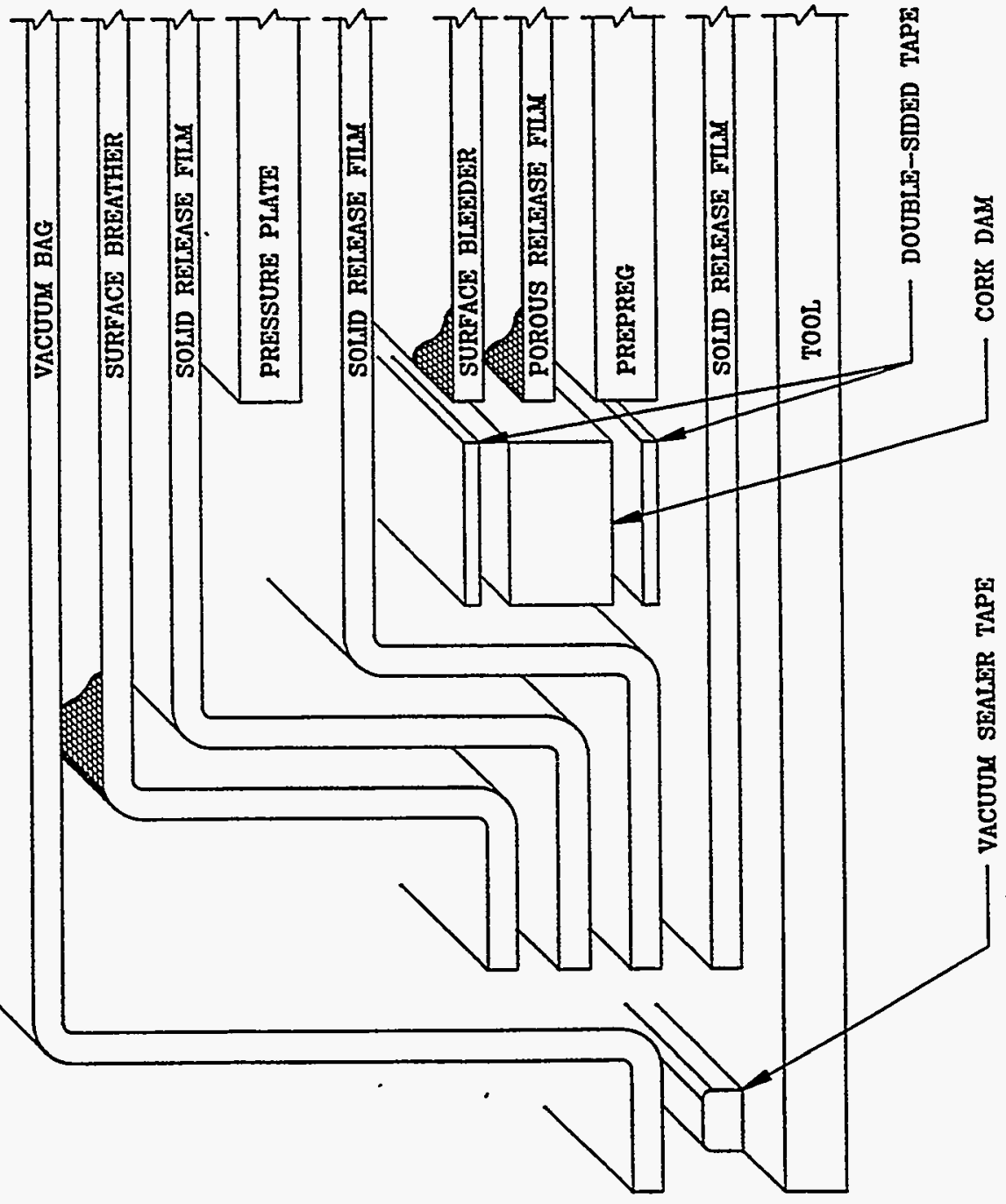




\section{Appendix 4 -- Cure Cycles}

Manufacturer's recommended cure cycles are presented in graphical form. 

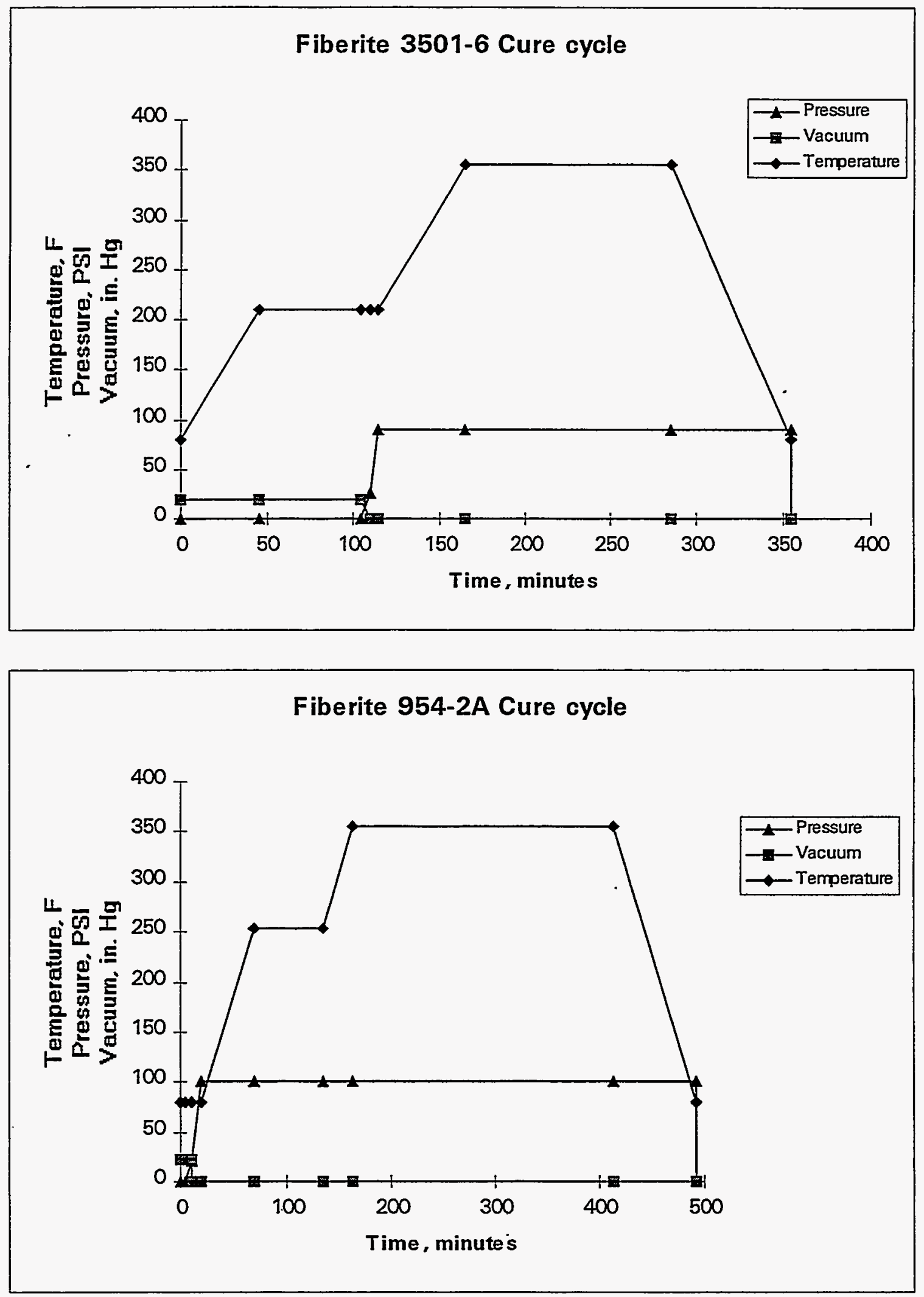

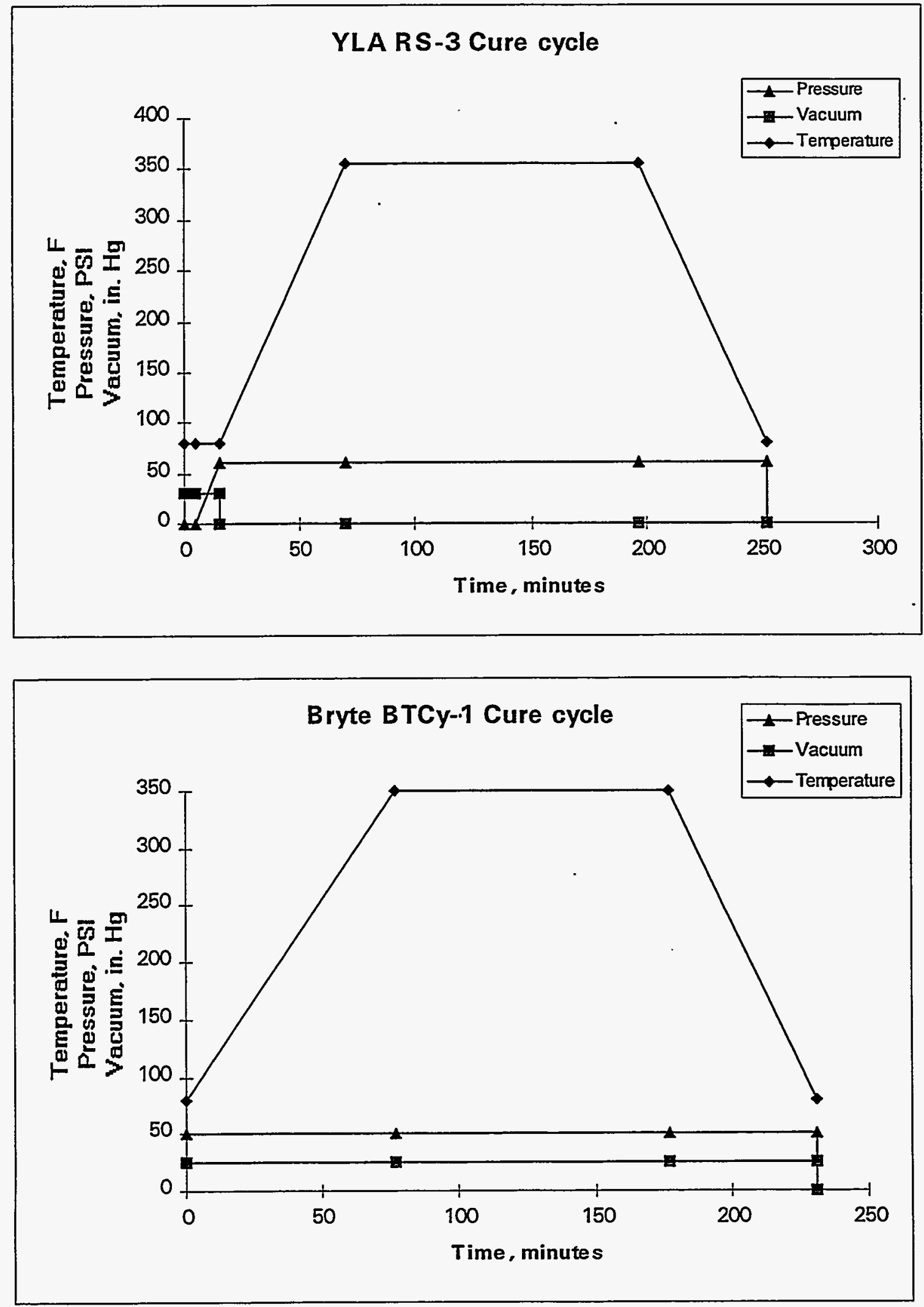


\section{Appendix 5 -- Deflection Data}

\section{Detailed Measurement Data}

These data are organized as follows:

Hercules 3501-6, unidirectional

pg 61-66

Hercules 3501-6, 0/90

pg 67-71

Hercules 3501-6, multidirectional

pg 72

Bryte BTCy-1, multidirectional

pg 73

Fiberite 954-2A, unidirectional

pg 74-75

YLA RS-3, unidirectional

pg 76-79 


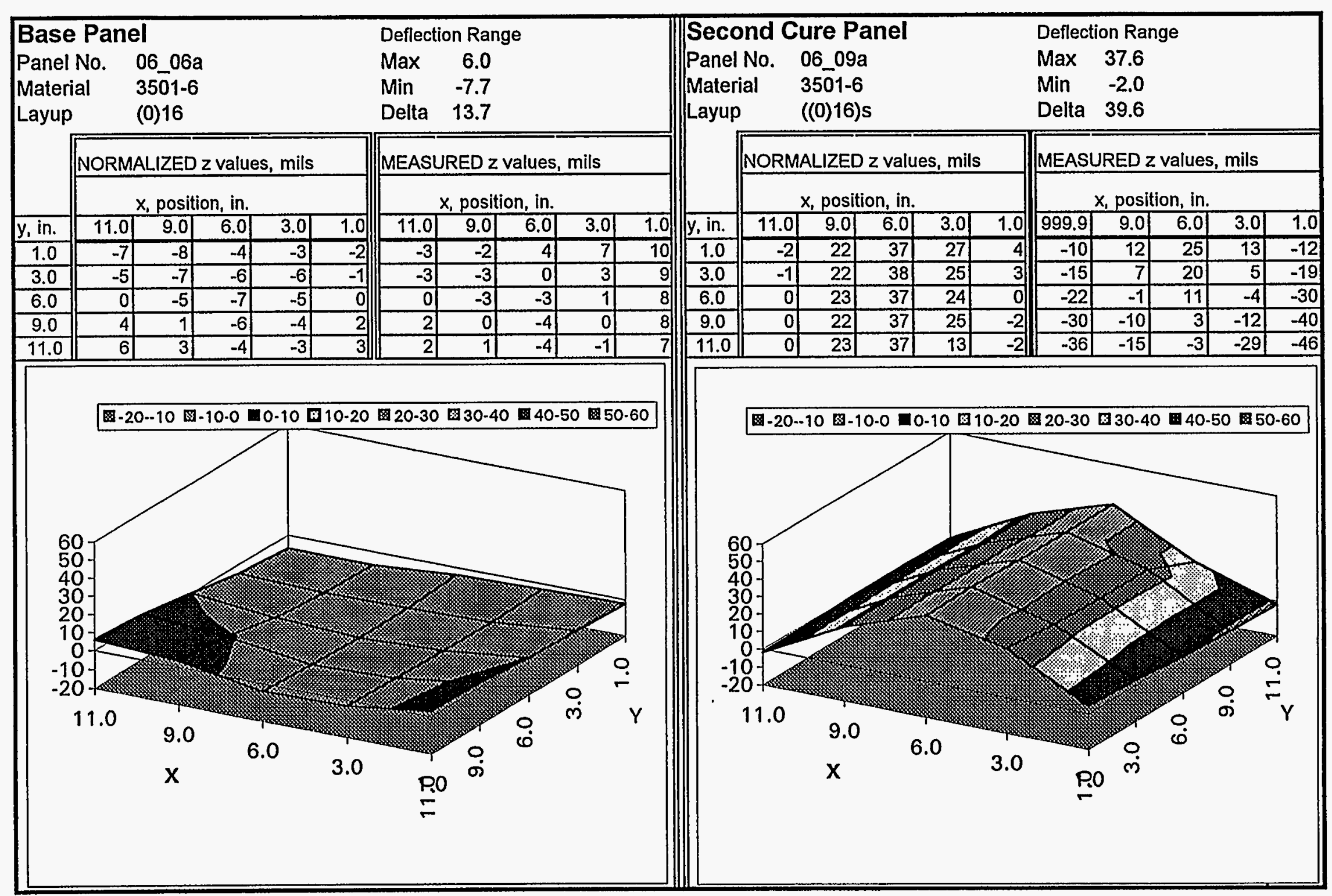




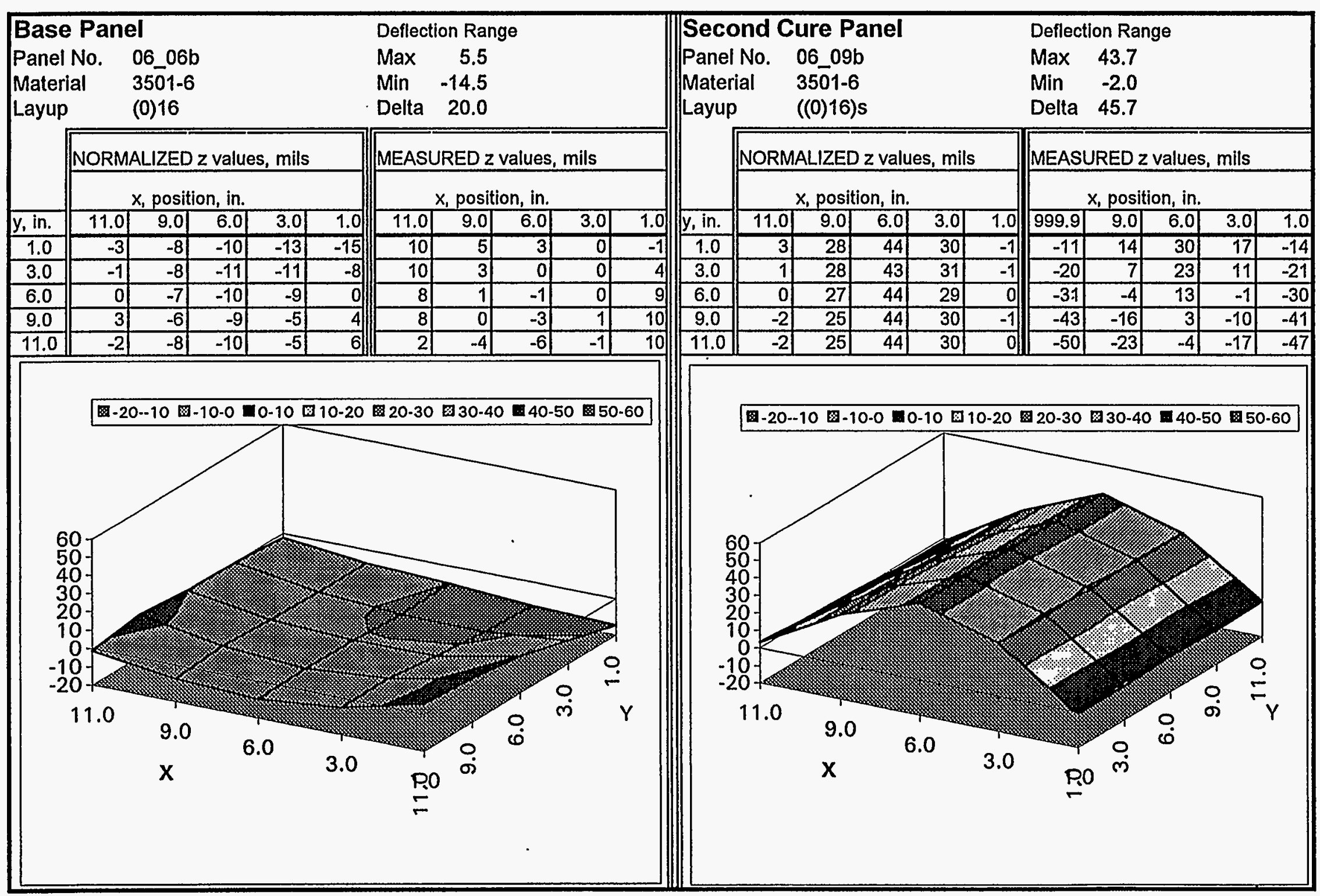




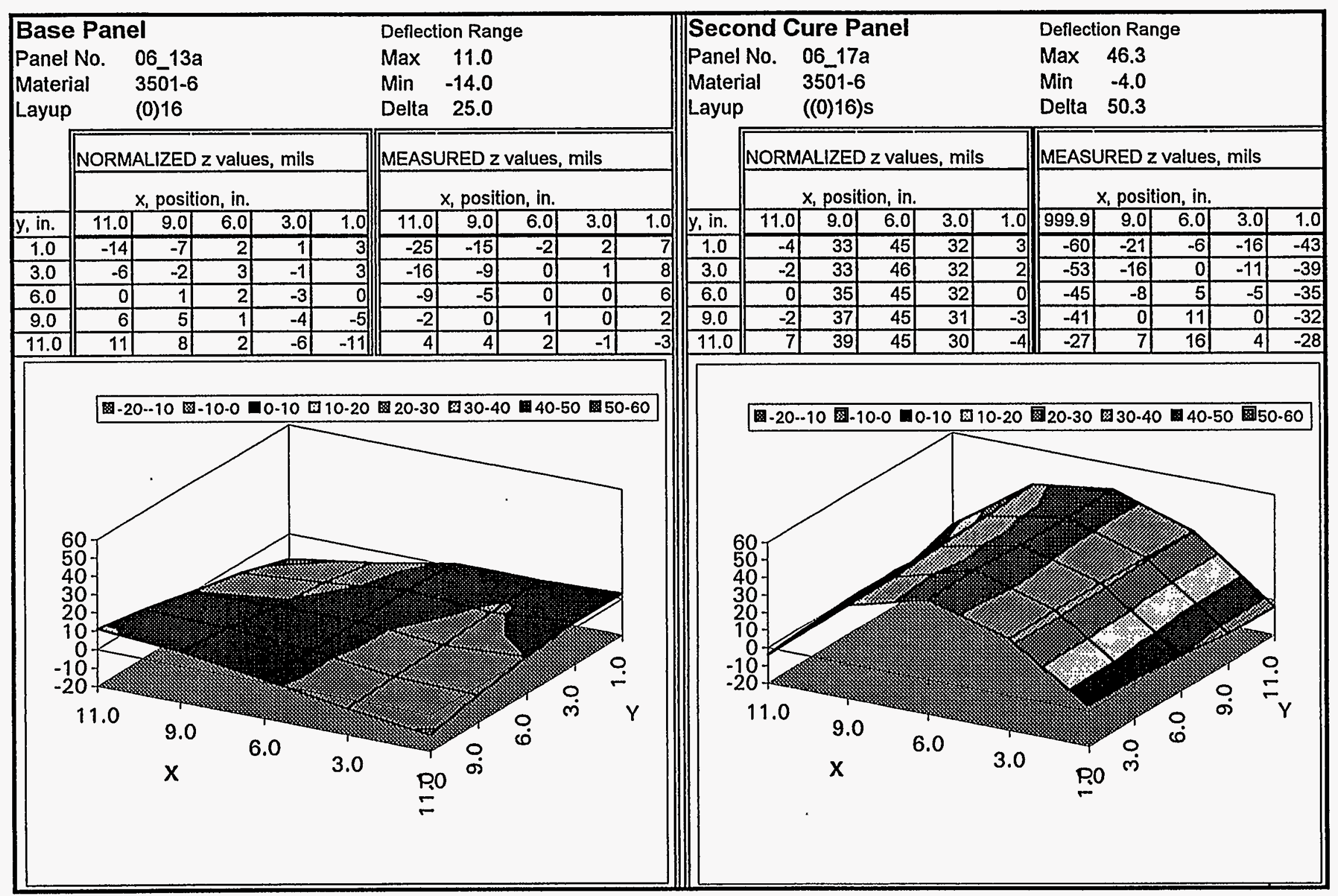




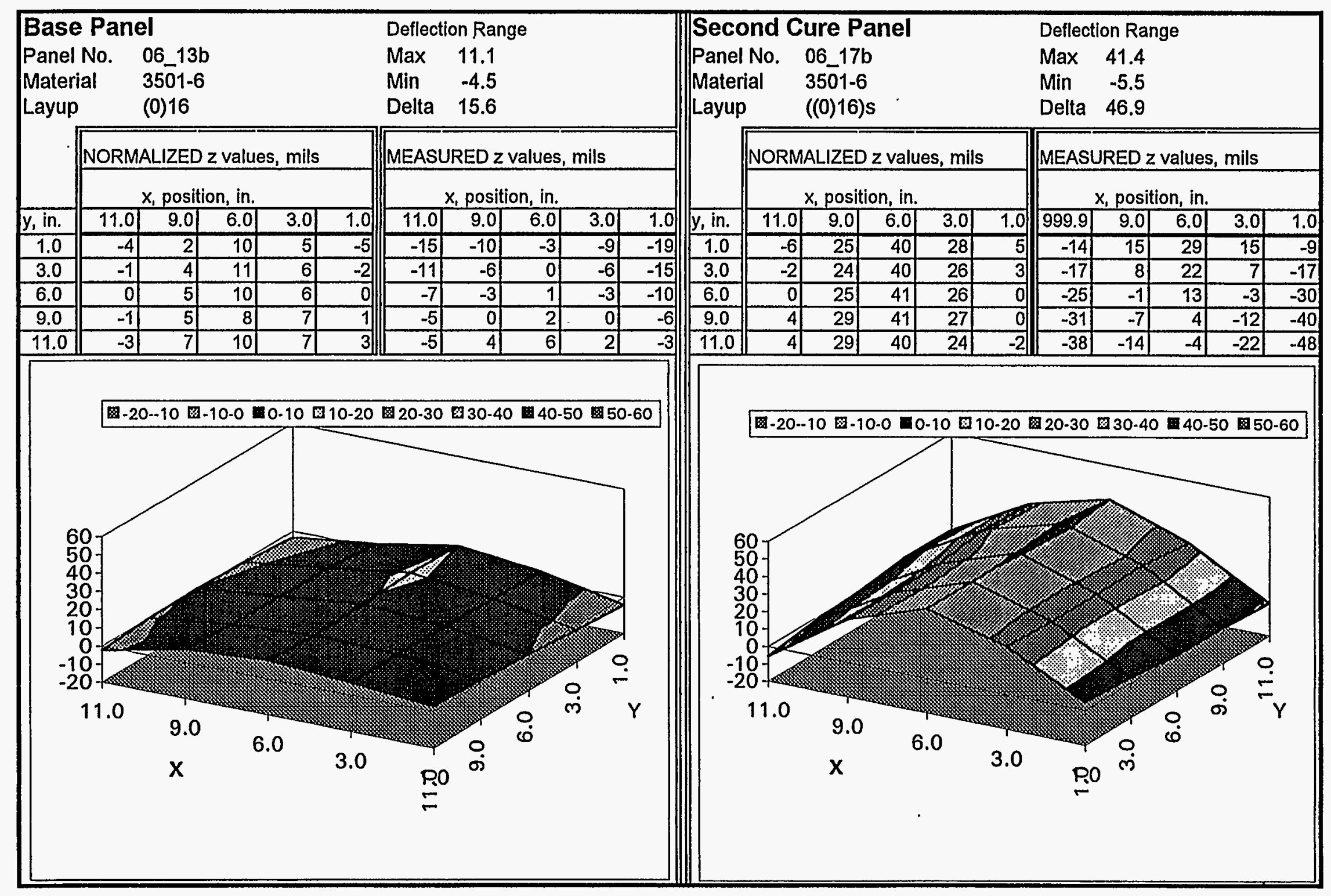




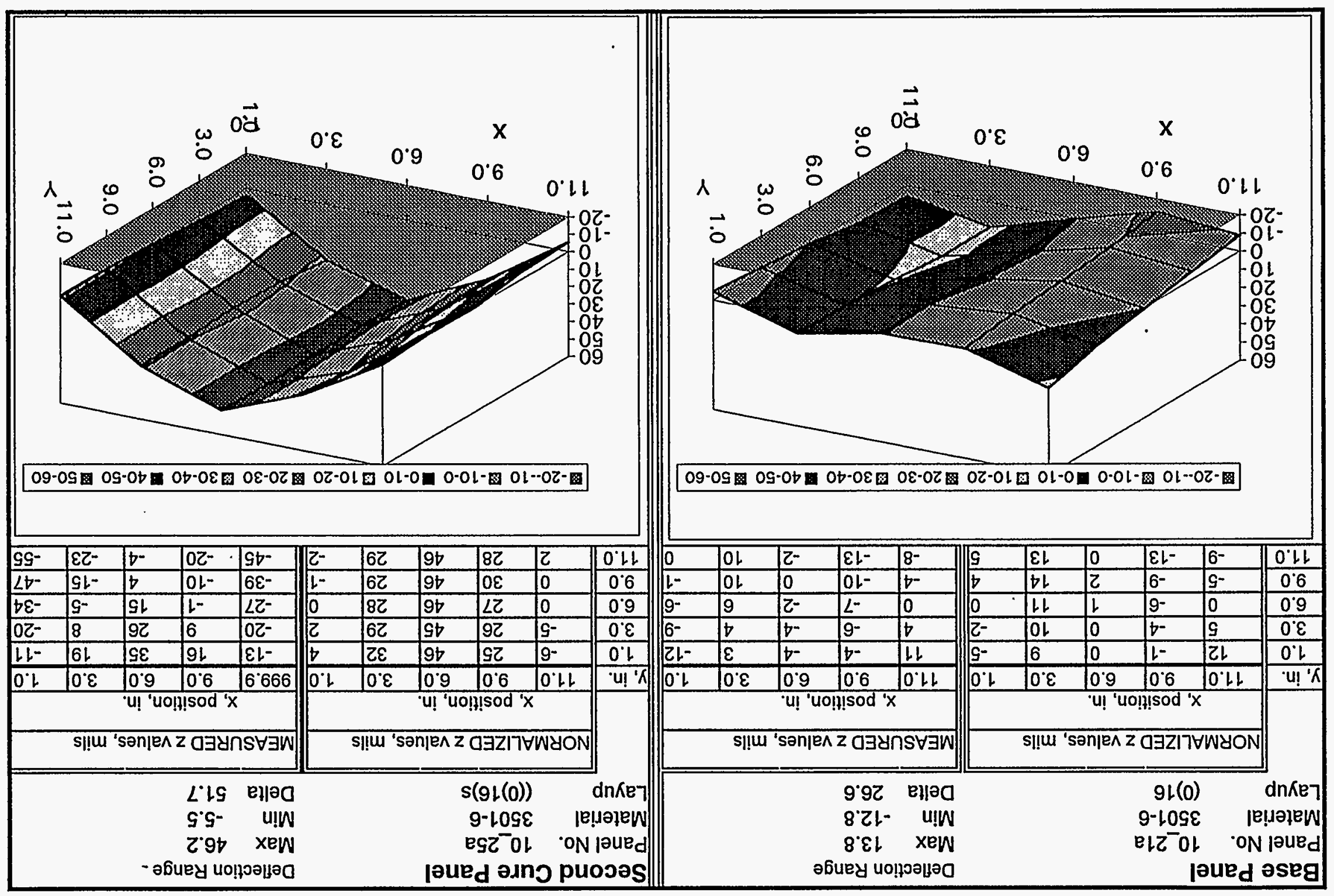




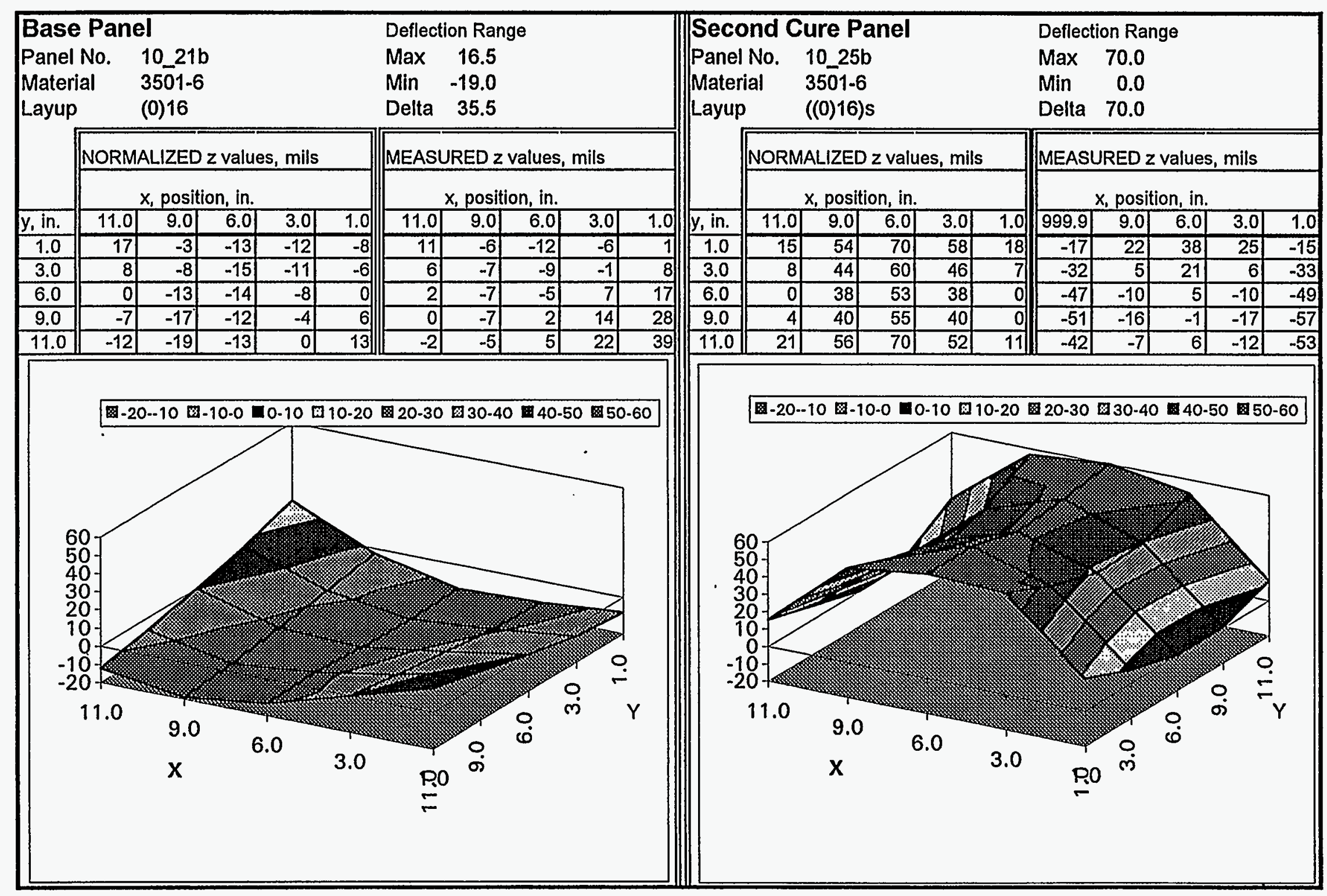




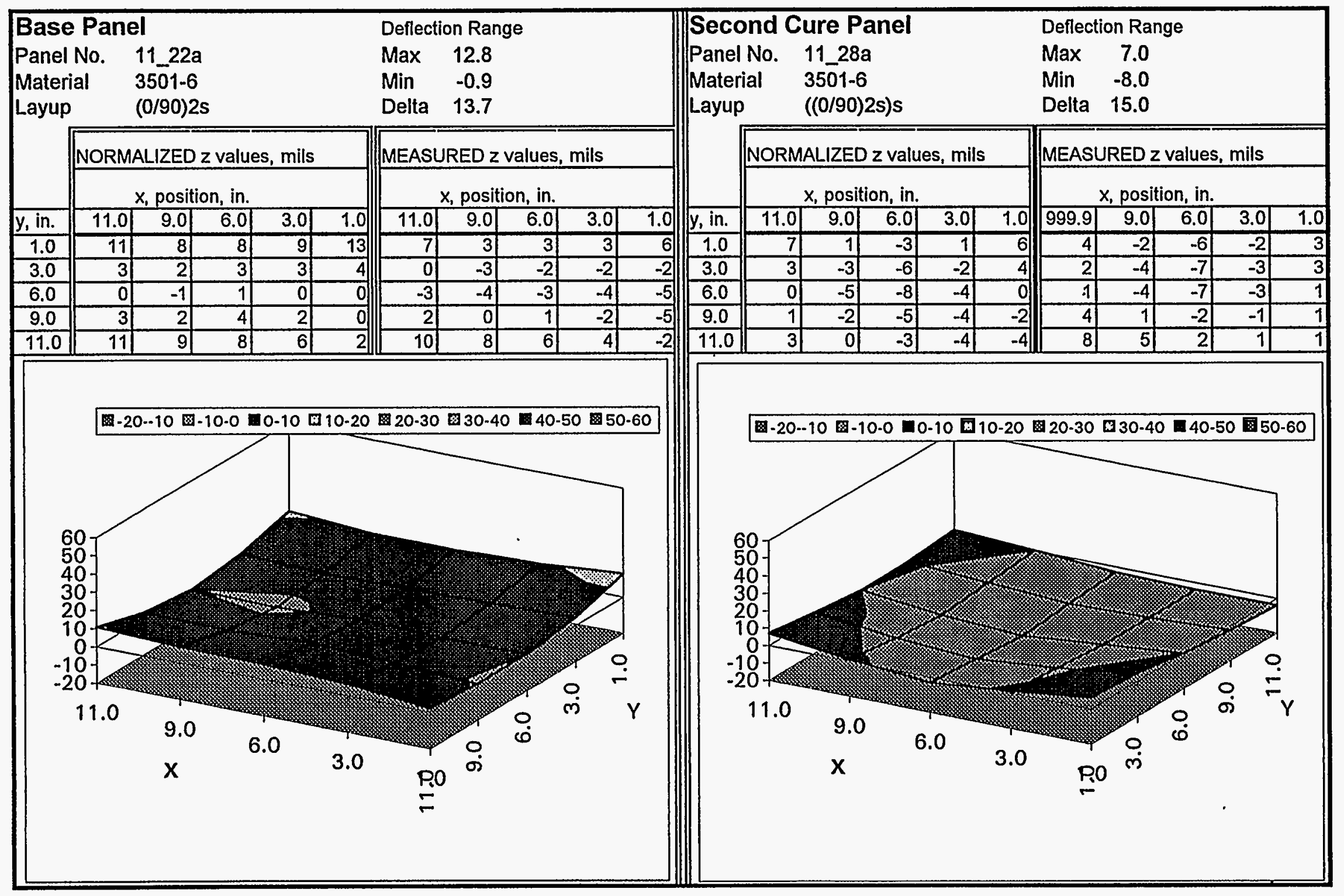




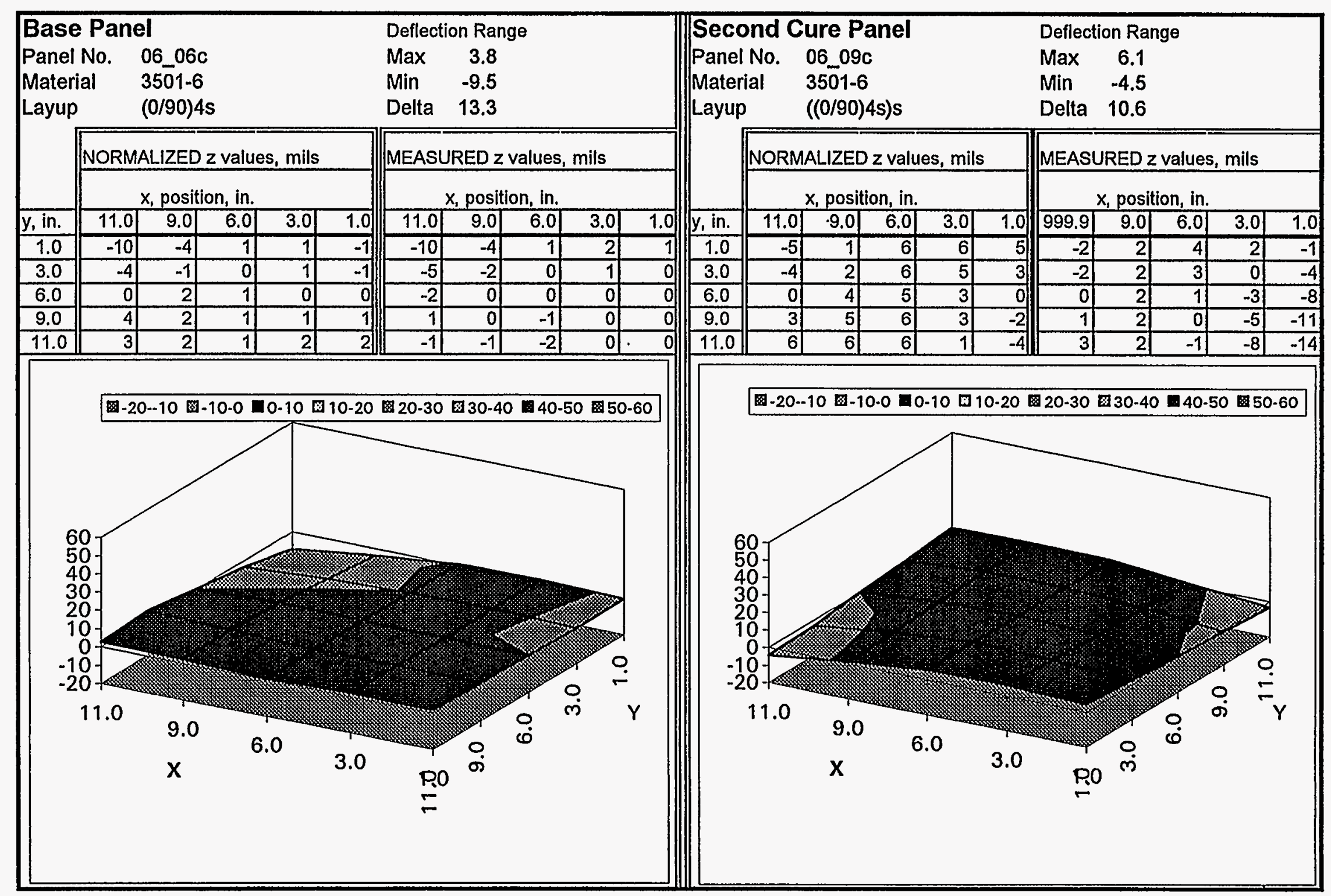




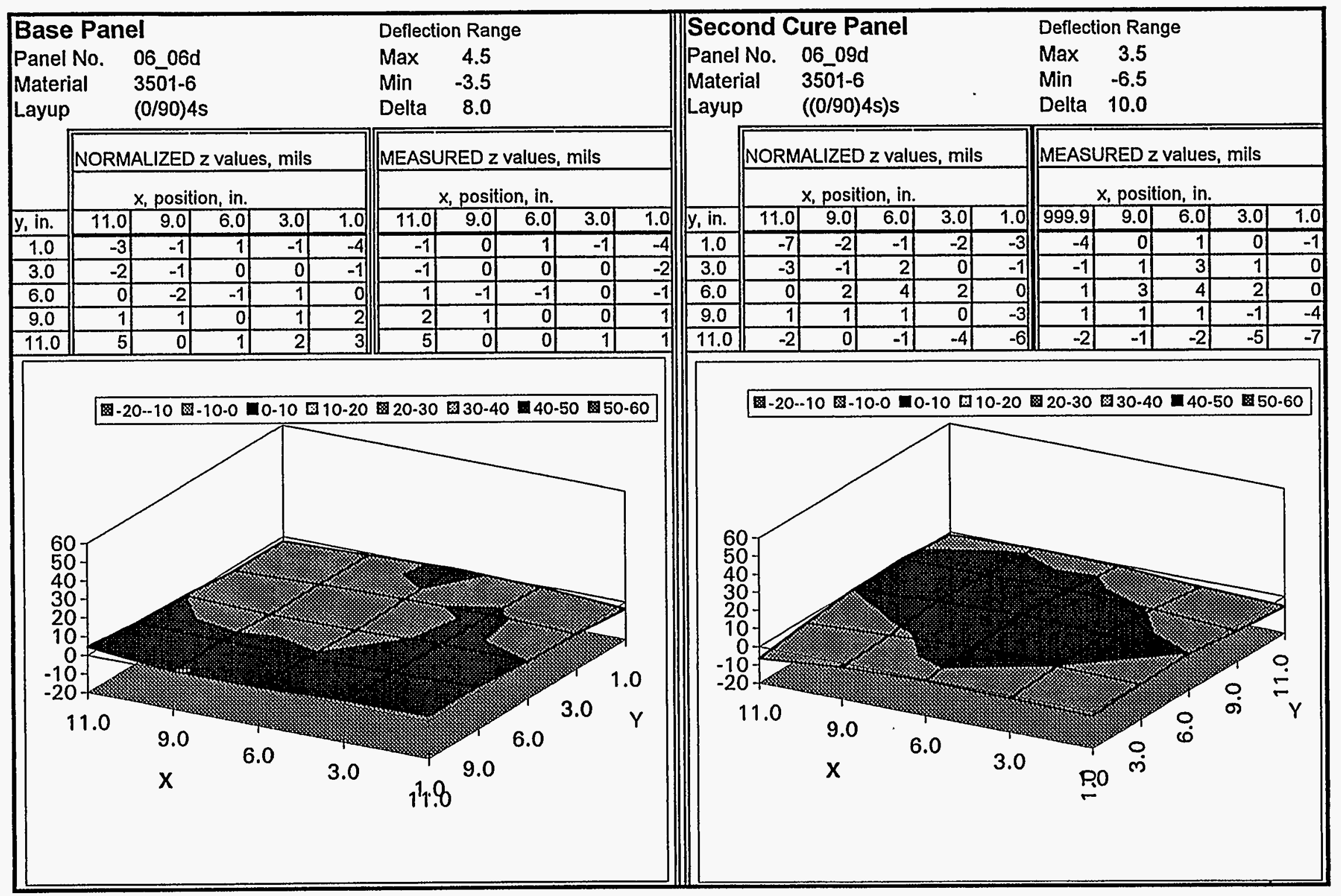




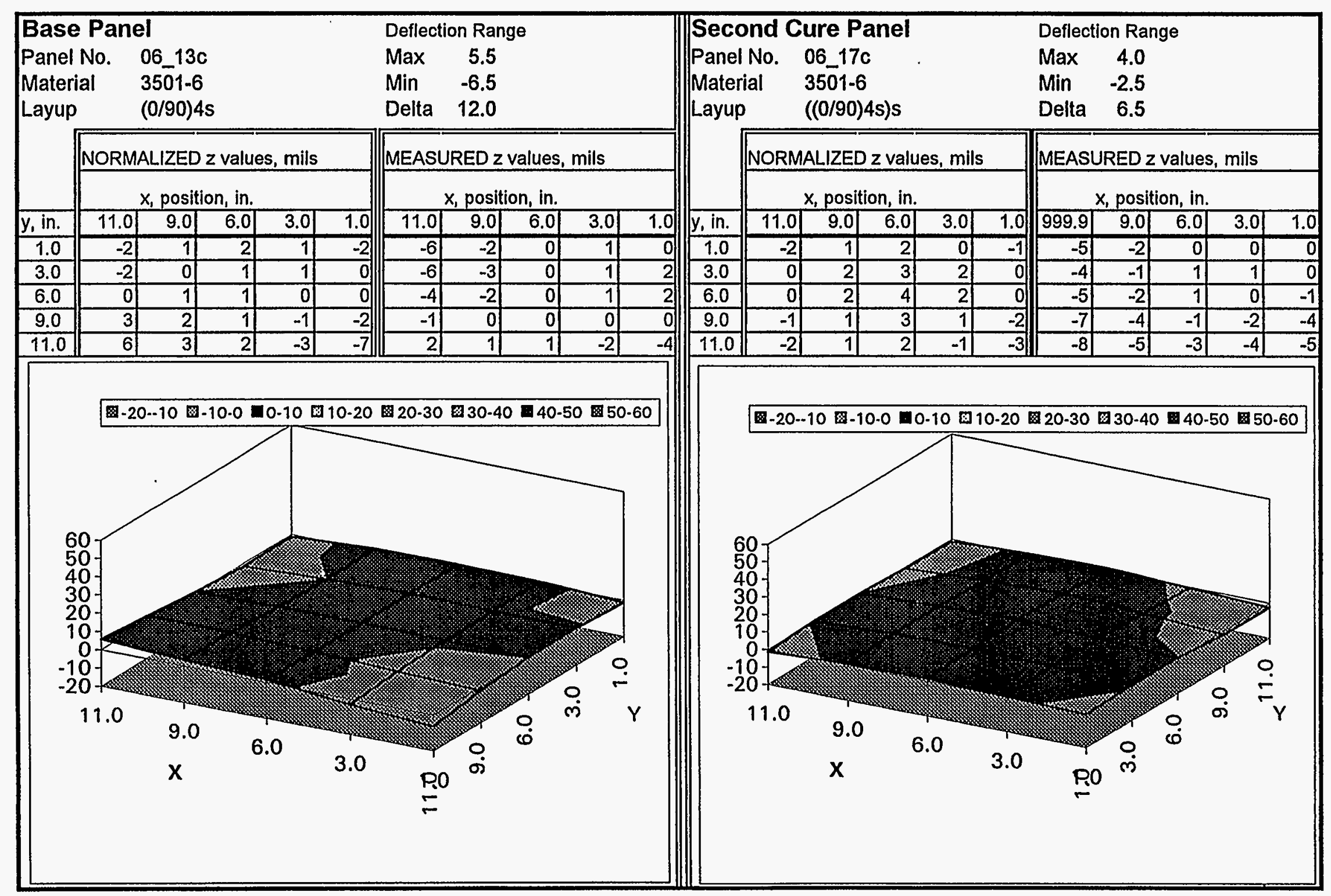




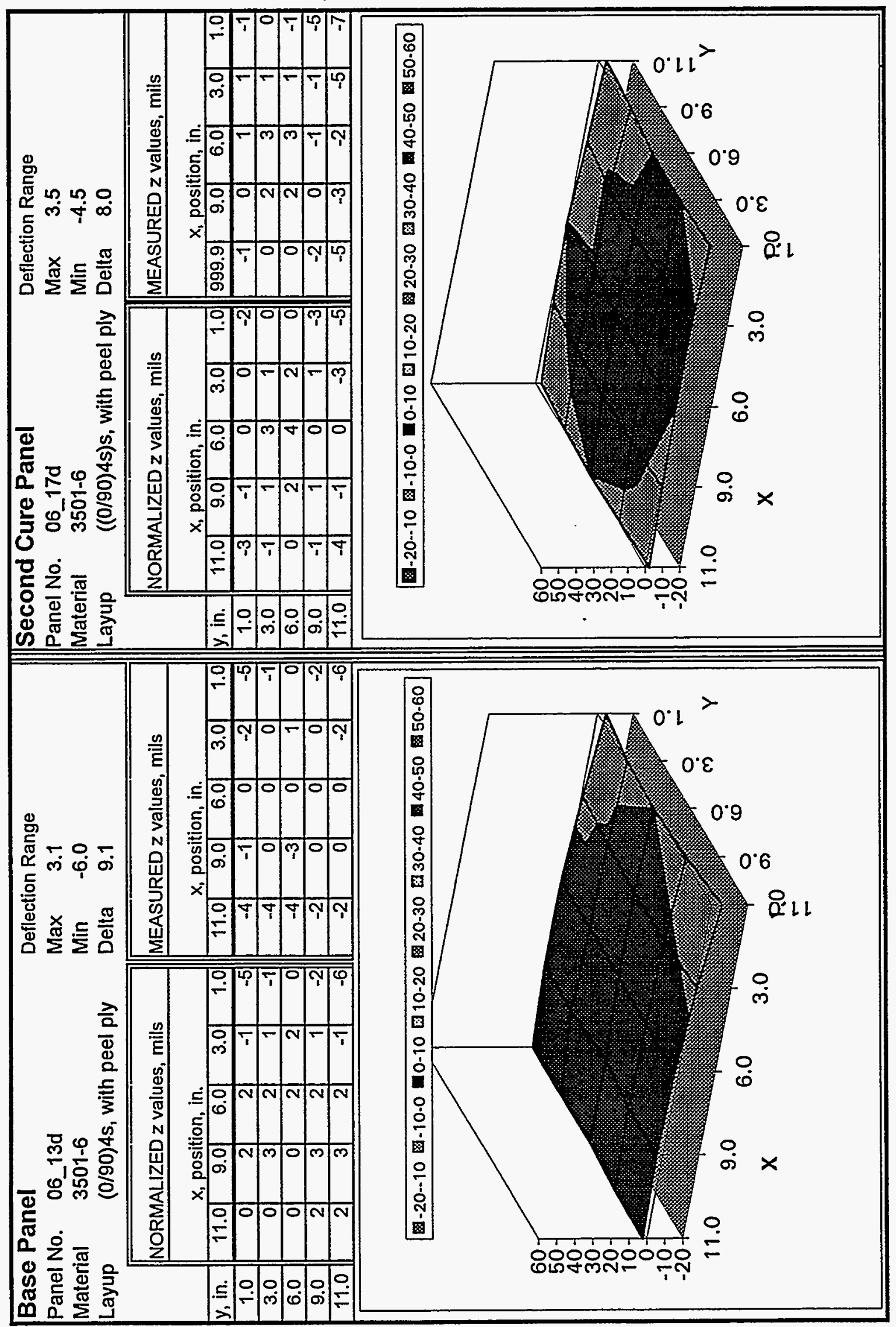




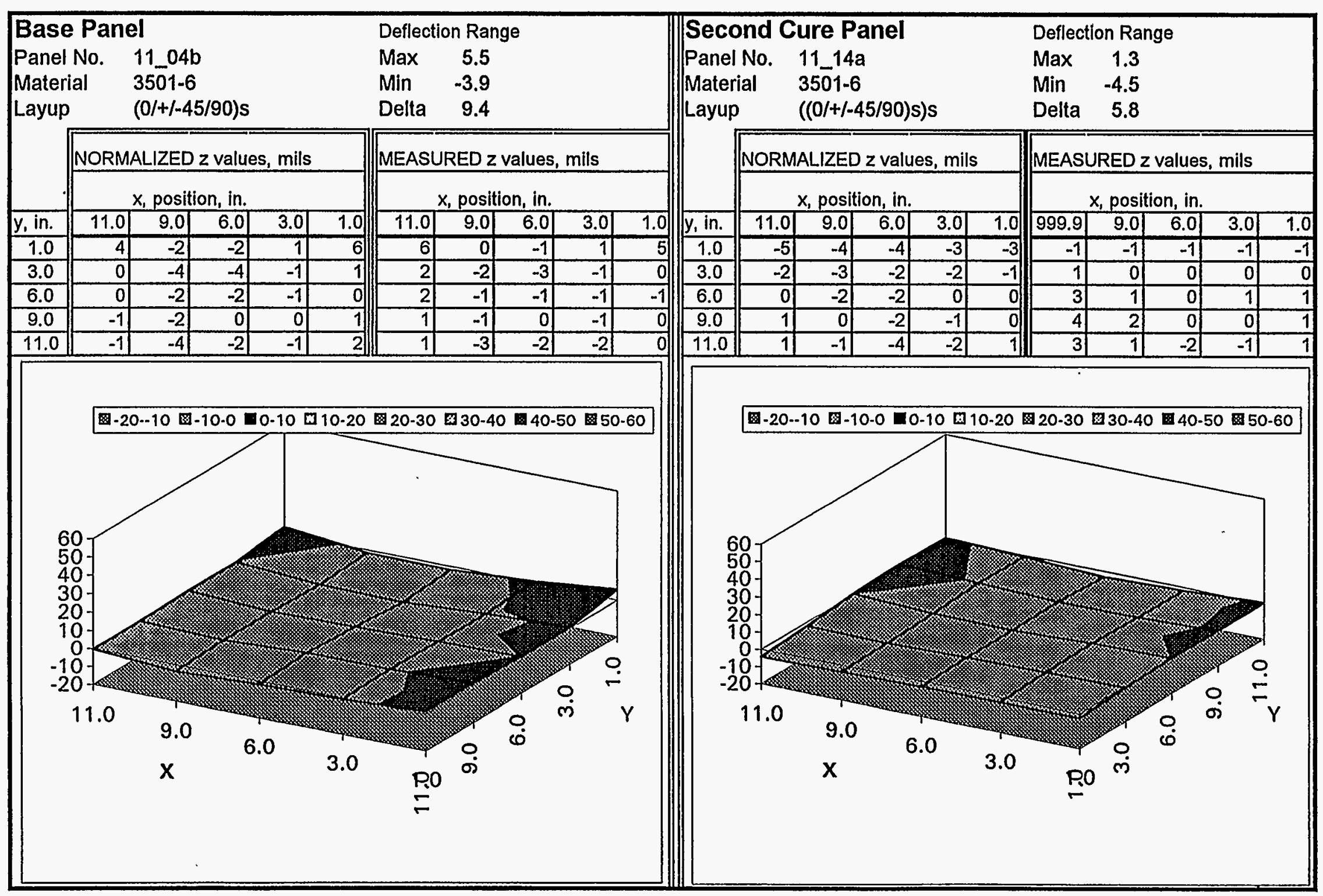




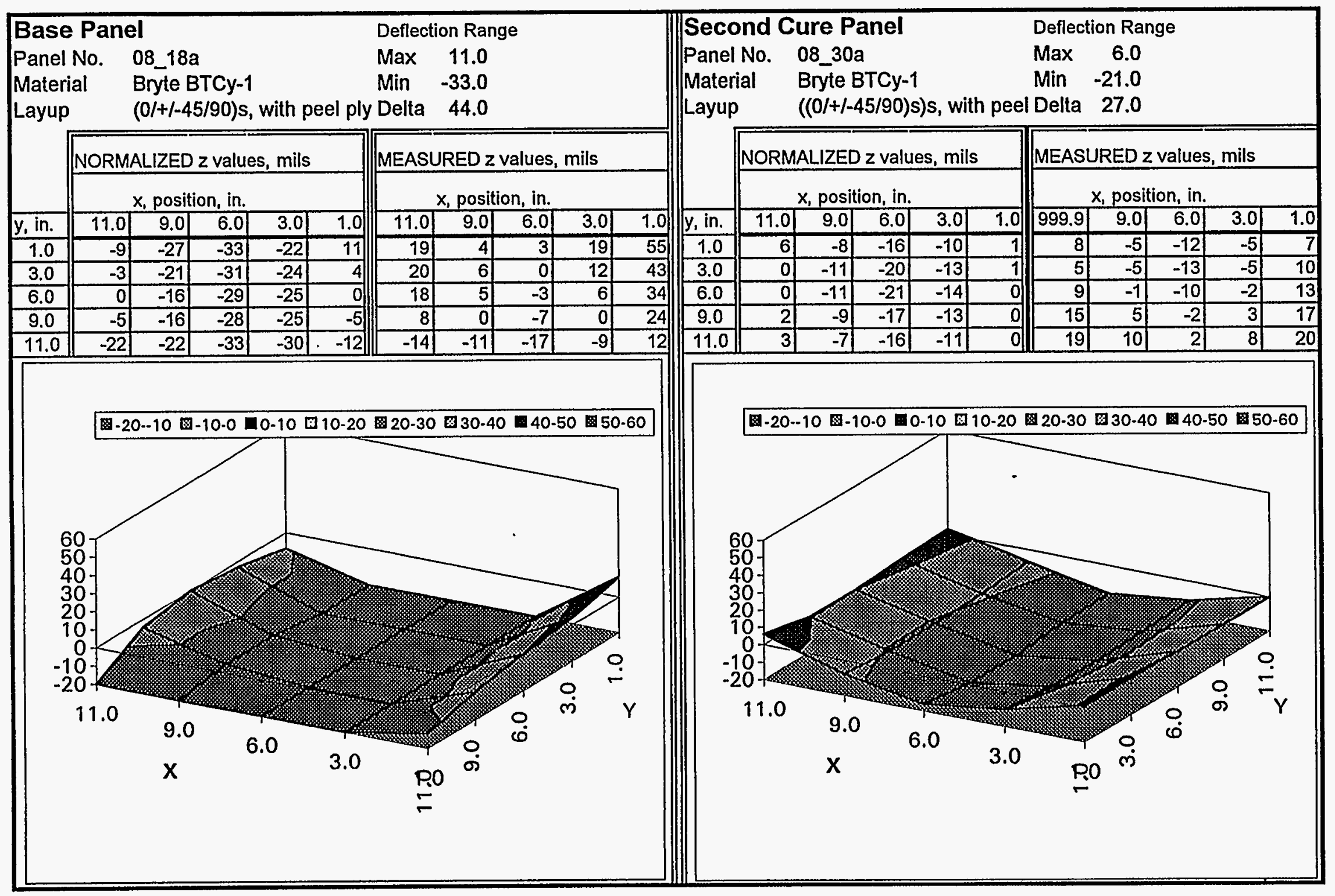




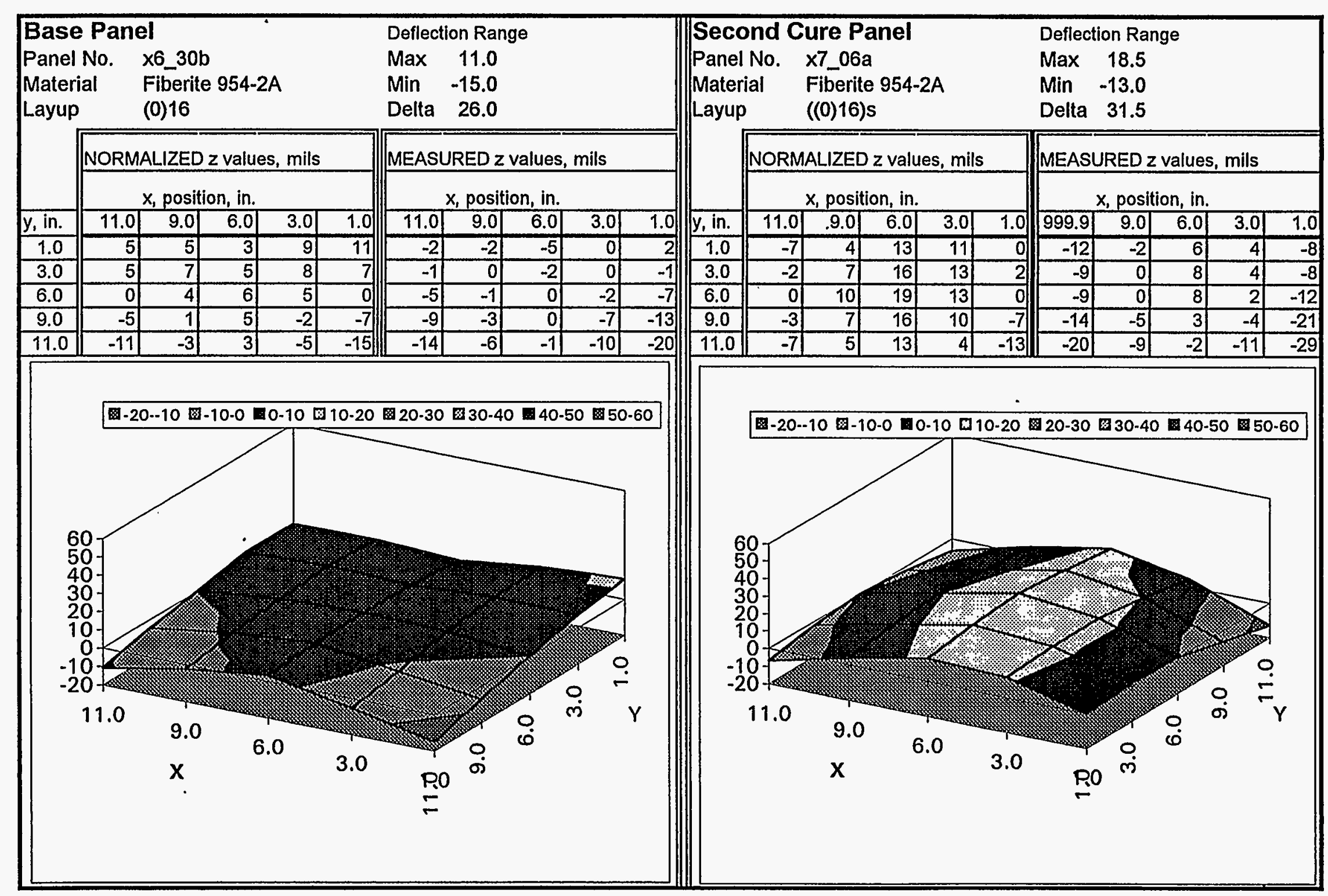




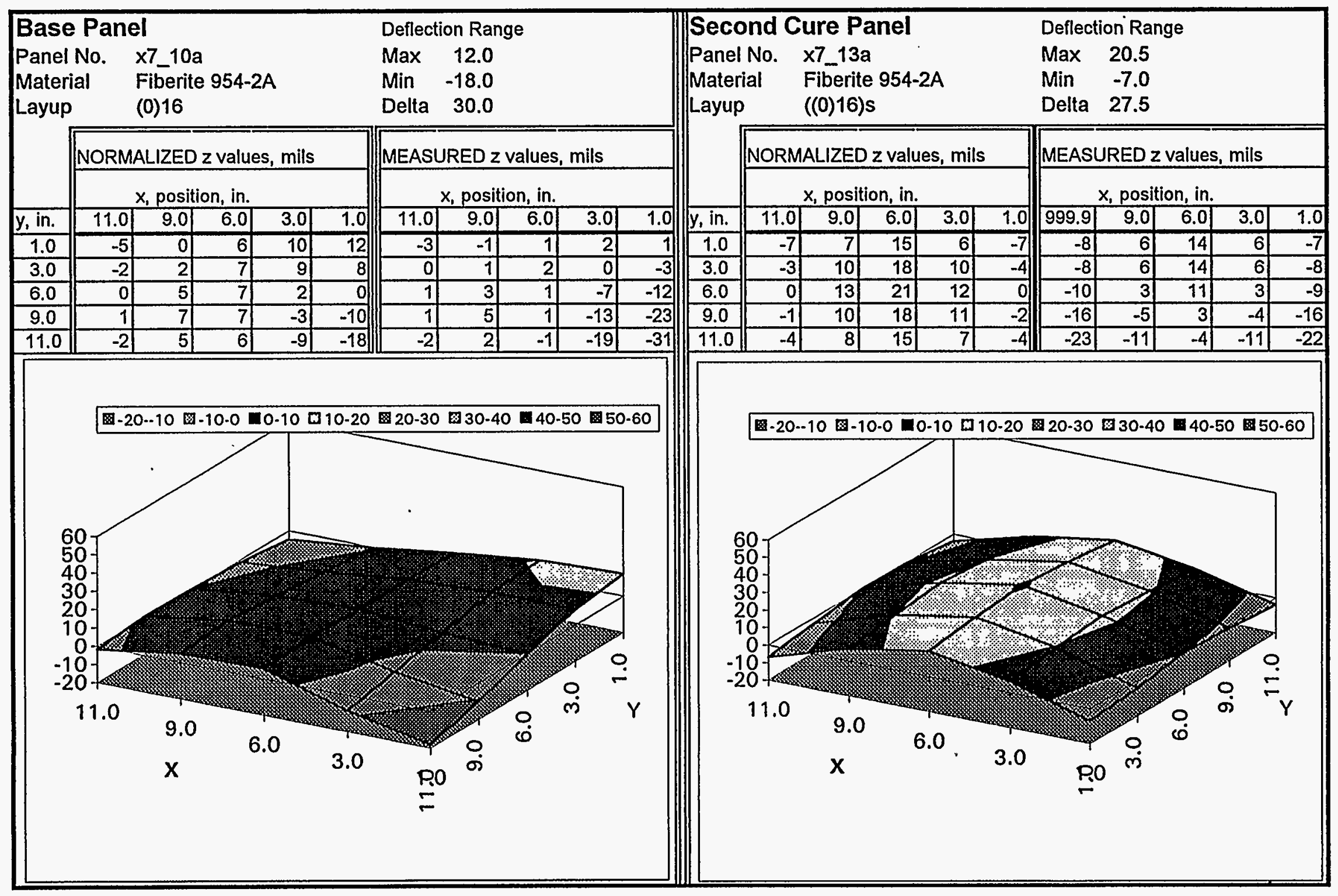




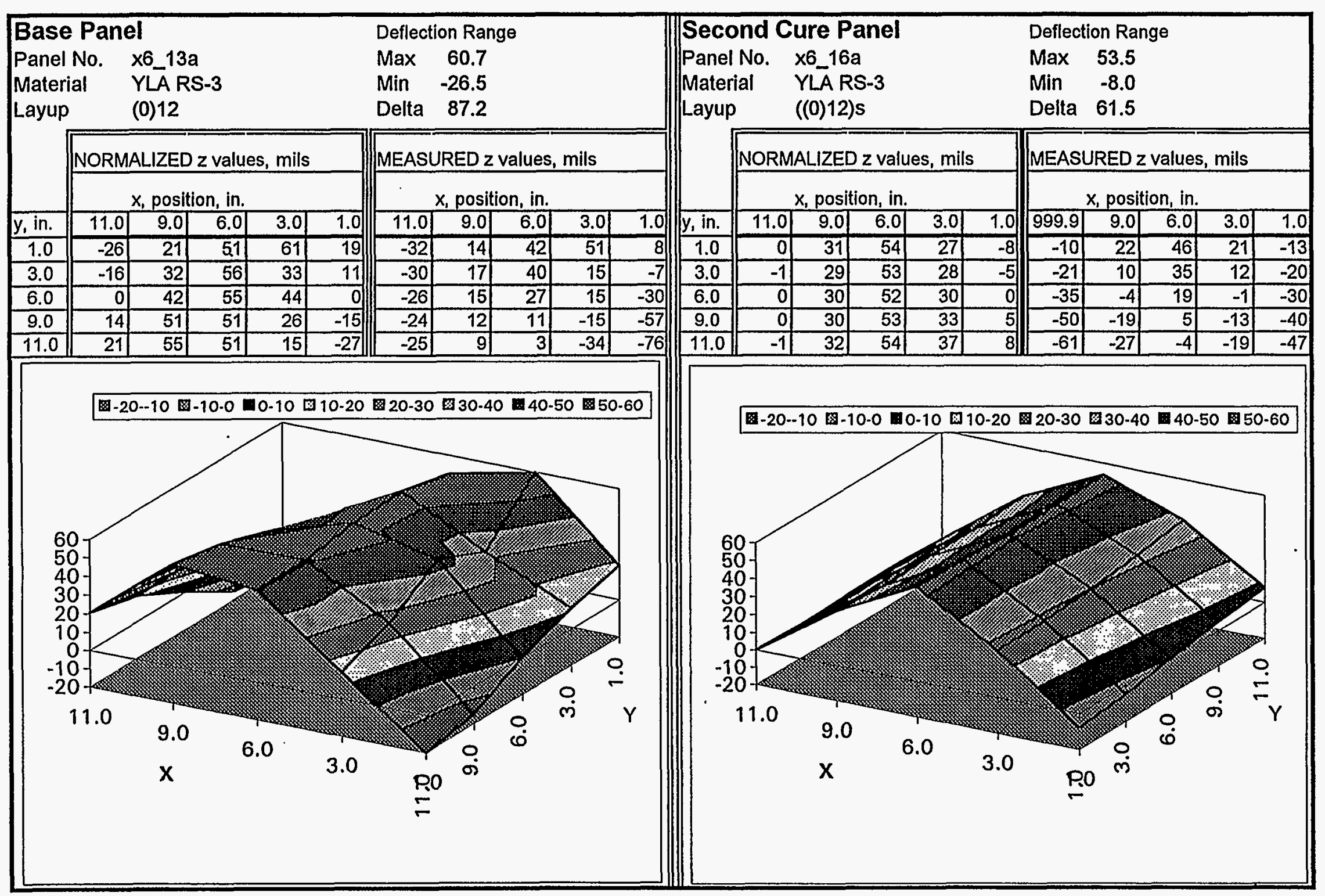




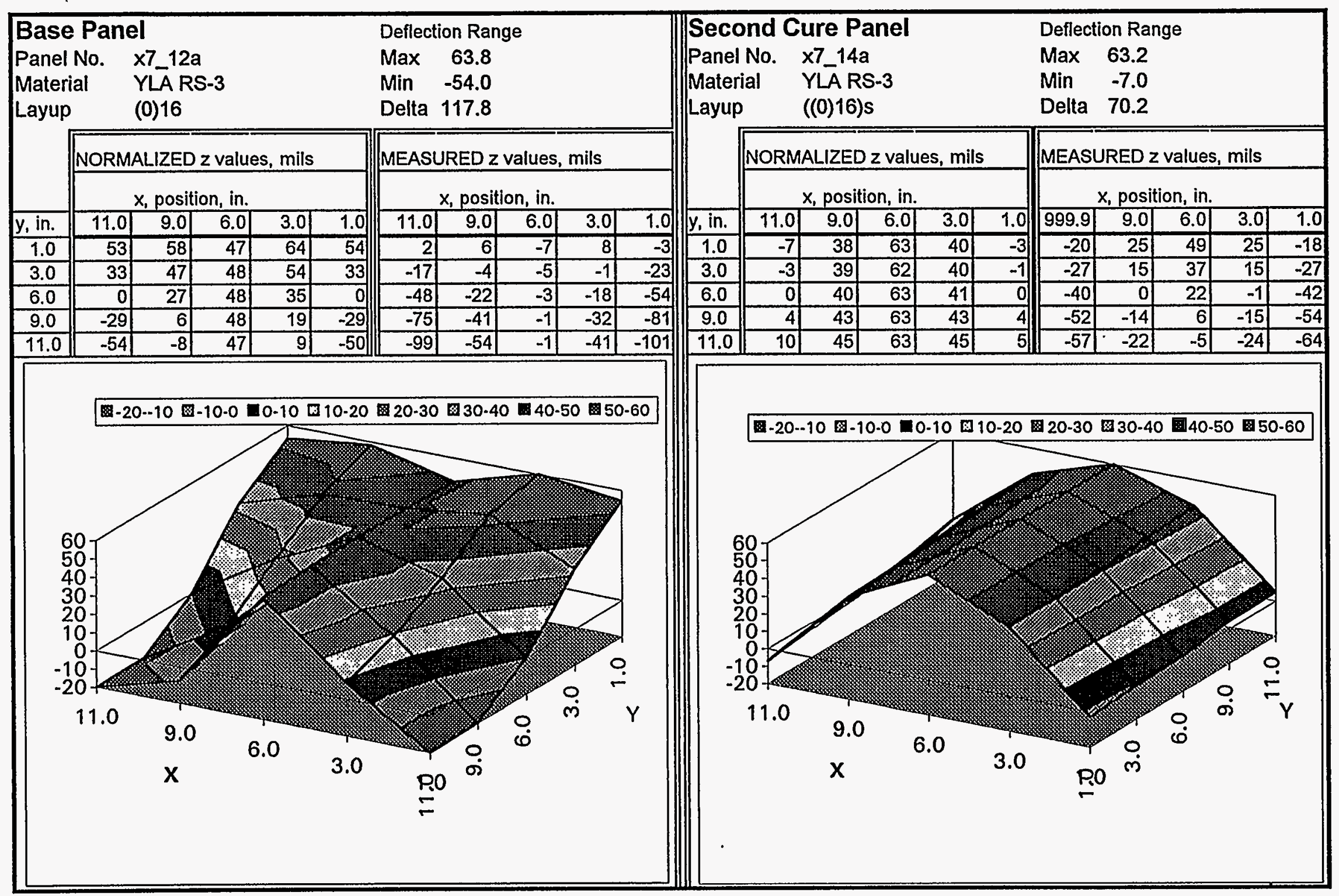




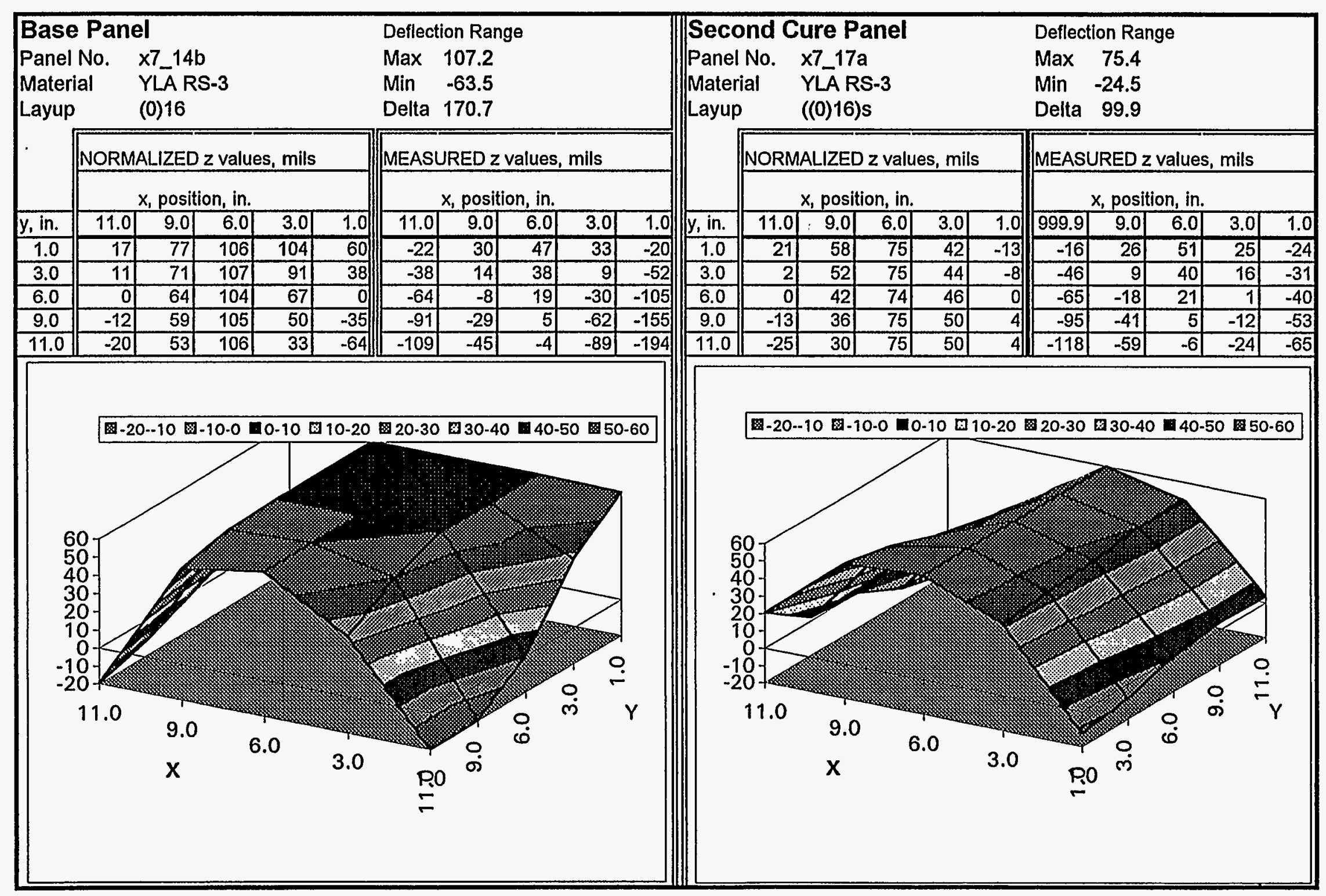




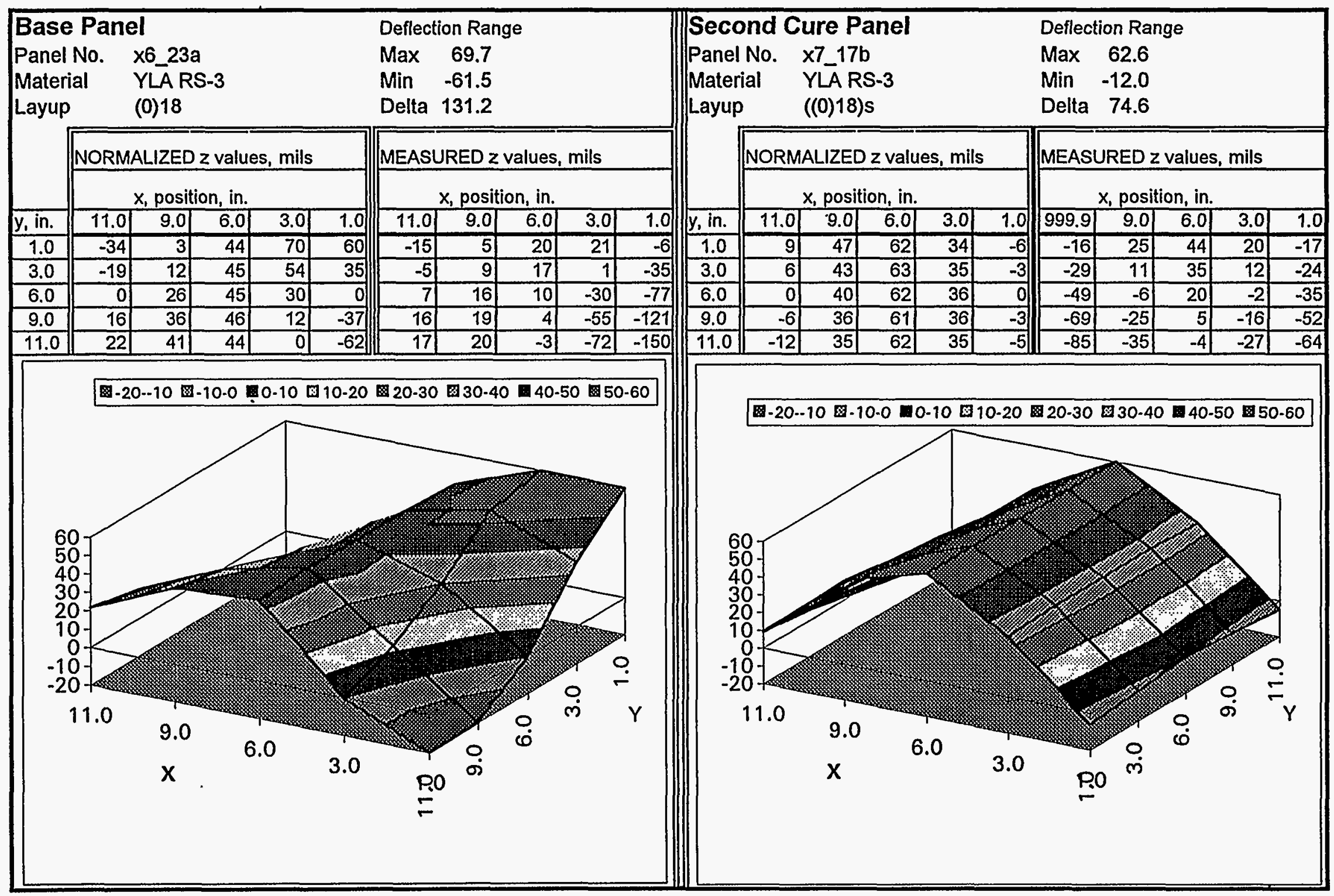




\section{Appendix 6 -- Cured Material Properties}

A table of mechanical properties of laminates is presented. This information was extracted from manufacturers literature with the permission of the manufacturer. A copy of a data sheet showing the mechancial properties of the ICl Fiberite 954-2A neat resin is included. 
Mechanical Properties

\begin{tabular}{|l|c|c|c|c|}
\hline \multicolumn{1}{|c|}{ Property } & $\begin{array}{c}\text { YLA } \\
\text { M55J } \\
\text { RS-3 }\end{array}$ & $\begin{array}{c}\text { Fiberite } \\
\text { IM7 } \\
954-2 \mathrm{~A}\end{array}$ & $\begin{array}{c}\text { Hercules } \\
\text { IM6 } \\
3501-6\end{array}$ & $\begin{array}{c}\text { Bryte } \\
7781 \\
\text { BTCy- } \\
1\end{array}$ \\
\hline $\begin{array}{l}\text { Tensile Strength } \\
\text { KSI }\end{array}$ & 265 & 388 & 350 & 70 \\
\hline $\begin{array}{l}\text { Tensile Modulus } \\
\text { MSI }\end{array}$ & 45 & 23 & 23 & 3.2 \\
\hline $\begin{array}{l}\text { Compressive Strength } \\
\text { KSI }\end{array}$ & 116 & 206 & 240 & 64 \\
\hline $\begin{array}{l}\text { Compressive Modulus } \\
\text { MSI }\end{array}$ & 41 & & 21 & 3.0 \\
\hline $\begin{array}{l}\text { Flexural Strength } \\
\text { KSI }\end{array}$ & 169 & & 260 & 86 \\
\hline $\begin{array}{l}\text { Flexural Modulus } \\
\text { MSI }\end{array}$ & 41 & & 21 & 3.0 \\
\hline
\end{tabular}

The above properties are for the zero degree orientation of a unidirectional laminate. 
Properties of ICl Fiberite 954-2A neat resin.

\section{A Data Sheet from (Ci) FIBERITE}

\section{4-2A CYANATE RESIN}

- Toughened cyanate using ICl Fiberite's proprietary thermoplastic technology

- High impact resistance

- $325^{\circ} \mathrm{F}\left(163^{\circ} \mathrm{C}\right)$ wet service temperature with post cure

- Attractive electrical properties

- $350^{\circ} \mathrm{F}\left(177^{\circ} \mathrm{C}\right)$ cure

- Controlled flow, good tack and out-life

- Available on a broad range of fibers and in forms including tape and fabric

- Autoclave or press-mold processable
Fiberite ${ }^{\otimes} 954-2 \mathrm{~A}$ is a $350^{\circ} \mathrm{F}\left(177^{\circ} \mathrm{C}\right)$ curing toughened cyanate resin with a $325^{\circ} \mathrm{F}\left(163^{\circ} \mathrm{C}\right)$ wet service capability. Fiberite 954-2A is formulated for autoclave or press molding. Recommended cure is four hours at $350^{\circ} \mathrm{F}\left(177^{\circ} \mathrm{C}\right)$. Service temperatures are maximized by a post cure of $428^{\circ} \mathrm{F}-450^{\circ} \mathrm{F}\left(220^{\circ} \mathrm{C}-232^{\circ} \mathrm{C}\right)$. The recommended lay-up procedure for this material is $L-7$. The recommended cure procedure is $\mathrm{C}-33$. The hold at $250^{\circ} \mathrm{F}\left(121^{\circ} \mathrm{C}\right)$ may be omitted, if desired.

Typical applications for 954-2A include primary and secondary aircraft structures, space structures, cryogenic tanks, or any application where impact resistance, light weight and excellent dielectric properties are required. Fiberite 954-2A can be impregnated via hot melt or solution techniquès on all available fibers and fabrics.

\section{TYPICAL NEAT RESIN PROPERTIES}

\begin{tabular}{|c|c|c|c|c|}
\hline & RT & $\begin{array}{c}325^{\circ} \mathrm{F} \\
\left(163^{\circ} \mathrm{C}\right)\end{array}$ & $\begin{array}{c}325^{\circ} \mathrm{F} / \mathrm{Wet} \\
\left(163^{\circ} \mathrm{C} / \mathrm{Wet}\right)\end{array}$ & $\begin{array}{c}350^{\circ} \mathrm{F} \\
\left(177^{\circ} \mathrm{C}\right)\end{array}$ \\
\hline $\begin{array}{l}\text { Tensile Strength, ksi } \\
\text { Tensile Modulus, Msi } \\
\text { Tensile Ult. Strain, \% } \\
\text { Tensile Poisson's Ratio } \\
\text { Tensile Strength, MPa } \\
\text { Tensile Modulus, GPa } \\
\text { Tensile Ult. Strain, \% } \\
\text { Tensile Poisson's Ratio }\end{array}$ & $\begin{array}{l}10.0 \\
0.44 \\
2.59 \\
0.38 \\
\\
68.9 \\
3.03 \\
2.59 \\
0.38\end{array}$ & & & \\
\hline $\begin{array}{l}\text { Flexural Strength, ksi } \\
\text { Flexural Modulus, Msi } \\
\text { Flexural Strength, MPa } \\
\text { Flexural Modulus, GPa }\end{array}$ & $\begin{array}{l}16.9 \\
0.44 \\
117 \\
3.03\end{array}$ & $\begin{array}{l}13.5 \\
0.35 \\
93.1 \\
2.41\end{array}$ & $\begin{array}{r}11.9 \\
0.34 \\
82.0 \\
2.34\end{array}$ & $\begin{array}{l}12.6 \\
0.35 \\
86.9 \\
2.41\end{array}$ \\
\hline $\begin{array}{l}\mathrm{H}_{2} \mathrm{O} \text { Uptake, wt. \% } \\
\text { Tg (DMA-Tan } \delta),{ }^{\circ} \mathrm{C} \\
\text { Density, g/cm }{ }^{3}\end{array}$ & $\mid \begin{array}{c}1.28 \\
215,249 \\
1.24\end{array}$ & & & \\
\hline
\end{tabular}

The data listed has been obtained from carefully controlled samples considered to be representative of the product described. Because the properties of this product can be significantly affected by the fabrication and testing techniques empioyed and since ICI Fiberite does not control the conditions under which its products are tested and used, ICI Fiberite cannot guarantee that the properties listed will be obtained with other processes and equipment. 